UNIVERSITAT POLITÈCNICA DE VALÈNCIA

Departament de Tecnologia d'Aliments

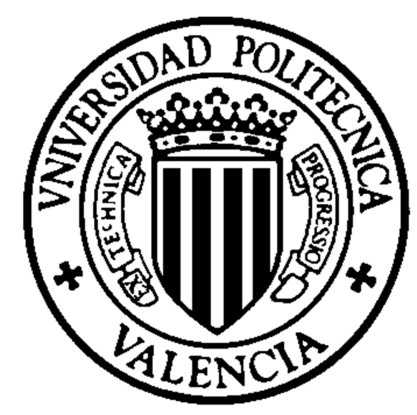

DOCTORAL THESIS

\title{
OBTENTION AND CHARACTERIZATION OF ROSEMARY AND ASH TREE SEED EXTRACTS AND STUDY OF THEIR PREVENTIVE EFFECTS ON METABOLIC DISORDERS
}

Presented by:

Sixto Alvin IBARRA BOBER

Directed by:

Dr. Amparo CHIRALT BOIX

Dr. Marc ROLLER

València, 2011 
DOCTORAL THESIS

\title{
OBTENTION AND CHARACTERIZATION OF ROSEMARY AND ASH TREE SEED EXTRACTS AND STUDY OF THEIR PREVENTIVE EFFECTS ON METABOLIC DISORDERS
}

\author{
Presented by: \\ Sixto Alvin IBARRA BOBER \\ Ingeniero Alimentario \\ UNIVERSIDAD FEDERICO VILLARREAL (LIMA - PERU) \\ Magister en Ciencia de los Alimentos \\ UNIVERSIDAD DE CHILE \\ Presented at: \\ UNIVERSITAT POLITÈCNICA DE VALÈNCIA
}

To obtain the degree:

"DOCTOR PER LA UNIVERSITAT POLITÈCNICA DE VALÈNCIA"

Directed by:

Dr. Amparo CHIRALT BOIX

Profesora catedrática de la Universidad Politécnica de Valencia

Dr. Marc ROLLER

Scientific Director of NATUREX

València, 2011 
Acknowledgments

To

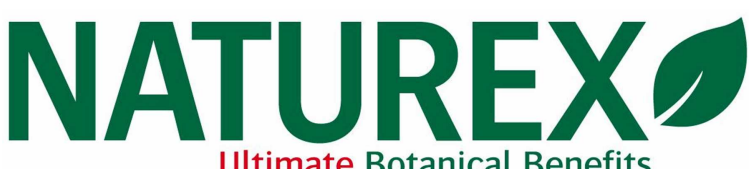

Ultimate Botanical Benefits 


\section{Dedicatory}

To my family, friends and colleagues 


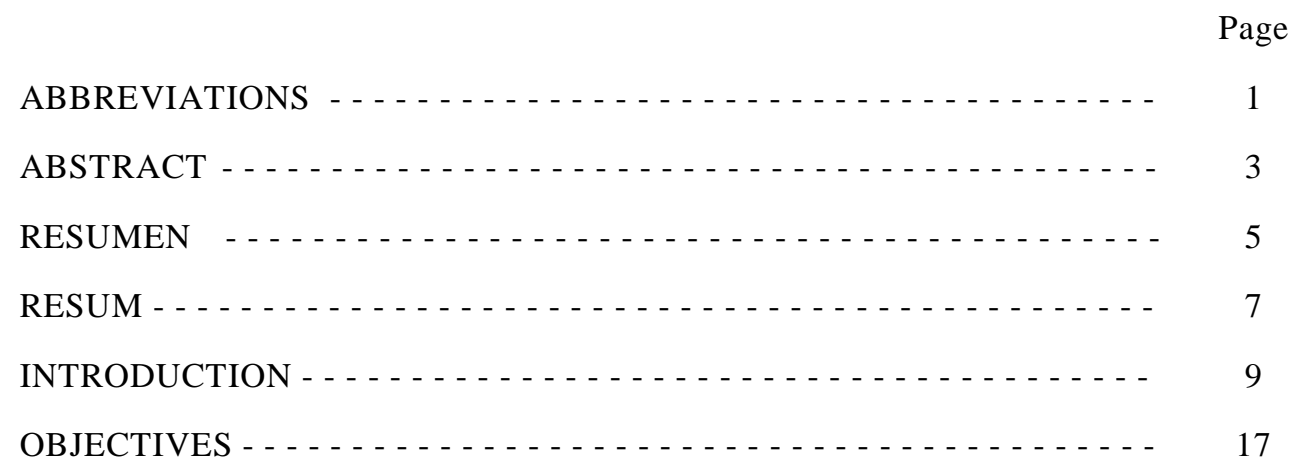

CHAPTER I: IMPORTANCE OF EXTRACT STANDARDIZATION AND IN VITROIEX VIVO ASSAY SELECTION FOR THE EVALUATION OF ANTIOXIDANT ACTIVITY OF BOTANICALS: A CASE STUDY ON THREE Rosmarinus officinalis L. EXTRACTS- - . - . - . - . - . - . . - .

CHAPTER II: CARNOSIC ACID-RICH ROSEMARY (Rosmarinus officinalis L.) LEAF EXTRACT LIMITS WEIGHT GAINS AND IMPROVES CHOLESTEROL LEVELS AND GLYCAEMIA IN MICE ON A

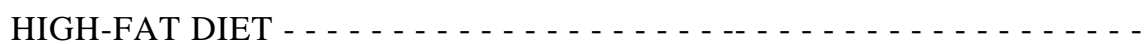

CHAPTER III: IRIDOIDS FROM Fraxinus excelsior L. WITH ADIPOCYTE DIFFERENTIATION-INHIBITORY AND PPAR $\alpha$ ACTIVATION

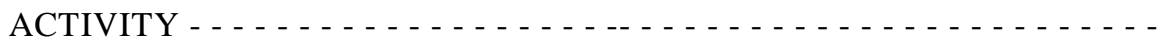

CHAPTER IV: Fraxinus excelsior L. SEED EXTRACT FRAXIPURETM LIMITS WEIGHT GAINS AND HYPERGLYCEMIA IN HIGH-FAT DIETINDUCED OBESE MICE - . . . . . . . . . . . . . . . . . . . . .

CHAPTER V: ACUTE EFFECTS OF Fraxinus excelsior L. SEED EXTRACT ON POSTPRANDIAL GLYCEMIA AND INSULIN SECRETION ON HEALTHY VOLUNTEERS - . - . - . - . - . - . - . . -

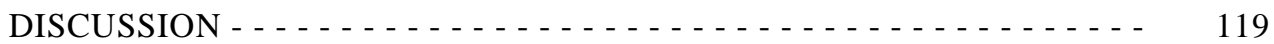

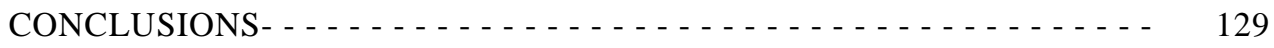

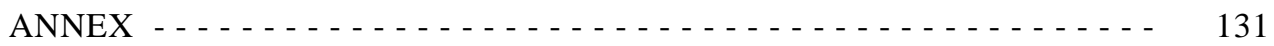




\section{ABBREVIATIONS}

AACC American association of cereal chemists

ALT Alanine transaminase

AUC/ABC Area under the curve / Area bajo la curva

CHD/CVD Coronary heart disease / Cardiovascular disease

ECLIA Electrochemiluminescence immunoassay

FE

Ash tree seed extract

FED High fat diet $+0.5 \%$ ash tree seed extract

FRAP Ferric reducing/antioxidant power

HFD High fat diet

HFD.RE High fat diet $+0.5 \%$ rosemary extract standardized to $20 \%$ carnosic acid

HPLC High pressure liquid chromatography

HPLC-MS HPLC - Mass spectroscopy

IEC Institutional human ethical committee

LDL Low-density lipoprotein

LFD Low fat diet

LPL Lipoprotein lipase

NMR/RMN Nuclear magnetic resonance / Resonancia magnética nuclear

ORAC Oxygen radical absorbance capacity

ORS Oxygen radical species

PPAR Peroxisome proliferator-activated receptor

RE Rosemary extract standardized to contain $20 \%$ carnosic acid

RCT/PCA Randomized controlled trials/ Prueba controlada aleatoria

RFMC Risk factor modification centre 


\section{ABSTRACT}

The prevalence of metabolic disorders is rising worldwide. Botanicals, such as rosemary (Rosmarinus officinalis L.) and ash tree seeds (Fraxinus excelsior L.), may be an alternative to ameliorate these disorders. The objective of this doctoral thesis was to generate industrial extracts from the edible parts of these plants; identify their chief constituents by HPLC, HPLC-MS, and NMR; and determine their efficacy and safety. Three rosemary extracts were developed - standardized to $20 \%$ carnosic acid, 20\% rosmarinic acid, and 40\% ursolic acid. The ursolic acid-rich extract showed the lowest antioxidant capacity in ORAC and FRAP in vitro models, while the other two extracts had higher capacities. However, the carnosic acid-rich extract (RE) was better in inhibiting the oxidation of LDL ex vivo, and was the only one selected for further studies. An ash tree seed extract (FE) was developed according to its traditional use in Morocco, being identified salidroside and 9 secoiridoid glycosides, two of them were discovered for the first time: Excelside A and Excelside B. In in vitro studies, RE and FE activated nuclear receptors that regulate glucose and energy homeostasis, and acted on antiobesity and dyslipidemia mechanisms -RE activated PPAR $\gamma$ and inhibited pancreatic lipase, and FE stimulated PPAR $\alpha$ and prevented preadipocyte differentiation. The capacities of both extracts to counteract metabolic disorders were confirmed in C57BL/6J mice administrated with low-fat diet; high-fat diet; or high-fat diet plus $0.5 \%$ RE (HFD.RE) or 0.5\% FE (FED) during 16-weeks. HFD.RE limited the increase of body and epididymal fat weight by $69 \%$ $(\mathrm{P}<0.01)$ and $79 \%(\mathrm{P}<0.001)$, respectively. HFD.RE also reduced fasting glycaemia $(72 \%$, $\mathrm{P}<0.01)$ and plasma cholesterol levels $(68 \%, \mathrm{P}<0.001)$. FED decreased blood glucose (76.52\%, $\mathrm{P}<0.001)$, plasma insulin level $(53.43 \%, \mathrm{P}<0.05)$, and body weight gain $(32.3 \%$, $\mathrm{P}<0.05)$. Finally, a screening model against glucose $(50 \mathrm{~g})$ was used to assess the effect of FE (1.0g) on plasma glucose and insulin levels in a RCT on 16 healthy volunteers. FE reduced the glycemic-AUC $(\mathrm{P}=0.02)$, but not the insulinemic-AUC. The two extracts were safe. Additional long-term interventions in humans are warranted.

Keywords: Antioxidant; glycaemia; body weight; FRAP; Fraxinus excelsior L.; insulin; ORAC; pancreatic lipase; polyphenols; PPAR; Rosmarinus officinalis L; secoiridoids. 


\section{RESUMEN}

La prevalencia de los trastornos metabólicos está creciendo a nivel mundial. Botánicos, como el romero (Rosmarinus officinalis L.) y las semillas de fresno (Fraxinus excelsior L.), pueden ser una alternativa para mejorar estos trastornos. El objetivo de esta tesis doctoral fue generar extractos industriales de las partes comestibles de estas plantas, identificar sus compuestos por HPLC, HPLC-MS y RMN, y determinar su eficacia y seguridad. Se desarrollaron tres extractos de romero - estandarizados al 20\% de ácido carnósico, 20\% de ácido rosmarínico, y 40\% de ácido ursólico. El extracto rico en ácido ursólico mostró la menor capacidad antioxidante en modelos ORAC y FRAP in vitro, mientras que los otros dos extractos tuvieron capacidades más elevadas. Sin embargo, el extracto rico en ácido carnósico (RE) fue superior en la inhibición de la oxidación de LDL ex vivo, y fue el único seleccionado para estudios posteriores. Se desarrolló un extracto de semilla de fresno (FE) de acuerdo a su uso tradicional en Marruecos, siendo identificados salidrosido y 9 glucósidos secoiridoides, dos de ellos fueron descubiertos por primera vez: Excelside A y Excelside B. En estudios in vitro, RE y FE activaron receptores nucleares que regulan la homeostasis de la glucosa y la energía, y actuaron sobre mecanismos contra la obesidad y la dislipidemia - RE activa PPAR $\gamma$ e inhibe la lipasa pancreática, y FE estimula PPAR $\alpha$ y evita la diferenciación de preadipocitos. La eficacia de ambos extractos para el control de trastornos metabólicos fue confirmada en ratones C57BL/6J administrados con una dieta baja en grasa, una dieta alta en grasa, o una dieta alta en grasa más 0.5\% RE (HFD.RE) o $0.5 \%$ FE (FED) durante 16 semanas. HFD.RE limitó el aumento del peso corporal y grasa en el epidídimo en un 69\% ( $\mathrm{P}<0.01)$ y 79\% ( $<<0.001)$, respectivamente. HFD.RE también redujo la glucemia $(72 \%, \mathrm{P}<0.01)$ y los niveles de colesterol $(68 \%, \mathrm{P}<0.001)$. FED redujo la glucemia $(76.52 \%, \mathrm{P}<0.001)$, insulinemia $(53.43 \%, \mathrm{P}<0.05)$, y la ganancia de peso (32.3\%, P <0.05). Por último, se utilizó un modelo de tolerancia a la glucosa $(50 \mathrm{~g})$ para evaluar el efecto de FE (1.0g) en glucemia e insulinemia en una PCA con 16 voluntarios sanos. FE redujo la $\mathrm{ABC}$-glucémica $(\mathrm{P}=0.02)$, pero no la $\mathrm{ABC}$-insulinémica. Los dos extractos fueron seguros. Futuros estudios en humanos estarían garantizados.

Palabras clave: Antioxidante; FRAP; Fraxinus excelsior L.; glucemia; insulina; lipasa pancreática; ORAC; peso; polifenoles; PPAR; Rosmarinus officinalis L.; secoiridoides. 


\section{RESUM}

La prevalença dels trastorns metabòlics està creixent a nivell mundial. Botànics, com el romaní (Rosmarinus officinalis L.) i les llavors de freixe (Fraxinus excelsior L.), poden ser una alternativa per millorar aquests trastorns. L'objectiu d'aquesta tesi doctoral va ser generar extractes industrials de les parts comestibles d'aquestes plantes, identificar els seus compostos per HPLC, HPLC-MS i RMN, i determinar la seva eficàcia i seguretat. Es van desenvolupar tres extractes de romaní - estandarditzats al 20\% d'àcid carns, 20\% d'àcid rosmarínic, i 40\% d'àcid ursolic. L'extracte ric en àcid ursolic va mostrar la menor capacitat antioxidant en models ORAC i FRAP in vitro, mentre que els altres dos extractes van tenir capacitats més elevades. No obstant això, l'extracte ric en àcid carns (RE) va ser superior en la inhibició de l'oxidació de LDL ex vivo, i va ser l'únic seleccionat per a estudis posteriors. Es va desenvolupar un extracte de llavor de freixe (FE) d'acord al seu ús tradicional al Marroc, sent identificats salidrosido i 9 glucòsids secoiridoids, dos d'ells van ser descoberts per primera vegada: Excelside A i Excelside B. En estudis in vitro, RE i FE activar receptors nuclears que regulen la homeòstasi de la glucosa i l'energia, i van actuar sobre mecanismes contra l'obesitat i la dislipidèmia -RE activa PPAR $\gamma$ i inhibeix la lipasa pancreàtica, i FE estimula PPAR $\alpha$ i evita la diferenciació de preadipocitos. L'eficàcia d'ambdós extractes per al control de trastorns metabòlics va ser confirmada en ratolins C57BL/6J administrats amb una dieta baixa en greix, una dieta alta en greix, o una dieta alta en greix més $0.5 \%$ RE (HFD.RE) o $0.5 \%$ FE (FED) durant 16 setmanes. HFD.RE va limitar l'augment del pes corporal i greix al epidídim en un 69\% ( $\mathrm{P}<0.01)$ i $79 \%(\mathrm{P}<0.001)$, respectivament. HFD.RE també va reduir la glucèmia $(72 \%, \mathrm{P}<0.01)$ i els nivells de colesterol $(68 \%, \mathrm{P}<0.001)$. FED va reduir la glucèmia $(76,52 \%, \mathrm{P}<0.001)$, insulinèmia $(53.43 \%, \mathrm{P}<0.05)$, i el guany de pes $(32.3 \%, \mathrm{P}<0.05)$. Finalment, es va utilitzar un model de tolerància a la glucosa $(50 \mathrm{~g})$ per avaluar l'efecte de $\mathrm{FE}(1.0 \mathrm{~g})$ en glucèmia i insulinèmia en una PCA amb 16 voluntaris sans. FE va reduir l'ABC-glucèmica $(\mathrm{P}=0.02)$, però no l'ABC-insulinémica. Els dos extractes van ser segurs. Futurs estudis en humans estarien garantits.

Paraules clau: Antioxidant; FRAP; Fraxinus excelsior L.; glucèmia; insulina; lipasa pancreàtica; ORAC; pes; polifenol; PPAR; Rosmarinus officinalis L.; secoiridoids. 


\section{INTRODUCTION}

The prevalence of metabolic disorders is rising dramatically in industrialized and developing nations. Obesity is reaching epidemic proportions worldwide (WHO, 2009) and is an established risk factor for various comorbidities, such as diabetes mellitus, dyslipidemia, and cardiovascular disease (Anderson and Konz, 2001;Czernichow et al., 2002; Unwin et al., 2010).

Due to dissatisfaction with high costs and potentially hazardous side effects of pharmaceutical drugs (de Simone G. and D'Addeo, 2008;Karamadoukis et al., 2009), the potential of using natural products to treat obesity and metabolic disorders is being examined (Yun, 2010). For example, the administration of plant-based treatments might be an excellent strategy to prevent obesity and diabetes (Ye, 2008).

Botanical extracts, however, are not always well accepted due to issues over the identification and standardization of active compounds and quality control (Raskin and Ripoll, 2004); thus, botanical extracts that are intended to elicit health benefits must be produced and characterized properly.

Metabolic disorders, including obesity and diabetes, are linked to an increased oxidative stress (Valko et al., 2007). This stress can be mitigated on administration of plant extracts that have antioxidant capacity (Seifried et al., 2007). Molecules can be targeted by plantbased compounds to prevent the development of metabolic disorders, such as peroxisome proliferator-activated receptor-alpha (PPAR $\alpha$ ) and -gamma (PPAR $\gamma$ ) (Shay and Banz, 2005), which are transcription factors that regulate energy homeostasis (Staels and Fruchart, 2005). PPAR $\alpha$ regulates genes that mediate fatty acid uptake and oxidation, inflammation, and vascular function, and PPAR $\gamma$ governs genes that control fatty acid uptake and storage, inflammation and glucose homeostasis (Staels and Fruchart, 2005).

One of the most promising strategies of reducing energy intake through gastrointestinal mechanisms without altering central physiological processes is the development and use of inhibitors of nutrient digestion and absorption (Birari and Bhutani, 2007). Dietary fat is not absorbed directly by the intestine unless it has been acted on by pancreatic lipase. Thus, pancreatic lipase activity is one of the most widely studied mechanisms for which a natural product's efficacy as antiobesity agent is determined (Birari and Bhutani, 2007). 
Alternatively, one can examine the inhibition of intestinal glucose uptake that is affected by secondary metabolites from plants (Welsch et al., 1989;Kottra and Daniel, 2007;Kwon et al., 2007).

Of plant extracts that have antiobesity and antidiabetic properties, those from the edible parts of rosemary (Rosmarinus officinalis L.) and the seeds of the ash tree (Fraxinus excelsior $\mathrm{L}$.) are among the most promising for use as nutraceuticals.

Rosemary is an aromatic Mediterranean plant that is used in traditional meals and several industrial food applications (Etter, 2004). Recently, rosemary extracts that have been standardized for carnosic acid and carnosol have attained antioxidant status, garneging an E rating from the European Food Safety Authority, confirming its importance as a natural preservative in foods and beverages (Aguilar et al., 2008). Rosemary has many health benefits (al-Sereiti et al., 1999), and its effects on oxidative stress (Etter, 2004), inflammation (Takaki et al., 2008;Altinier et al., 2007); obesity (Takahashi et al., 2009; Harach et al., 2009), and diabetes (Bakirel et al., 2008;Rau et al., 2006) are central to the prevention of metabolic disorders.

Several studies have demonstrated that the biological activities of rosemary are attributed to its carnosic acid, carnosol, rosmarinic acid, and ursolic acid content (Jang et al., 2010;Aruoma et al., 1992;Lo et al., 2002;Kosaka and Yokoi, 2003;Ninomiya et al., 2004;Perez-Fons et al., 2006;Wijeratne and Cuppett, 2007;Yu et al., 2009;Ibarra et al., 2010). But, whether these activities are due to a single bioactive compound or the combination of several agents is unknown.

The common ash is a tree that grows naturally in temperate regions across Europe and Asia (Pliûra and Heuertz, 2003;Eddouks et al., 2005) and exists throughout southeastern Morocco (Eddouks et al., 2002). Several reports have demonstrated that ash seeds have been used traditionally as food and as a condiment (Hedrick, 1919;Kunkel, 1984;Sinclair, 1998;Vergne, 2001;Boisvert, 2003;Eddouks and Maghrani, 2004;Eddouks et al., 2005; Maghrani et al., 2004) and administered to improve several health conditions (Parsa, 1959;Eddouks and Maghrani, 2004).

In Europe, there is evidence that these seeds have been used since the Middle Ages (Vermeeren and Gumbert, 2008). The aqueous seed extract of the ash tree is an effective hypoglycemic and antidiabetic agent, as evidenced by its use by traditional healers in Morocco (Eddouks et al., 2005). Moreover, ash seed extract has hypoglycemic and 
antidiabetic effects in normal and streptozotocin-induced diabetic rats (Eddouks and Maghrani, 2004;Maghrani et al., 2004).

Therefore, this evidence encourages the study of rosemary and ash tree seed extracts to prevent the development of metabolic disorders. It is important to identify their active compounds, and to confirm their efficacy and safety in relevant biological models. The results derived from this research program could lead to the discovery of new natural agents to counteract the rise of obesity and associated comorbidities, with applications in food, food supplement, pharmaceutical and cosmetic industries.

\section{References}

Aguilar,F., H.Autrup, S.Barlow, L.Castle, W.Dekant, K.H.Engel, N.Gontard, D.Gott, S.Grilli, R.Gürtler, R.Chr.Larsen, C.Leclercq, J.C.Leblanc, F.X.Malcata, W.Mennes, M.R.Milana, I.Pratt, I.Rietjens, P.Tobback, and F.Toldra. 2008. Use of rosemary exracts as a food additive. Scientific opinion of the panel on food additives, flavourings, processing aids and materials in contact with food. The EFSA journal 721:1-29.

Al-Sereiti,M.R., K.M.Abu-Amer, and P.Sen. 1999. Pharmacology of rosemary (Rosmarinus officinalis Linn.) and its therapeutic potentials. Indian J. Exp. Biol. 37:124-130.

Altinier,G., S.Sosa, R.P.Aquino, T.Mencherini, R.D.Loggia, and A.Tubaro. 2007. Characterization of Topical Antiinflammatory Compounds in Rosmarinus officinalis L. Journal of Agricultural and Food Chemistry 55:1718-1723.

Anderson,J.W., and E.C.Konz. 2001. Obesity and disease management: effects of weight loss on comorbid conditions. Obes. Res. 9 Suppl 4:326S-334S.

Aruoma,O.I., B.Halliwell, R.Aeschbach, and J.Loligers. 1992. Antioxidant and pro-oxidant properties of active rosemary constituents: carnosol and carnosic acid. Xenobiotica 22:257-268.

Bakirel,T., U.Bakirel, O.U.Keles, S.G.Ulgen, and H.Yardibi. 2008. In vivo assessment of antidiabetic and antioxidant activities of rosemary (Rosmarinus officinalis) in alloxan-diabetic rabbits. J Ethnopharmacol 116:64-73

Birari,R.B., andK.K.Bhutani. 2007. Pancreatic lipase inhibitors from natural sources: unexplored potential. Drug Discovery Today 12:879-889.

Boisvert,C. 2003. Plantes et remèdes naturels. Genève. 
Czernichow,S., L.Mennen, S.Bertrais, P.Preziosi, S.Hercberg, and J.M.Oppert. 2002. Relationships between changes in weight and changes in cardiovascular risk factors in middle-aged French subjects: effect of dieting. Int. J. Obes. Relat Metab Disord. 26:1138-1143.

De Simone G., and G.D'Addeo. 2008. Sibutramine: balancing weight loss benefit and possible cardiovascular risk. Nutr. Metab Cardiovasc. Dis. 18:337-341.

Eddouks,M., and M.Maghrani. 2004. Phlorizin-like effect of Fraxinus excelsior in normal and diabetic rats. J Ethnopharmacol. 94:149-154.

Eddouks,M., M.Maghrani, A.Lemhadri, M.Ouahidi, and H.Jouad. 2002. Ethnopharmacological survey of medicinal plants used for the treatment of diabetes mellitus, hypertension and cardiac diseases in the south-east region of Morocco (Tafilalet). J Ethnopharmacol. 82:97-103.

Eddouks,M., M.Maghrani, N.A.Zeggwagh, M.Haloui, and J.B.Michel. 2005. Fraxinus excelsior L. evokes a hypotensive action in normal and spontaneously hypertensive rats. J Ethnopharmacol. 99:49-54.

Etter,S.C. 2004. Rosmarinus officinalis as an antioxidant. Journal of herbs, spices \& medicinal plants 11:121-159.

Harach,T., O.Aprikian, I.Monnard, J.Moulin, M.Membrez, J.C.Béolor, T.Raab, K.Macé, and C.Darimont. 2009. Rosemary (Rosmarinus officinalis L.) Leaf Extract Limits Weight Gain and Liver Steatosis in Mice Fed a High-Fat Diet. Planta Med.76:566-571.

Hedrick,U.P. 1919. Sturtevant's Notes on Edible Plants. 1 ed. State of New York Department of Agriculture, Albany.

Ibarra,A., J.Cases, A.Bily, K.He, N.Bai, M.Roller, A.Coussaert, and C.Ripoll. 2010. Importance of extract standardization and in vitrolex vivo assay selection for the evaluation of antioxidant activity of botanicals: a case study on three Rosmarinus officinalis L. extracts. J Med Food. 13:1167-1175

Jang,S.M., M.J.Kim, M.S.Choi, E.Y.Kwon, and M.K.Lee. 2010. Inhibitory effects of ursolic acid on hepatic polyol pathway and glucose production in streptozotocininduced diabetic mice. Metabolism 59:512-519.

Karamadoukis,L., G.H.Shivashankar, L.Ludeman, and A.J.Williams. 2009. An unusual complication of treatment with orlistat. Clin. Nephrol. 71:430-432. 
Kosaka,K., and T.Yokoi. 2003. Carnosic acid, a component of rosemary (Rosmarinus officinalis L.), promotes synthesis of nerve growth factor in T98G human glioblastoma cells. Biol. Pharm. Bull. 26:1620-1622.

Kottra,G., and H.Daniel. 2007. Flavonoid glycosides are not transported by the human $\mathrm{Na} /$ glucose transporter when expressed in Xenopus laevis oocytes, but effectively inhibit electrogenic glucose uptake. J. Pharmacol. Exp. Ther. 322:829835 .

Kunkel,G. 1984. Plants for Human Consumption. 1 ed. Koenigstein.

Kwon,O., P.Eck, S.Chen, C.P.Corpe, J.H.Lee, M.Kruhlak, and M.Levine. 2007. Inhibition of the intestinal glucose transporter GLUT2 by flavonoids. FASEB J. 21:366-377.

Lo,A.H., Y.C.Liang, S.Y.Lin-Shiau, C.T.Ho, and J.K.Lin. 2002. Carnosol, an antioxidant in rosemary, suppresses inducible nitric oxide synthase through down-regulating nuclear factor-kappaB in mouse macrophages. Carcinogenesis 23:983-991.

Maghrani,M., N.Zeggwagh, A.Lemhadri, M.El Amraoui, J.Michel, and M.Eddouks. 2004. Study of the hypoglycaemic activity of Fraxinus excelsior and Silybum marianum in an animal model of type 1 diabetes mellitus. J Ethnopharmacol. 91:309-316

Ninomiya,K., H.Matsuda, H.Shimoda, N.Nishida, N.Kasajima, T.Yoshino, T.Morikawa, and M.Yoshikawa. 2004. Carnosic acid, a new class of lipid absorption inhibitor from sage. Bioorganic \& Medicinal Chemistry Letters 14:1943-1946.

Parsa,A. 1959. Medicinal plants and drugs of plant origin in Iran III. In Springer Netherland (ed.) .

Perez-Fons,L., F.J.Aranda, J.Guillen, J.Villalain, and V.Micol. 2006. Rosemary (Rosmarinus officinalis) diterpenes affect lipid polymorphism and fluidity in phospholipid membranes. Arch. Biochem. Biophys. 453:224-236.

Pliûra, Alfas and Heuertz, Myriam. Technical Guidelines for genetic conservation: Common ash (Fraxinus excelsior). European Forest Genetic Resources Programme 1[1]. 2003.

Raskin,I., and C.Ripoll. 2004. Can an apple a day keep the doctor away? Curr. Pharm. Des 10:3419-3429.

Rau,O., M.Wurglics, A.Paulke, J.Zitzkowski, N.Meindl, A.Bock, T.Dingermann, M.AbdelTawab, and M.Schubert-Zsilavecz. 2006. Carnosic Acid and Carnosol, Phenolic Diterpene Compounds of the Labiate Herbs Rosemary and Sage, are Activators of the Human Peroxisome Proliferator-Activated Receptor Gamma. Planta Med 72:881-887. 
Seifried,H.E., D.E.Anderson, E.I.Fisher, and J.A.Milner. 2007. A review of the interaction among dietary antioxidants and reactive oxygen species. J Nutr Biochem. 18:567-579.

Shay,N.F., and W.J.Banz. 2005. Regulation of gene transcription by botanicals: novel regulatory mechanisms. Annu. Rev. Nutr. 25:297-315.

Sinclair,C.G. 1998. International Dictionary of Food \& Cooking. 1st ed. London.

Staels,B., and J.C.Fruchart. 2005. Therapeutic Roles of Peroxisome Proliferator-Activated Receptor Agonists. Diabetes 54:2460-2470.

Takahashi,T., T.Tabuchi, Y.Tamaki, K.Kosaka, Y.Takikawa, and T.Satoh. 2009. Carnosic acid and carnosol inhibit adipocyte differentiation in mouse 3T3-L1 cells through induction of phase 2 enzymes and activation of glutathione metabolism.Biochem Biophys Res Commun. 382:549-554.

Takaki,I., L.E.Bersani-Amado, A.Vendruscolo, S.M.Sartoretto, S.P.Diniz, C.A.BersaniAmado, and R.K.Cuman. 2008. Anti-inflammatory and antinociceptive effects of Rosmarinus officinalis L. essential oil in experimental animal models. J. Med. Food 11:741-746.

Unwin,N., D.Gan, and D.Whiting. 2010. The IDF Diabetes Atlas: providing evidence, raising awareness and promoting action. Diabetes Res. Clin. Pract. 87:2-3.

Valko,M., D.Leibfritz, J.Moncol, M.T.Cronin, M.Mazur, and J.Telser. 2007. Free radicals and antioxidants in normal physiological functions and human disease. Int. J Biochem. Cell Biol. 39:44-84.

Vergne,E. 2001. Moroccan Cafe: Casual Moroccan Cooking at Home. Silverback Books.

Vermeeren,C., and B.Gumbert. 2008. "Ontellicke boomen" or "countless trees": reconstructing the late medieval vegetation surrounding the 16th century St Margaretha Convent, Leiden, The Netherlands. Veget Hist Archaeobot. 17:93103.

Welsch,C.A., P.A.Lachance, and B.P.Wasserman. 1989. Dietary phenolic compounds: inhibition of sodium-dependant D-glucose uptake in rat intestinal brush border membrane vesicles. J. Nutr. 119:1698-1704

WHO. Obesity and Overweight. 2009. Ref type: Internet communication

Wijeratne,S.S.K., and S.L.Cuppett. 2007. Potential of Rosemary (Rosemarinus officinalis L.) Diterpenes in Preventing Lipid Hydroperoxide-Mediated Oxidative Stress in Caco-2 Cells. J Agric Food Chem. 55:1193-1199. 
Ye,J. 2008. Botanical treatments for diabetes and obesity. Endocr. Metab Immune. Disord. Drug Targets. 8:77.

Yu,Y.M., C.H.Lin, H.C.Chan, and H.D.Tsai. 2009. Carnosic acid reduces cytokine-induced adhesion molecules expression and monocyte adhesion to endothelial cells. Eur. J. Nutr. 48:101-106.

Yun,J.W. 2010. Possible anti-obesity therapeutics from nature--a review. Phytochemistry 71:1625-1641. 


\section{OBJECTIVES}

\section{General objectives}

The aim of this doctoral thesis was to generate specific extracts from the edible parts of rosemary and ash tree seeds, identify their active compounds, and evaluate their effects in in vitro, in vivo and human models. Their chief compounds were identified and evaluated for their activities in vitro with regard to their antioxidant effects, activation of PPAR $\alpha$ and PPAR $\gamma$, and capacity to inhibit preadipocyte differentiation. The extracts were tested for their ability to control obesity and glycemia in animal models, and the ash tree seed extract was examined for its capacity to control glucose regulation in humans.

\section{Specific objectives}

- Screen antioxidant activities on three commercial extracts obtained from rosemary leaves standardized to contain, respectively, $20 \%$ carnosic acid, $40 \%$ ursolic acid, or $20 \%$ rosmarinic acid. These extracts were evaluated for their total antioxidant effects on oxygen radical absorbance capacity (ORAC), ferric reducing/antioxidant power (FRAP), and for their capacity to inhibit $\mathrm{Cu}^{2+}$-induced LDL oxidation ex vivo.

- Determine the preventive effects of a rosemary extract (20\% carnosic acid) on weight gain, glycaemia levels, and lipid homeostasis in mice, and study its effects on pancreatic lipase and PPAR $\gamma$ agonist activity in vitro.

- Identify secoiridoid glycosides from Fraxinus excelsior L. seed extract, and determine their capacity to activate PPAR $\alpha$ and inhibit the differentiation of pre-adipocytes into adipocytes in vitro.

- Determine whether a Fraxinus excelsior L. seed extract limits weight gain and hyperglycemia in mice.

- Asses the acute clinical efficacy and safety of Fraxinus excelsior L. seed extract on plasma glucose and insulin levels against glucose $(50 \mathrm{~g})$ induced postprandial glycemia in healthy humans. 


\section{CHAPTER I}

\section{IMPORTANCE OF EXTRACT STANDARDIZATION AND IN VITRO/EX VIVO ASSAY SELECTION FOR THE EVALUATION OF ANTIOXIDANT ACTIVITY OF BOTANICALS: A CASE STUDY ON THREE Rosmarinus officinalis L. EXTRACTS}

\footnotetext{
Alvin Ibarra ${ }^{1}$, Julien Cases ${ }^{2}$, Antoine Bily ${ }^{1}$, Kan $\mathrm{He}^{1}$, Naisheng Bai ${ }^{1}$, Marc Roller $^{2}$, Aurélie Coussaert ${ }^{3}$ and Christophe Ripoll ${ }^{3}$

${ }^{1}$ Naturex Inc., 375 Huyler St., South Hackensack, New Jersey 07606, USA

${ }^{2}$ Naturex SA, BP 1218 site d'Agroparc, 84911 Avignon Cedex 9, France

${ }^{3}$ Naturalpha SAS, Parc Eurasanté Lille Métropole, 85, rue Nelson Mandela, 59120

Loos, France
} 


\section{Abstract}

The overproduction of free radicals and oxygen reactive species is suspected to be implicated in a wide range of metabolic reactions that can have pernicious consequences in the development of a variety of human diseases. Botanical extracts are sources of antioxidants which counteract both free radicals and ORS. The processing conditions used in the botanical extraction may influence the antioxidant composition; therefore, different extracts from the same plant may have different antioxidant properties. To illustrate this fact, we conducted a study using three commercial rosemary (Rosmarinus officinalis L.) leaf extracts. The three extracts were standardized to respectively contain, $20 \%$ carnosic acid, $40 \%$ ursolic acid, or $20 \%$ rosmarinic acid. They were evaluated for their total (hydrophilic + lipophilic) antioxidant effects on oxygen radical absorbance capacity (ORAC), their ferric reducing/antioxidant power (FRAP), and their capacity to inhibit $\mathrm{Cu}^{2+}$-induced low-density lipoprotein (LDL) oxidation ex vivo. The ursolic acid extract showed the lowest antioxidant capacity on all models. The rosmarinic acid extract had an antioxidant capacity 1.5 times higher on ORAC and 4 times higher on FRAP than the carnosic acid extract. However, the carnosic acid extract was better than the rosmarinic acid extract in inhibiting the oxidation of LDL ex vivo. These results encourage conducting further studies to evaluate the carnosic acid and rosmarinic acid extracts in vivo. Our study offers an example of the importance of the extraction procedures, on which depends the nature of the antioxidant composition, and highlights interest to proceed with in vitro/ex vivo assay selection for the evaluation of the antioxidant properties of botanical extracts.

Keywords: antioxidant capacity, carnosic acid, ferric reducing/antioxidant power, LDL oxidation, ORAC, rosemary, rosmarinic acid. 


\section{Introduction}

The overproduction of free radicals and reactive oxygen species in living organisms can damage cellular lipids, proteins, or DNA; this process contributes to loss of functionality, which has been described as being related to the development of a wide range of human diseases, including cancer, cardiovascular disease, atherosclerosis, hypertension, ischemia/reperfusion injury, diabetes mellitus, neurodegenerative diseases (Alzheimer's disease and Parkinson's disease), rheumatoid arthritis, and aging (Valko et al., 2007; Fuhrman et al., 2000; Hsieh et al., 2007;Lee et al., 2007). It has been postulated that supplementation with phytochemicals such as polyphenols, including flavonoids, may offer some protection against these complications through their roles as free radical scavengers and antioxidant compounds, therefore reducing the negative effect of oxidative stress and free radicals (Seifried et al., 2007).

Botanical extracts are well-recognized sources of antioxidant molecules. They are commonly used in functional foods and as dietary supplements, and contribute to the composition of several drugs (Raskin et al., 2002). However, botanical extracts are not always well accepted because of issues concerning active compound identification, standardization, and quality control (Raskin and Ripoll, 2004). In our study, we used rosemary extracts obtained through industrial processes. Various technologies are involved to produce botanical extracts at industrial levels; the most important include solvent extraction and column purification (D'Amelio FS, 1998). It is noteworthy that the physicalchemical properties of the solvent, the extraction conditions, and the nature of resins in columns influence the nature of the extracted molecules with consequences on the nutritional profile and, overall, on the physiological protective efficiency of the final extract (D'Amelio FS, 1998;Mahady et al., 2001). Therefore, different extracts from the same botanical origin may have different standardization rates and composition, providing different antioxidant properties (Mahady et al., 2001), which may lead to ambiguous efficacy data when studied in clinical trials (Raskin and Ripoll, 2004). Based on these considerations, it is of great interest to develop well-characterized extracts in order to achieve biochemical and functional consistency between batches.

Rosemary (Rosmarinus officinalis L.) is an aromatic Mediterranean plant used in traditional meals and several industrial food applications (Etter, 2004). Recently, rosemary 
extracts standardized in carnosic acid and carnosol have received the antioxidant status, with an attributed E number, from the European Food Safety Authority (Aguilar et al., 2008), confirming the importance of this ingredient as a natural preservative in foods and beverages. Moreover, rosemary may also contribute to reduce the oxidation of low-density lipoprotein (LDL) because of its elevated antioxidant capacity (Pitsavos et al., 2005). The properties of rosemary's active compounds are well documented, but information regarding the preventive antioxidant potential of standardized rosemary extracts is still scarce and should be investigated with more attention. Each of the extracts we studied for the present article was standardized on one of rosemary's main active compounds: carnosic acid, a diterpene phenolic acid (Figure I-1A); ursolic acid, a pentacyclic triterpene acid (Figure I1B); and rosmarinic acid, a caffeic acid dimer (Figure I-1C) (del Bano et al., 2003).

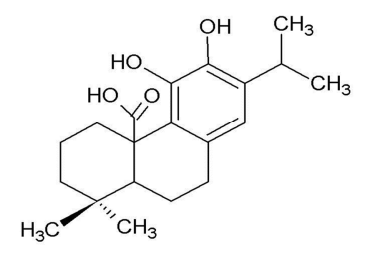

(A)

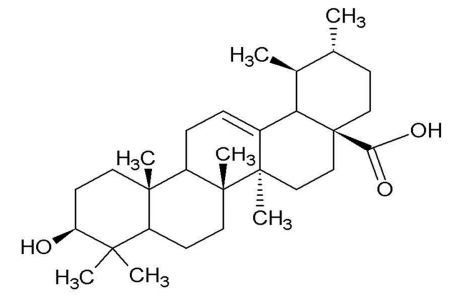

(B)

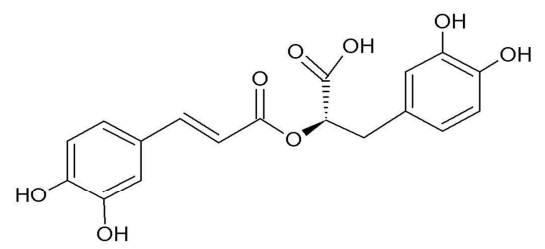

(C)

Figure I-1. Chemical structures of the main compounds present in the R. officinalis L. leaf extracts: (A) carnosic acid, (B) ursolic acid, or (C) rosmarinic acid.

In this pursuit, we conducted a screening of antioxidant activities on three commercial extracts obtained from rosemary leaves standardized to contain, respectively, $20 \%$ carnosic acid, $40 \%$ ursolic acid, or $20 \%$ rosmarinic acid. These extracts were evaluated for their total antioxidant effects on oxygen radical absorbance capacity (ORAC) with a special focus on both their hydrophilic and lipophilic antioxidant capacities, for their ferric 
reducing/antioxidant power (FRAP), and for their capacity to inhibit $\mathrm{Cu}^{2+}$-induced LDL oxidation in an ex vivo assay. These models will allow us to select and classify the extracts according to their antioxidant properties, which may have different effects in further applications (Aguilar et al., 2008), with specific attention to the prevention of healthdeleterious effects of a much too high oxidative stress (Valko et al., 2007).

\section{Materials and Methods}

\section{Rosemary extracts}

Rosemary leaves were collected from the Atlas Mountains in Morocco and authenticated using macroscopic, microscopic, and high-performance thin-layer chromatography techniques (Reich and Schibli, 2007). Figure I-2 shows the industrial process involved to obtain the three rosemary extracts (Naturex, Avignon, France). The rosemary extract standardized to contain $20 \%$ carnosic acid was prepared according to the U.S. patent 5,859,293 (Baley et al., 1997): this extract, in powdered form after drying, contains $45 \%$ of maltodextrin as a carrier and has an extraction ratio of 10:1 (rosemary leaves: powdered extract). The rosemary extract standardized to contain $40 \%$ ursolic acid is obtained by extraction with acetone for 2 hours, followed by precipitation at $5^{\circ} \mathrm{C}$ for 8 hours. The ursolic acid extract, in powdered form after drying, contains $7.5 \%$ of maltodextrine as a carrier and has an extraction ratio of 8:1 (rosemary leaves: powdered extract). The rosemary extract standardized to contain $20 \%$ rosmarinic acid is obtained by water extraction at $65^{\circ} \mathrm{C}$ for 2 hours, followed by purification on a styrene-divinyl-benzene XAD-16 resin (Rohm and Haas, Philadelphia, PA, USA) packed in an industrial column. The rosmarinic acid extract, in powdered form after drying, contains $8.9 \%$ of maltodextrine as a carrier and has an extraction ratio of 25:1 (rosemary leaves: powdered extract).

\section{Chromatographic analyses}

High-performance liquid chromatography methods were developed for the quantification of carnosic acid, ursolic acid, and rosmarinic acid in the rosemary extracts. The high-performance liquid chromatography system used was an Agilent Technologies (Palo Alto, CA, USA) model 1100. 
To evaluate the carnosic acid concentration, the standard (catalog number 03198, ChromaDex, Santa Ana, CA, USA) and the carnosic acid extract sample were diluted in methanol with $0.5 \%$ acetonitrile. The stationary phase was a Zorbax SBC18 column $(250 \mathrm{x}$ $4.6 \mathrm{~mm}$ i.d, particle size $5 \mu \mathrm{m}$; Agilent Technologies) thermostatted at $25^{\circ} \mathrm{C}$. The flow rate was $1.5 \mathrm{~mL} /$ minute, and the elution was monitored at $230 \mathrm{~nm}$. The mobile phases were (A) acetonitrile and (B) water with $0.5 \% \mathrm{H}_{3} \mathrm{PO}_{4}$. Elution started with $65 \% \mathrm{~A}$ and $35 \% \mathrm{~B}$ under isocratic conditions. The retention time of carnosic acid was 11 minutes (Figure I-3A).

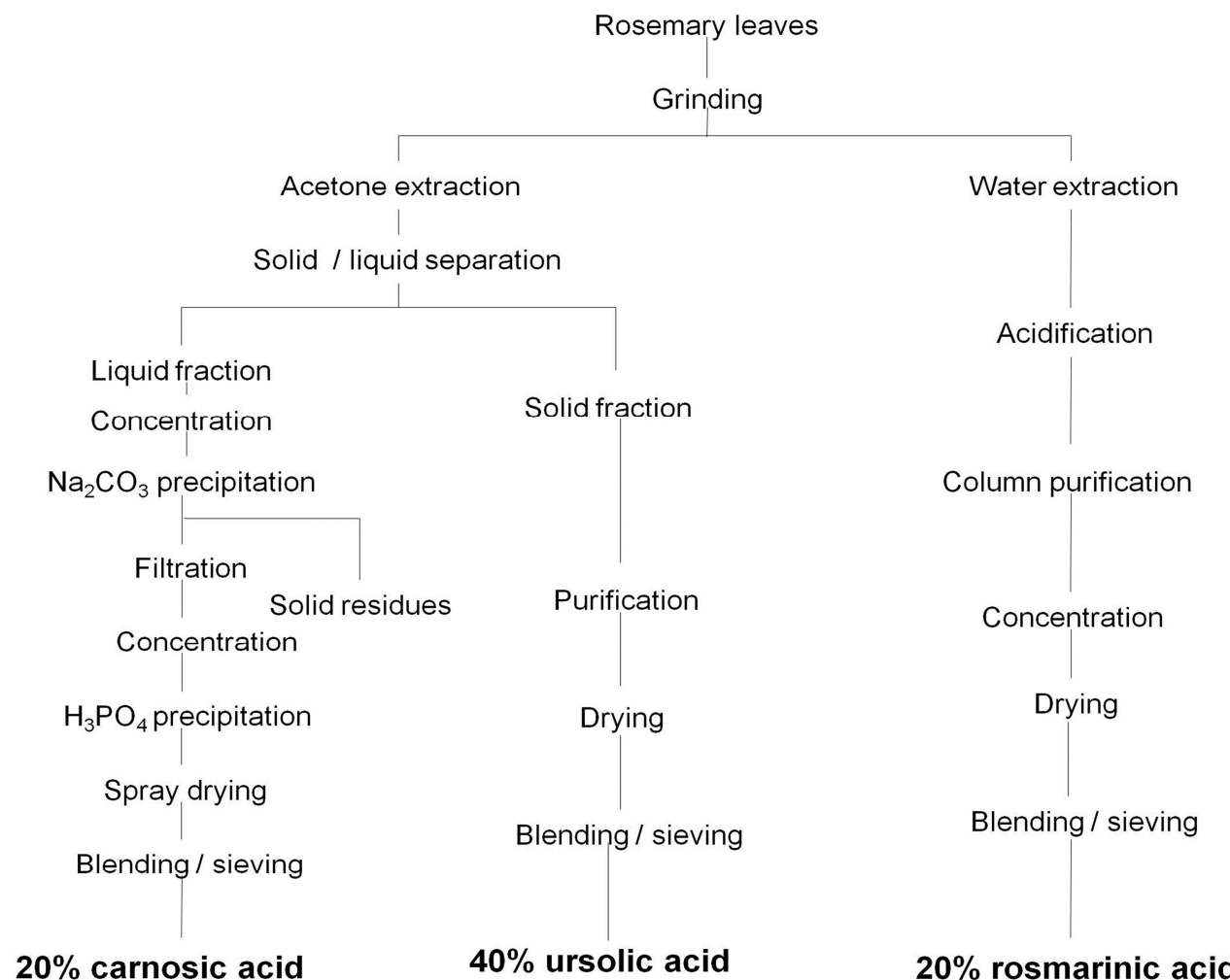

Figure I-2. Extraction scheme of the three R. officinalis L. leaf extracts standardized to contain $20 \%$ carnosic acid, $40 \%$ ursolic acid, or $20 \%$ rosmarinic acid. 

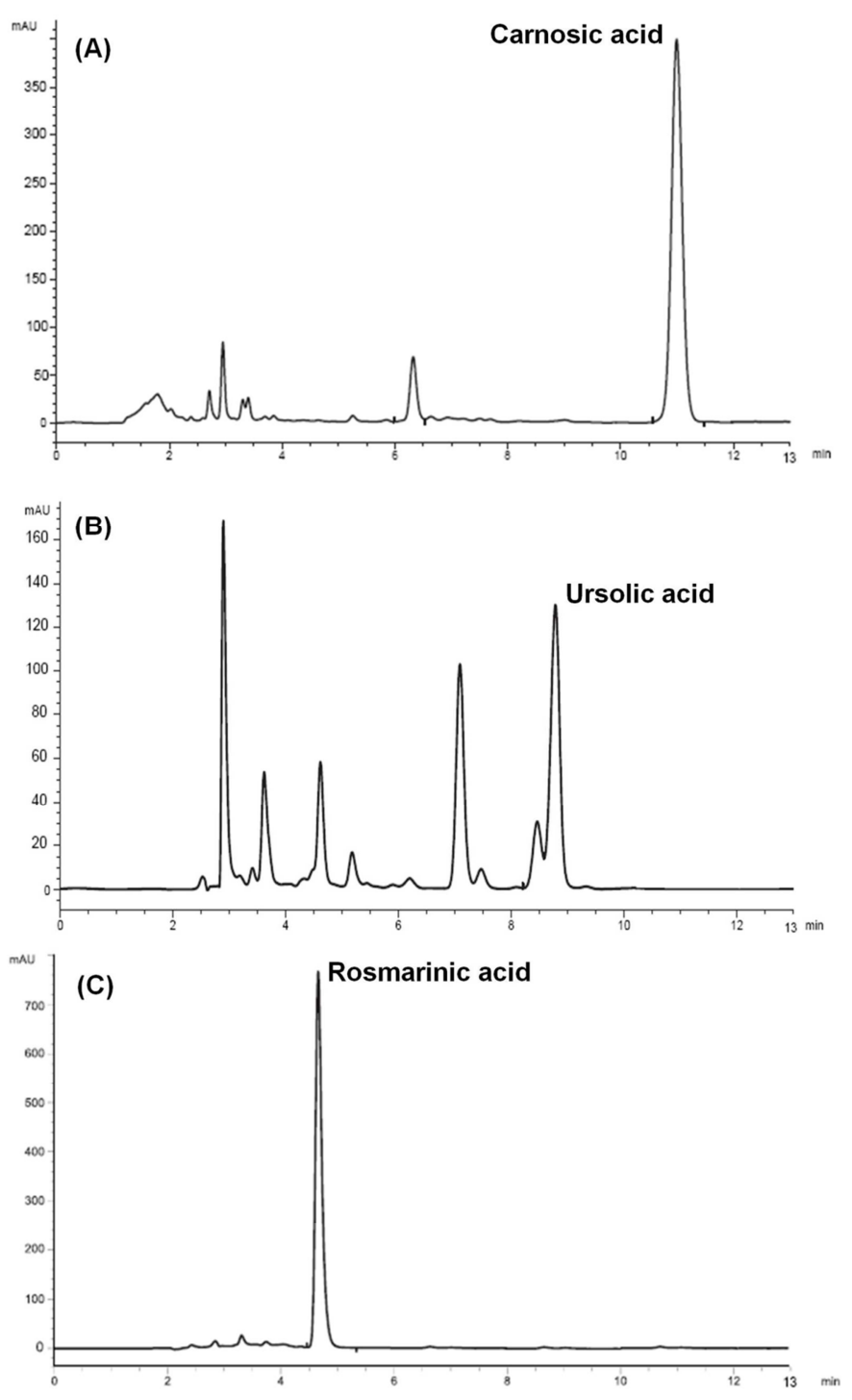

Figure I-3. High-performance liquid chromatogram profile of the three $R$. officinalis L. leaf extracts: (A) $20 \%$ carnosic acid, (B) $40 \%$ ursolic acid, or (C) $20 \%$ rosmarinic acid. mAU, milli-absorbance units (i.e., optical density). 
To evaluate the ursolic acid concentration, the standard (catalog number 0037S, Extrasynthese, Genay, France) and the ursolic acid sample were diluted in acetone. The stationary phase was a Luna $^{\mathrm{TM}} \mathrm{C} 18$ column $(150 \times 4.0 \mathrm{~mm}$ i.d; particle size $3 \mu \mathrm{m}$; Phenomenex, Utrecht, The Netherlands) thermostatted at $30^{\circ} \mathrm{C}$. The flow rate was 0.6 $\mathrm{mL} /$ minute, and the elution was monitored at $210 \mathrm{~nm}$. The mobile phases were (A) acetonitrile and (B) water with $0.1 \% \mathrm{H}_{3} \mathrm{PO}_{4}$. Elution started with $90 \% \mathrm{~A}$ and $10 \% \mathrm{~B}$ under isocratic conditions. The retention time of ursolic acid was 8.7 minutes (Figure I-3B).

To evaluate the rosmarinic acid concentration, standard (catalog number 4957S; Extrasynthese) and rosmarinic acid sample were diluted in methanol/water (50:50, vol/vol). The stationary phase was a Zorbax SBC18 column ( 250 x $4.6 \mathrm{~mm}$ i.d.; particle size $5 \mu \mathrm{m}$; Agilent Technologies) thermostatted at $20^{\circ} \mathrm{C}$. The flow rate was $1 \mathrm{~mL} /$ minute, and the elution was monitored at $328 \mathrm{~nm}$. The mobile phases were (A) acetonitrile and (B) water with $0.1 \%$ trifluoroacetic acid. Elution started with $32 \%$ A and $68 \%$ B under isocratic conditions. The retention time of rosmarinic acid was 4.6 minutes (Figure I-3C).

\section{ORAC assay}

The ORAC value provides a measure of the scavenging capacity of antioxidants against the peroxyl radical, which is one of the most common reactive oxygen species produced during the body metabolism. The ORAC values of each sample were determined according to an adaptation of methods previously described (Cao et al., 1993;Huang et al., 2002b;Ou et al., 2001), based on a fluorimetric detection. Analyses were conducted at Brunswick Laboratories (Norton, MA, USA) according to a patented method (Ou et al., 2006). The lipophilic ORAC assay ( $\mathrm{ORAC}_{\text {lipo }}$ ) was based on a previous reported method (Huang et al., 2002a), and the hydrophilic ORAC assay $\left(\right.$ ORAC $\left._{\text {hydro }}\right)$ was based on a different reported method (Ou et al., 2002). The $\mathrm{ORAC}_{\text {hydro }}$ assay reflects the water-soluble antioxidant capacity, and the $\mathrm{ORAC}_{\text {lipo }}$ assay reflects the lipid-soluble antioxidant capacity; the $\mathrm{ORAC}_{\text {total }}$ is the sum of ORAC $\mathrm{Ohdro}_{\text {ha }}$ and $\mathrm{ORAC}_{\text {lipo. }}$. All data were expressed as $\mu \mathrm{mol}$ of 6hydroxy-2,5,7,8-tetramethylchroman-2-carboxylic acid (Trolox, Sigma Chemical Co., St. Louis, MO, USA) equivalents (TE)/g of dry sample ( $\mu \mathrm{mol}$ TE/g). For each analysis, a 20$\mu \mathrm{L}$ acetone/water (50:50, vol/vol) sample was assessed for one extract. 


\section{FRAP assay}

The FRAP values of samples were determined according to the method previously described (Pulido et al., 2000). Two types of calibration curves were made: one with aqueous solutions of known $\mathrm{Fe}^{2+}$ concentration, in the range of $100-1,000 \mu \mathrm{mol} / \mathrm{L}$, and another with solutions of known Trolox concentration, in the range of 100-750 $\mu \mathrm{mol} / \mathrm{L}$. Extracts were measured in triplicate at three different concentrations after appropriate dilution. In the FRAP assay, reductants in the sample (i.e. antioxidants) reduce the $\mathrm{Fe}^{3+} /$ tripyridyltriazine complex, present in stoichiometric excess, to the blue-colored ferrous form, with an increase in absorbance at $593 \mathrm{~nm}$; the variation of absorbance $(\Delta \mathrm{A})$ is proportional to the combined FRAP of the sample. Results are expressed as $\mu \mathrm{mol}$ of TE/ $\mathrm{g}$ of $30-\mu \mathrm{L}$ triplicate sample extracts and as $\mathrm{mmol} \mathrm{Fe}^{2+} / \mathrm{g}$ of triplicate sample extracts.

\section{5. $\mathrm{Cu}^{2+}$-induced LDL oxidation assay}

Blood from a 33-years-old healthy normolipemic female donor was obtained by venipuncture and collected in EDTA-containing Vacutainer blood collection set (BD, Franklin Lakes, NJ, USA) at the local blood bank (Etablissement Français du Sang, Lille, France). LDL was prepared from the plasma by two density gradient ultracentrifugation within a density cutoff range of $1.019-1.063 \mathrm{~g} / \mathrm{mL}$. Prior to oxidation, LDL was diluted in phosphate-buffered saline and dialyzed against phosphate-buffered saline at $4^{\circ} \mathrm{C}$. The protein content was determined and adjusted to obtain $0.125 \mathrm{mg}$ of protein $/ \mathrm{mL}$. Next, the oxidation was induced at $30^{\circ} \mathrm{C}$ by adding $20 \mu \mathrm{L}$ of $\mathrm{CuSO}_{4}(1.66 \mu \mathrm{mol})$ with the addition of $0 \mu \mathrm{g} / \mathrm{mL}$ (control condition), $5 \mu \mathrm{g} / \mathrm{mL}, 25 \mu \mathrm{g} / \mathrm{mL}$, and $100 \mu \mathrm{g} / \mathrm{mL}$ rosemary extracts (respectively, $20 \%$ carnosic acid, $40 \%$ ursolic acid, or $20 \%$ rosmarinic acid), or $2.5 \mu \mathrm{g} / \mathrm{mL}$ and $25 \mu \mathrm{g} / \mathrm{mL}$ of Trolox as the positive control. The amounts of conjugated dienes were measured by determining the increased absorbance at $234 \mathrm{~nm}$ at 10 minute intervals for a course span of 720 min using an Ultra Spectrophotometer (Ultra 384, Tecan Group Ltd., Grödig, Austria). Results were expressed as the relative absorbance at $234 \mathrm{~nm}$. The lag phase, the oxidation rate, and the maximum quantity of conjugated dienes were calculated. 


\section{Statistical analysis}

Excepted for ORAC assay, all tests were carried out in triplicate, and the results were presented as means \pm SD values. Significant differences were calculated according to Student's $t$ test (XLSTAT 2008, Addinsoft ${ }^{\mathrm{TM}}$, New York, NY, USA), and the statistical significance was set at $P<.05$.

\section{Results}

\section{Antioxidant capacity}

Antioxidant capacities were measured using ORAC and FRAP assays. Results for the three rosemary extracts are presented in Table I-1. The rosemary extract standardized to contain 20\% rosmarinic acid showed the highest antioxidant capacity in both ORAC and FRAP assays, with the ORAC $_{\text {hydro }}$ explaining more than $97 \%$ of its total antioxidant capacity according to ORAC assay, evidencing the high polarity of the rosmarinic fraction. On the other hand, the rosemary extract standardized to contain $20 \%$ carnosic acid showed a strong antioxidant capacity in both ORAC and FRAP tests; however, its total antioxidant capacity is only $36 \%$ by the $\mathrm{ORAC}_{\text {hydro }}$ assay and is $64 \%$ by the $\mathrm{ORAC}_{\text {lipo }}$ assays, which is not surprising because carnosic acid is a terpene compound with more hydrophobic properties. Finally, the rosemary extract standardized to contain $40 \%$ ursolic acid showed, by far, the lowest antioxidant capacity.

Table I-1. Oxygen radical absorbance capacity and ferric reducing/antioxidant power values for rosemary $(R$. officinalis L.) extracts

\begin{tabular}{lccc|cc}
\hline Rosemary extracts & $\begin{array}{c}\text { ORAC }_{\text {hydro }} \\
(\mu \mathrm{mol} \text { of } \\
T E / g)^{*}\end{array}$ & $\begin{array}{c}\text { ORAC } \\
(\mu \mathrm{mol} \text { of } \\
T E / g)^{*}\end{array}$ & $\begin{array}{c}\text { ORAC }_{\text {total }} \\
(\mu \mathrm{mol} \text { of } \\
T E / g)^{*}\end{array}$ & $\begin{array}{c}\text { FRAP } \\
(\mu \mathrm{mol} \text { of } \\
T E / g)\end{array}$ & $\begin{array}{c}\text { FRAP } \\
(\mathrm{mmol} \text { of } \\
\left.F e^{2+} / g\right)\end{array}$ \\
\hline $\mathbf{2 0 \%}$ Carnosic acid & 2,345 & 4,144 & 6,489 & $699 \pm 26^{\mathrm{b}}$ & $1.28 \pm 0.002^{\mathrm{b}}$ \\
\hline $\mathbf{4 0 \%}$ Ursolic acid & 163 & 141 & 304 & $81 \pm 3^{\mathrm{a}}$ & $0.15 \pm 0.0003^{\mathrm{a}}$ \\
\hline $\mathbf{2 0 \%}$ Rosmarinic acid & 9,880 & 238 & 10,118 & $2,957 \pm 107^{\mathrm{c}}$ & $5.30 \pm 0.01^{\mathrm{c}}$ \\
\hline
\end{tabular}

"Data are obtained from one sample with acceptable precision of the ORAC assay being $15 \%$ relative SD (Huang et al., 2002b;Ou et al., 2001;Ou et al., 2006).

abc For FRAP results in the same column, values with different letters are significantly $(P<.05)$ different compared with the blank control alone ( $t$ test). FRAP, ferric reducing/antioxidant power: ORAC, oxygen radical absorbance capacity, where the subscripts hydro, lipo, and total designate water-soluble, lipophilic, and total, respectively. 
The rosmarinic fraction has an antioxidant capacity 1.5 times higher than the carnosic acid according to $\mathrm{ORAC}_{\text {total }}$, and is four times stronger according to FRAP. However, the carnosic acid fraction demonstrates a very good hydrophilic/lipophilic balanced antioxidant power, whereas the rosmarinic acid does not.

\section{2. $\mathrm{Cu}^{2+}$-induced LDL oxidation inhibitory capacity}

The incubation of isolated human LDL with $\mathrm{CuSO}_{4}$ resulted in the oxidation of polyunsaturated fatty acids, as monitored by the generation of conjugated dienes after a variable period of inhibition called lag phase (Figure I-4) (Perugini et al., 1997). The inhibitory activities of the three rosemary extracts on LDL oxidation mediated by $\mathrm{Cu}^{2+}$ have been evaluated with comparison to a blank control and to the Trolox positive control (Table I-2). The three extracts showed different antioxidant behaviors on this assay.

The extract standardized on rosmarinic acid provided a pro-oxidant activity at the lowest concentration $(5 \mu \mathrm{g} / \mathrm{mL})$, with an increase of $40.1 \%(P<0.001)$ of the oxidation rate and a strong shortening of the lag phase (-52.8 minutes) compared to the blank control; nevertheless, an inversion of the tendency with a strong antioxidant activity started from 25 $\mu \mathrm{g} / \mathrm{mL}$, providing a complete inhibition of LDL oxidation in a manner similar to that of Trolox at $25 \mu \mathrm{g} / \mathrm{mL}$. With more efficiency, the extract standardized on carnosic acid was able to decrease the oxidation rate by $27.3 \%(P<.001)$ and to prolong the lag phase $(+24.1$ minutes) from the lowest concentration tested $(5 \mu \mathrm{g} / \mathrm{mL})$ and to totally inhibit LDL oxidation from $25 \mu \mathrm{g} / \mathrm{mL}$, in a manner similar to that of Trolox at $25 \mu \mathrm{g} / \mathrm{mL}$. For the last rosemary extract, which was standardized to contain $40 \%$ ursolic acid, results appeared to be less active than the two other rosemary extracts but permitted a decrease in the oxidation rate with a dose-effect response (up to $41.1 \%$ for the highest dose $100 \mu \mathrm{g} / \mathrm{mL}$ ) correlated to a prolongation of the lag phase. 

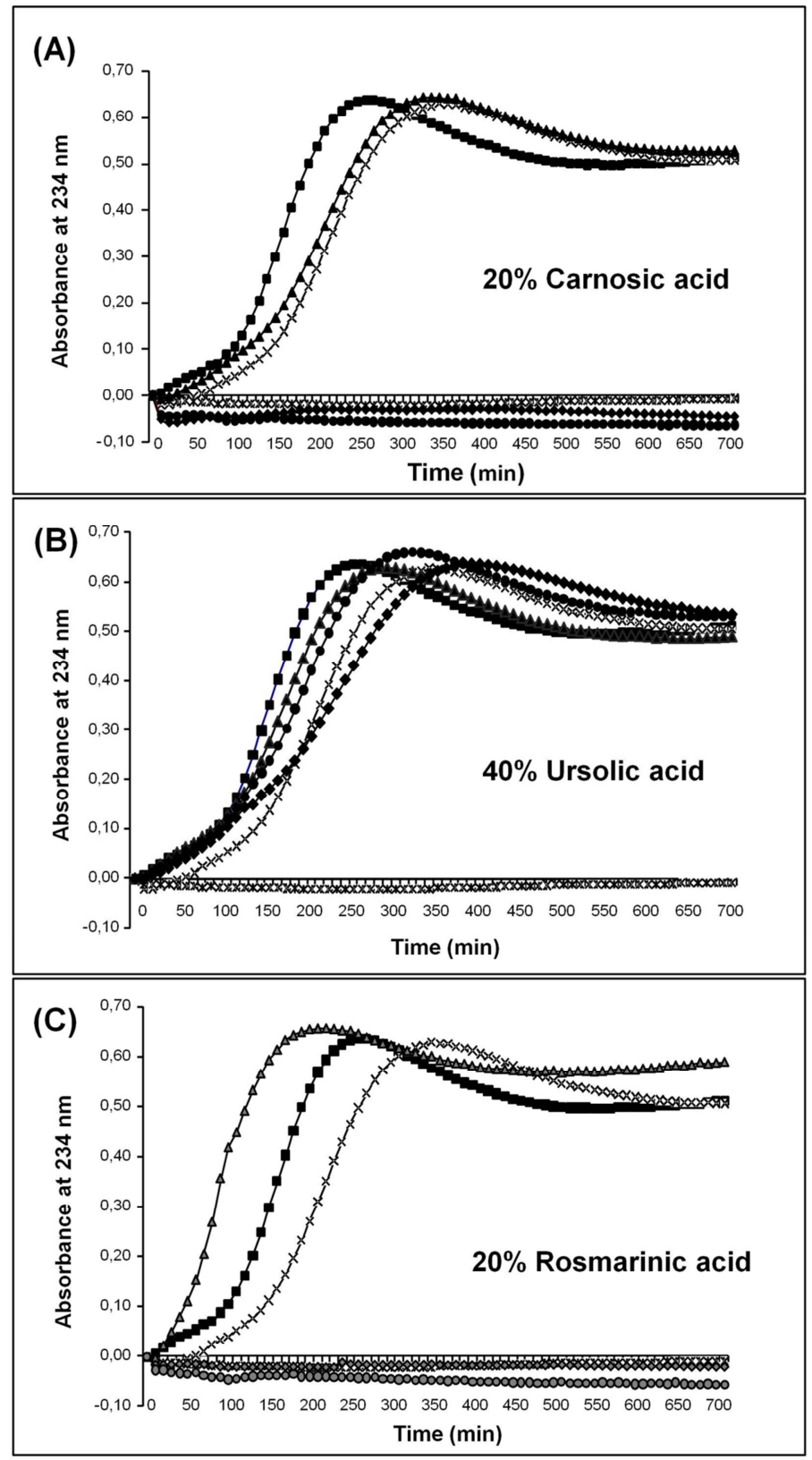

Figure 1-4. Curve for $\mathrm{Cu}^{2+}$-induced oxidation of LDL with different concentrations $(\boldsymbol{\square}, 0 \mu \mathrm{g} / \mathrm{mL} ; \boldsymbol{\Delta}, 5$ $\mu \mathrm{g} / \mathrm{mL} ; \diamond, 25 \mu \mathrm{g} / \mathrm{mL} ; \bullet, 100 \mu \mathrm{g} / \mathrm{mL}$ ) of $R$. officinalis L. leaf extracts standardized to contain (A) $20 \%$ carnosic acid, (B) $40 \%$ ursolic acid, or (C) $20 \%$ rosmarinic acid. Trolox ( $\times, 2.5 \mu \mathrm{g} / \mathrm{mL} ; *, 25 \mu \mathrm{g} / \mathrm{mL}$ ) was used as the positive control. 
Table I-2. Overall results for inhibition of low-density lipoprotein $\mathrm{Cu}^{2+}$-induced oxidation by rosemary (R. officinalis L.) extracts.

\begin{tabular}{|c|c|c|c|c|}
\hline \multirow[b]{2}{*}{ Rosemary extracts } & \multicolumn{4}{|c|}{$\mathrm{Cu}^{2+}{ }_{- \text {induced oxidation } L D L \text { assay }}$} \\
\hline & Concentration & $\begin{array}{l}\text { Lag phase } \\
\quad \text { (min) }\end{array}$ & $\begin{array}{l}\text { Oxidation rate } \\
\qquad\left(\mathrm{min}^{-1}\right)\end{array}$ & $\begin{array}{l}\text { Maximum quantity of } \\
\quad \text { dienes } \\
\text { (nmol/mg of } L D L)\end{array}$ \\
\hline \multirow{3}{*}{$20 \%$ Carnosic acid } & $5 \mu \mathrm{g} / \mathrm{ml}$ & $112.3 \pm 7.4$ & $1.27 \pm 0.04^{\mathrm{c}}$ & $370.0 \pm 3.8$ \\
\hline & $25 \mu \mathrm{g} / \mathrm{ml}$ & $\mathrm{NC}$ & $\mathrm{NC}$ & $\mathrm{NC}$ \\
\hline & $100 \mu \mathrm{g} / \mathrm{ml}$ & $\mathrm{NC}$ & $\mathrm{NC}$ & $\mathrm{NC}$ \\
\hline \multirow{3}{*}{$40 \%$ Ursolic acid } & $5 \mu \mathrm{g} / \mathrm{ml}$ & $91.7 \pm 1.7$ & $1.4 \pm 0.2^{\mathrm{c}}$ & $361.7 \pm 22.0$ \\
\hline & $25 \mu \mathrm{g} / \mathrm{ml}$ & $102.3 \pm 7.35$ & $1.2 \pm 0.24^{\mathrm{a}}$ & $379.8 \pm 8.1^{\mathrm{a}}$ \\
\hline & $100 \mu \mathrm{g} / \mathrm{ml}$ & $109.5 \pm 16.05$ & $0.97 \pm 0.09^{\mathrm{c}}$ & $369.1 \pm 21.2$ \\
\hline \multirow{3}{*}{$\begin{array}{l}\text { 20\% Rosmarinic } \\
\text { acid }\end{array}$} & $5 \mu \mathrm{g} / \mathrm{ml}$ & $35.4 \pm 2.14^{\mathrm{b}}$ & $2.14 \pm 0.07^{\mathrm{c}}$ & $376.1 \pm 3.9^{c}$ \\
\hline & $25 \mu \mathrm{g} / \mathrm{ml}$ & $\mathrm{NC}$ & $\mathrm{NC}$ & $\mathrm{NC}$ \\
\hline & $100 \mu \mathrm{g} / \mathrm{ml}$ & $\mathrm{NC}$ & $\mathrm{NC}$ & $\mathrm{NC}$ \\
\hline \multirow{2}{*}{ Control: Trolox ${ }^{\circledR}$} & $2.5 \mu \mathrm{g} / \mathrm{ml}$ & $130.9 \pm 3.8^{\mathrm{a}}$ & $1.32 \pm 0.07$ & $364.0 \pm 3.7$ \\
\hline & $25 \mu \mathrm{g} / \mathrm{ml}$ & $\mathrm{NC}$ & $\mathrm{NC}$ & $\mathrm{NC}$ \\
\hline $\mathrm{Cu}^{2+}$ alone & & $88.2 \pm 2.3$ & $1.65 \pm 0.02$ & $360.3 \pm 4.4$ \\
\hline
\end{tabular}

${ }^{\mathrm{a}} P<.05 ;{ }^{\mathrm{b}} P<.01 ;{ }^{\mathrm{c}} P<.001$ versus $\mathrm{Cu}^{2+}$-induced oxidation of LDL alone ( $t$ test).

LDL, low-density lipoprotein; NC, not calculated because the samples totally inhibit the LDL from oxidation.

\section{Discusion}

Rosemary is a key ingredient in the Mediterranean diet (Pitsavos et al., 2005). During the last few years, the production of rosemary extracts has been increased considerably because of their use in the food, beverage, flavor, nutraceutical, and cosmetic industries. Consequently, the technology to develop standardized extracts from rosemary has experienced a quick evolution in terms of quality and reproducibility.

The two rosemary extracts standardized on carnosic and rosmarinic acids are primarily used as preservatives in foods and beverages and as stability enhancers for natural colorants, especially those susceptible of oxidation like carotenoids and anthocyanins 
(Etter, 2004). On the other hand, the ursolic acid fraction is mainly used in the cosmetic industry because of its topical anti-inflammatory capacity (Altinier et al., 2007). Across the board, the antioxidant effects of rosemary's active compounds have been extensively reported in literature (del Bano et al., 2003;Wijeratne and Cuppett, 2007); however, there are still few reports on commercial extracts obtained through industrial processes and that are available to the consumers.

Several techniques have been developed in order to determine the antioxidant power of food products, vegetable extracts, and pure molecules (Huang et al., 2005;Cao et al., 1993). The methods chosen for our study are based on the two major mechanisms that intervene in the stabilization of pro-oxidant species by antioxidants: the first mechanism (ORAC) is based on hydrogen transfer from the antioxidant to the oxidant and reflects the capacity to inhibit oxidation at the early step of initiation and/or propagation; the second (FRAP) is based on electron transfer from the antioxidant to the oxidant and reflects capacity to reduce the oxidant (Cao et al., 1993;Huang et al., 2002b;Pulido et al., 2000;Huang et al., 2005;Benzie and Strain, 1996;Prior and Cao, 1999). Consequently, ORAC and FRAP results give different, and not comparable, values of antioxidant capacities of the three extracts, with, however, the classification of the antioxidant capacity being always the same: $20 \%$ rosmarinic acid $>20 \%$ carnosic acid $>40 \%$ ursolic acid.

When compared with ORAC values of different food or spice products, both rosemary extracts, titrated in carnosic and rosmarinic acids, which are, respectively, 6,489 and 10,118 $\mu \mathrm{mol}$ of TE/g appeared to provide a very high antioxidative protection value. Indeed, as an example, a berry juice serving, which is well known for its contribution to antioxidant protection in the five fruits and vegetables a day diet (Huntley, 2009) and that provides from blueberry, bilberry, and grape 4,750, 6,932 and 6,290 $\mu \mathrm{mol}$ of TE, gives the same range of protection as the carnosic extract and 30-50\% below the rosmarinic extract. In 2007, scientists in collaboration with the U.S. Department of Agriculture published an updated list of ORAC values for 277 foods commonly consumed by the U.S. population (USDA, 2007). The best results, apart from fruits and vegetables, were obtained for spices; among them, the highest ORAC values were obtained from ground cinnamon tissue, providing 2,675 $\mu \mathrm{mol}$ of TE/g (100\% as hydrophilic total ORAC value), and from cloves buds, providing 3,144 $\mu \mathrm{mol}$ of $\mathrm{TE} / \mathrm{g}$ (50\% as hydrophilic and $50 \%$ as lipophilic ORAC values). 
The FRAP values obtained with both rosmarinic and carnosic extracts in our study showed higher results than those obtained for an artichoke extract titrated in 5\% total phenolic acids with $343 \mu \mathrm{mol}$ of TE/g (Jimenez-Escrig et al., 2003). In general, the FRAP values of vegetables are much lower compared to the values obtained in our study; this is confirmed by results from a screening of 927 freeze-dried vegetable samples (Ou et al., 2002). The authors reported a range of FRAP values for vegetables between $4 \mu \mathrm{mol}$ of $\mathrm{TE} / \mathrm{g}$ for peas and $261 \mu \mathrm{mol}$ of TE/g for red peppers.

During our in vitro antioxidant studies, it appeared that results obtained from ORAC and FRAP methods were not completely comparable because the physical-chemical principle of each antioxidant assay varied. It has been postulated that the ORAC method was found to be more useful as an estimate of "total antioxidant activity" as it is more ubiquitous and can monitor different kinds of activity (both slow- and fast-acting antioxidants) during a scavenging and/or an inhibiting oxidative process, with only few exceptions (Price et al., 2007); moreover, the ORAC method is able to give an opportunity to evaluate both hydrophilic and lipophilic values, which seems to better correspond to biological conditions because plasma circulation and cell cytosols are rather hydrophilic and cell and lipoprotein membranes are rather lipophilic. On the other hand, FRAP is designed to offer a putative index of reductive potential of biological fluids (Benzie and Strain, 1996) and consequently bring complementary evaluation to the ORAC method for the assessment of botanical extracts in the control of oxidative stress.

However, because the relationship between ORAC or FRAP values and the health benefit has not yet been established, evaluation of rosemary extract efficiency in rather more biological conditions, such as ex vivo LDL oxidation assay, appeared to be able to improve analyzing capacities, with a high-throughput screening methodology for the evaluation of botanical protective efficiency in biological-like conditions.

During our study, we observed that the extract standardized to contain $20 \%$ carnosic acid showed a stronger inhibition activity against oxidation of LDL induced by $\mathrm{Cu}^{2+}$ than the rosemary extract standardized to contain $20 \%$ rosmarinic acid. As proposed, according to previous results obtained with ORAC and FRAP assays, the rosemary extract standardized to contain $40 \%$ ursolic acid had only a weak protective effect against the oxidation of LDL. 
Our results corroborate previous reports that have shown that rosemary bioactive compounds, extracted with water or with acetone (respectively, rosmarinic and carnosic acids), had similar effects reported on LDL oxidation models (Fuhrman et al., 2000;Hsieh et al., 2007). Even if ursolic acid from olives has been reported for its capacity to inhibit the oxidation of LDL (Andrikopoulos et al., 2002), we, however, did not observe a similar effect using our rosemary extract standardized to contain $40 \%$ ursolic acid for the tested concentrations.

To explain the better results observed with the carnosic acid extract, showing a longer lag phase than with rosmarinic acid at the same concentration $(5 \mu \mathrm{g} / \mathrm{mL})$ and providing consequently better protection for LDL, it could be assumed that during the lag phase of $\mathrm{Cu}^{2+}$-induced LDL oxidation, the lipid-soluble antioxidants (carnosic acid) are preferentially consumed, and the length of the lag phase is assumed to be proportional to the antioxidant content of the LDL particle (Esterbauer et al., 1992). In contrast, it is also noteworthy that the extract containing $20 \%$ rosmarinic acid and tested at $5 \mu \mathrm{g} / \mathrm{mL}$, showed a pro-oxidant activity on LDL oxidation. In a previous study, rosmarinic acid was shown to have a strong activity to reduce transition metals that can form reactive oxygen species and participate in LDL oxidation, especially when lipoproteins previously contain traces of lipid hydroperoxides (Murakami et al., 2007;Briante et al., 2004); consequently, the presence of polyphenol at a concentration much lower than that of $\mathrm{Cu}^{2+}$ would contribute to the accumulation of hydroperoxides in LDL, induced by copper under its reduced form $\left(\mathrm{Cu}^{+}\right)$, and this would not be balanced by an antiperoxidant capacity that would be in insufficient amount. A similar property has been reported for oleuropein, a secoiridoid phenolic compound of olive (Briante et al., 2004). The authors suggested that the prooxidant mechanism would be due to polyphenol copper-reducing activity in presence of oleuropein; indeed, the reduced metal $\left(\mathrm{Cu}^{+}\right)$could simultaneously catalyze the production of $\mathrm{OH}^{\circ}$ hydroxyl radicals by the Fenton reaction and contribute to lipid radical formation by the decomposition of preformed lipid hydroperoxides in lipoproteins.

The global lower efficiency of the rosmarinic extract observed compared with the carnosic extract would also be due to its water solubility, which often decreases the activity of antioxidants because hydrogen-bonded complexes formed with water are ineffective in scavenging lipid radicals by hydrogen donation; it seems to play a crucial role for rosmarinic acid, which is more polar than carnosic acid. However, rosmarinic acid extract, 
which is rather hydrophilic, is able to show a strong total protective effect rising from 25 $\mu \mathrm{g} / \mathrm{mL}$, which seems to confirm that mechanism of protection would rather be a reducing and chelating activity of the transition ion $\mathrm{Cu}^{2+}$ in the aqueous medium than an antioxidant protection inside the lipoproteins. According to the polar paradox (Porter, 1993), less polar antioxidants are effective in emulsions because they are concentrated at oil-water interfaces, whereas more polar antioxidants are less effective in emulsions because they are mainly present in the aqueous phase.

In conclusion, our results show that, depending on the extraction procedure used from the same botanical source, the antioxidant properties of the final extracts can be totally different. Indeed, in our study, the ursolic acid extract presented a very low antioxidant capacity, and, based on the ORAC and FRAP assays, the rosmarinic acid extract had more antioxidant power than the carnosic acid extract, with both being more antioxidant, by far, than the ursolic acid extract. However, in the LDL oxidation ex vivo assay, the carnosic acid extract presented better results compared to the rosmarinic acid extract, suggesting that the antioxidant effect could be different in biological conditions for this specific ex vivo model than in vitro; indeed, because the carnosic acid extract showed good antioxidant properties in both hydrophilic and lipophilic ORAC assays whereas the rosmarinic acid extract only showed good antioxidant activity in the hydrophilic ORAC assay and because LDL oxidation is the product of a hydrophilic/lipophilic interface oxidative reaction, it appeared to be normal that the carnosic rosemary extract provided more efficient results in the ex vivo assay. These results encourage us to conduct further studies in order to evaluate the intestinal absorption, the body metabolism, and the antioxidant effects of the carnosic and rosmarinic acids extracts in animals and humans trials. Following these bioavailability studies, both extracts could appear to be promising candidates for protecting an organism against metabolic disorders related to elevated oxidative stress.

\section{Acknowledgments}

Financial assistance from Naturex is gratefully acknowledged. Special thanks are due to Maxine Bober, M.Sc. for her valuable assistance and to Mrs. Laure Begouaussel and Mr. Antoine Dauby for their kind contribution. 


\section{Authors disclosure statement}

A.I., A.B., K.H., and N.B employees of Naturex Inc., USA, J.C. and M.R. are employees of Natures SA, and A.C. and C.R. are employees of Naturalpha SAS. Naturex is involved in research/development and marketing/sales of rosemary extracts as ingredients for food, cosmetic and nutraceutical industries. Therefore Naturex has a commercial interest in this publication. Naturalpha, the conducting laboratory, was paid by Naturex to perform and report the scientific work that formed the basis of the publication. Naturalpha and Naturex declare that the data presented in this publication represent a true and faithful representation of the work performed.

\section{References}

Aguilar,F., H.Autrup, S.Barlow, L.Castle, W.Dekant, K.H.Engel, N.Gontard, D.Gott, S.Grilli, R.Gürtler, R.Chr.Larsen, C.Leclercq, J.C.Leblanc, F.X.Malcata, W.Mennes, M.R.Milana, I.Pratt, I.Rietjens, P.Tobback, and F.Toldra. 2008. Use of rosemary exracts as a food additive. Scientific opinion of yhe panel on food additives, flavourings, processing aids and materials in contact with food. The EFSA journal 721:1-29.

Altinier,G., S.Sosa, R.P.Aquino, T.Mencherini, R.D.Loggia, and A.Tubaro. 2007. Characterization of Topical Antiinflammatory Compounds in Rosmarinus officinalis L. Journal of Agricultural and Food Chemistry 55:1718-1723.

Andrikopoulos,N.K., A.C.Kaliora, A.N.Assimopoulou, and V.P.Papageorgiou. 2002. Inhibitory activity of minor polyphenolic and nonpolyphenolic constituents of olive oil against in vitro low-density lipoprotein oxidation. J Med Food 5.

Baley,D.T., S.L.Richeimer, V.R.Bank, and B.T.King. High purity carnosic acid from rosemary and sage extracts by $\mathrm{pH}$-controlled precipitation. 5,859,293.

Benzie,I.F., andJ.J.Strain. 1996. The ferric reducing ability of plasma (FRAP) as a measure of "antioxidant power": the FRAP assay. Anal. Biochem. 239:70-76.

Briante,R., F.Febbraio, and R.Nucci. 2004. Antioxidant/prooxidant effects of dietary nonflavonoid phenols on the $\mathrm{Cu} 2+$-induced oxidation of human low-density lipoprotein (LDL). Chem. Biodivers. 1:1716-1729.

Cao,G., H.Alessio, and R.Cutler. 1993. Oxygen-radical absorbance capacity assay for antioxidants. Free Radic Biol Med 14. 
D'Amelio FS. 1998. Botanicals: A phytocosmetic desk reference. p. 361. In CRC press (ed.) .

del Bano,M.J., J.Lorente, J.Castillo, O.Benavente-Garcia, J.A.Del Rio, A.Ortuno, K.W.Quirin, and D.Gerard. 2003. Phenolic diterpenes, flavones, and rosmarinic acid distribution during the development of leaves, flowers, stems, and roots of Rosmarinus officinalis. Antioxidant activity. J Agric. Food Chem. 51:4247-4253.

Esterbauer,H., J.Gebicki, H.Puhl, and G.J3rgens. 1992. The role of lipid peroxidation and antioxidants in oxidative modification of LDL. Free Radical Biology and Medicine 13:341-390.

Etter,S.C. 2004. Rosmarinus officinalis as an antioxidant. Journal of herbs, spices \& medicinal plants 11:121-159.

Fuhrman,B., N.Volkova, M.Rosenblat, and M.Aviram. 2000. Lycopene synergistically inhibits LDL oxidation in combination with vitamin E, glabridin, rosmarinic acid, carnosic acid, or garlic. Antioxid Redox Signal 2.

Hsieh,C.L., C.H.Peng, C.C.Chyau, Y.C.Lin, H.E.Wang, and R.Y.Peng. 2007. Low-density lipoprotein, collagen, and thrombin models reveal that Rosemarinus officinalis L. exhibits potent antiglycative effects. J Agric Food Chem 55.

Huang,D., B.Ou, M.Hampsch-Woodill, J.Flanagan, and R.Prior. 2002a. High-throughput assay of oxygen radical absorbance capacity (ORAC) using a multichannel liquid handling system coupled with a microplate fluorescence reader in 96-well format. J Agric Food Chem 50.

Huang,D., B.Ou, and R.Prior. 2005. The chemistry behind antioxidant capacity assays. J Agric Food Chem 53.

Huang,D., B.Ou, M.Hampsch-Woodill, J.A.Flanagan, and E.K.Deemer. 2002b. Development and validation of oxygen radical absorbance capacity assay for lipophilic antioxidants using randomly methylated beta-cyclodextrin as the solubility enhancer. J Agric Food Chem 50.

Huntley,A.L. 2009. The health benefits of berry flavonoids for menopausal women: Cardiovascular disease, cancer and cognition. Maturitas 63:297-301.

Jimenez-Escrig,A., L.O.Dragsted, B.Daneshvar, R.Pulido, and F.Saura-Calixto. 2003. In vitro antioxidant activities of edible artichoke (Cynara scolymus L.) and effect on biomarkers of antioxidants in rats. J Agric Food Chem 51. 
Lee,J.J., Y.R.Jin, J.H.Lee, J.Y.Yu, X.H.Han, K.W.Oh, J.T.Hong, T.J.Kim, and Y.P.Yun. 2007. Antiplatelet activity of carnosic acid, a phenolic diterpene from Rosmarinus officinalis. Planta Med 73.

Mahady,G.B., H.H.S.Fong, and N.R.Farnsworth. 2001. Botanical dietary supplements: quality, safety and efficacy. p. 271.

Murakami,K., M.Haneda, S.Qiao, M.Naruse, and M.Yoshino. 2007. Prooxidant action of rosmarinic acid: transition metal-dependent generation of reactive oxygen species. Toxicol. In Vitro 21:613-617.

Ou,B., M.Hampsch-Woodill, and R.Prior. 2001. Development and validation of an improved oxygen radical absorbance capacity assay using fluorescein as the fluorescent probe. J Agric Food Chem 49.

Ou,B., D.Huang, M.Hampsch-Woodill, J.Flanagan, and E.Deemer. 2002. Analysis of antioxidant activities of common vegetables employing oxygen radical absorbance capacity (ORAC) and ferric reducing antioxidant power (FRAP) assays: a comparative study. J Agric Food Chem 50.

Ou B, Huang D, Hampsch-Woodill M: Method for assaying the antioxidant capacity of a sample. U.S. Patent 7,132,296. November 7, 2006.

Perugini,C., M.Seccia, E.Albano, and G.Bellomo. 1997. The dynamic reduction of $\mathrm{Cu}(\mathrm{II})$ to $\mathrm{Cu}(\mathrm{I})$ and not $\mathrm{Cu}(\mathrm{I})$ availability is a sufficient trigger for low density lipoprotein oxidation. Biochimica et Biophysica Acta (BBA) - Lipids and Lipid Metabolism 1347:191-198.

Pitsavos,C., D.B.Panagiotakos, N.Tzima, C.Chrysohoou, M.Economou, A.Zampelas, and C.Stefanadis. 2005. Adherence to the Mediterranean diet is associated with total antioxidant capacity in healthy adults: the ATTICA study. Am J Clin Nutr 82:694699.

Porter,W.L. 1993. Paradoxical behavior of antioxidants in food and biological systems. Toxicol. Ind. Health 9:93-122.

Price,J.A., C.G.Sanny, and D.Shevlin. 2007. Application of manual assessment of oxygen radical absorbent capacity (ORAC) for use in high throughput assay of "total" antioxidant activity of drugs and natural products. Journal of Pharmacological and Toxicological Methods 54:56-61.

Prior,R.L., andG.Cao. 1999. In vivo total antioxidant capacity: comparison of different analytical methods. Free Radic. Biol. Med. 27:1173-1181. 
Pulido,R., L.Bravo, and F.Saura-Calixto. 2000. Antioxidant activity of dietary polyphenols as determined by a modified ferric reducing/antioxidant power assay. J Agric Food Chem 48.

Raskin,I., D.M.Ribnicky, S.Komarnytsky, N.Ilic, A.Poulev, N.Borisjuk, A.Brinker, D.A.Moreno, C.Ripoll, N.Yakoby, J.M.O'Neal, T.Cornwell, I.Pastor, and B.Fridlender. 2002. Plants and human health in the twenty-first century. Trends Biotechnol. 20:522-531.

Raskin,I., andC.Ripoll. 2004. Can an apple a day keep the doctor away? Curr. Pharm. Des 10:3419-3429.

Reich,E., and A.Schibli. 2007. High-performance thin-layer chromatography for the analysis of medicinal plants. p. 264. In N.Y.Thieme medicinal publishers Inc. (ed.)

Seifried,H.E., D.E.Anderson, E.I.Fisher, and J.A.Milner. 2007. A review of the interaction among dietary antioxidants and reactive oxygen species. The Journal of Nutritional Biochemistry 18:567-579.

USDA. 2007. Oxygen radical absorbance capacity (ORAC) of selected foods.

Valko,M., D.Leibfritz, J.Moncol, M.T.Cronin, M.Mazur, and J.Telser. 2007. Free radicals and antioxidants in normal physiological functions and human disease. Int. J Biochem. Cell Biol. 39:44-84.

Wijeratne,S.S.K., andS.L.Cuppett. 2007. Potential of Rosemary (Rosemarinus officinalis L.) Diterpenes in Preventing Lipid Hydroperoxide-Mediated Oxidative Stress in Caco-2 Cells. Journal of Agricultural and Food Chemistry 55:1193-1199. 


\title{
CHAPTER II
}

\section{CARNOSIC ACID-RICH ROSEMARY (Rosmarinus officinalis L.) LEAF EXTRACT LIMITS WEIGHT GAINS AND IMPROVES CHOLESTEROL LEVELS AND GLYCAEMIA IN MICE ON A HIGH-FAT DIET}

\author{
Alvin Ibarra ${ }^{1}$, Julien Cases ${ }^{2}$, Marc Roller ${ }^{2}$, Amparo Chiralt-Boix ${ }^{3}$, \\ Aurélie Coussaert ${ }^{4}$, and Christophe Ripoll ${ }^{4}$ \\ ${ }^{1}$ Naturex Inc., 375 Huyler St., South Hackensack, New Jersey 07606, USA \\ ${ }^{2}$ Naturex SA, BP 1218 site d'Agroparc, 84911 Avignon Cedex 9, France \\ ${ }^{3}$ Universidad Politécnica de Valencia, Departamento de Tecnología de los Alimentos, \\ Camino de Vera s/n, Valencia, Spain \\ ${ }^{4}$ Naturalpha SAS, Parc Eurasanté Lille Métropole, 85, rue Nelson Mandela, 59120 Loos, \\ France
}

Br. J. Nutr. Accepted. 


\section{Abstract}

Rosemary (Rosmarinus officinalis L.) extracts are natural antioxidants that are used in food, food supplements, and cosmetic applications; exert anti-inflammatory and antihyperglycaemic effects; and promote weight loss, which can be exploited to develop new preventive strategies against metabolic disorders. Therefore, our aim was to evaluate the preventive effects of rosemary leaf extract that was standardized to $20 \%$ carnosic acid (RE) on weight gain, glucose levels, and lipid homeostasis in mice that had begun a high-fat diet as juveniles. Animals were given a low-fat diet, a high-fat diet, or a high-fat diet that was supplemented with $500 \mathrm{mg}$ of rosemary extract per $\mathrm{kg}$ body weight per day (mpk). Physiological and biochemical parameters were monitored for 16 weeks. Body and epididymal fat weight in animals on the high-fat diet that was supplemented with rosemary extract increased $69 \%$ and $79 \%$ less than those in the high-fat diet group. Treatment with rosemary extract was associated with increased faecal fat excretion but not with decreased food intake. The extract also reduced fasting glycaemia and plasma cholesterol levels. In addition, we evaluated the inhibitory effects of RE in vitro on pancreatic lipase and peroxisome proliferator-activated receptor gamma (PPAR $\gamma$ ) agonist activity; the in vitro findings correlated with our observations in the animal experiments. Thus, our results suggest that rosemary extract that is rich in carnosic acid can be used as a preventive treatment against metabolic disorders, which merits further examination at physiological doses in randomized controlled trials.

Keywords: Rosmarinus officinalis L.; carnosic acid; pancreatic lipase; PPAR $\gamma$ 


\section{Introduction}

The prevalence of metabolic disorders, such as obesity, hyperlipidaemia, and hyperglycaemia, is rising dramatically in developing and industrialized nations. Obesity is reaching epidemic proportions worldwide (Baena Diez et al., 2005) and is an established risk factor for various comorbidities, such as type 2 diabetes mellitus (T2DM) and cardiovascular disease (Anderson and Konz, 2001;Czernichow et al., 2002;Unwin et al., 2010). The development of obesity induces systemic oxidative stress (Furukawa et al., 2004) and effects an inflammatory state (Gregor and Hotamisligil, 2010). The constant increase in fat intake that is linked with sedentary lifestyles is a chief cause of this phenomenon (Anderson and Konz, 2001).

Developing preventive and therapeutic solutions that impede the rise in metabolic disorders has become a primary goal in the past decade. In addition to pharmaceutical approaches, the use of natural products at physiological doses has been recognized as an effective regimen to improve several health conditions (Jouad et al., 2001;Raskin et al., 2002;Balunas and Kinghorn, 2005). Plant-based treatments have been validated as strategies in the prevention of obesity and T2DM (Ye, 2008).

Rosemary (Rosmarinus officinalis L.) extracts are natural antioxidants that are used in food, food supplements, and cosmetic applications (Panda H., 2009;Etter, 2004;Aguilar et al., 2008;al-Sereiti et al., 1999;Ibarra et al., 2010). Recently, rosemary extracts that have been standardized for carnosic acid and carnosol attained antioxidant status, garnering an additive E classification from the European Food Safety Authority (EFSA), confirming its importance as a natural preservative in foods and beverages (Aguilar et al., 2008).

Carnosic acid-rich rosemary extract has been reported to have antioxidant activity in vitro by oxygen radical absorbance capacity (ORAC) and ferric reducing/antioxidant power (FRAP) assays and inhibits the oxidation of $\mathrm{Cu}^{2+}$-induced low-density lipoprotein (LDL) $e x$ vivo (Ibarra et al., 2010). These antioxidant effects have been recapitulated in vivo. Consequently, carnosic acid-rich rosemary extract reduces oxidative stress in aged rats (Posadas et al., 2009). Carnosic acid, has anti-inflammatory effects in cellular (Yu et al., 2009) and animal (Mengoni et al., 2010) models. Further, carnosic acid has promising antiobesity and anti-glycaemic effects. 
In in vitro trials, carnosic acid inhibits pancreatic lipase (Ninomiya et al., 2004), activates peroxisome proliferators-activated receptor gamma (PPAR $\gamma$ ) (Rau et al., 2006), and prevents the differentiation of mouse pre-adipocytes into adipocytes (Takahashi et al., 2009) - all of which are important mechanisms in glucose and lipid homeostasis. The capacity of rosemary to regulate weight gain (Harach et al., 2010;Wang et al., 2011) and glycaemia (Erenmemisoglu et al., 1997;Harach et al., 2010;Wang et al., 2011) has been observed in vivo. Nevertheless, no randomized clinical trials have been reported using rosemary extracts to control obesity and hyperglycaemia, but this evidence encourages further study of carnosic acid-rich rosemary extracts to prevent the development of metabolic disorders.

In this study, we aimed to determine the preventive effects of a rosemary extract that was standardized to contain $20 \%$ carnosic acid (RE) on weight gain, glycaemia levels, and lipid homeostasis in mice that were started on a high-fat diet as juveniles. Animals were given a low-fat diet (LFD), a high-fat diet (HFD), or a high-fat diet with $500 \mathrm{mg}$ RE per kg body weight per day (mpk) (HFD.RE). Physiological and biochemical parameters were measured throughout the 16 weeks of treatment, and the effects on pancreatic lipase and PPAR $\gamma$ agonist activity in vitro were examined.

\section{Experimental Methods}

\section{Rosemary leaf extract}

RE was prepared as described by Ibarra et al. (2010).

\section{Animals and diet}

Male C57BL/6J mice, aged 4 weeks, were purchased from Elevage Janvier (CERJ, Le Genest saint Isle, France). All mice were housed 4 to a cage on a 12-hour light/12-hour dark cycle in a temperature-controlled environment during a 2-week acclimatization, with ad libitum access to water and lean, control standard diet - a calorically balanced diet. After acclimatization, mice were randomized by body weight into 3 groups of 8 animals. Each group was fed an experimental diet (Research Diets Inc., USA) for 16 weeks, as described in Table II-1 (LFD, HFD, and HFD.RE). Body weight was measured twice per week, and food intake was recorded once per week. All procedures were performed per French guidelines for the care and use of experimental animals. 


\section{Blood biochemistry}

Blood was collected from the retro-orbital sinus in EDTA-coated tubes under isoflurane anaesthesia after overnight fasting. Samples were collected at the beginning of the study (Day 0) and after 16 weeks on the experimental diets. Blood samples were centrifuged at $4000 \mathrm{rpm}$ for 15 minutes at $4^{\circ} \mathrm{C}$ to recover the plasma.

Biochemical levels were measured using commercial kits. Total cholesterol, triglycerides, and glucose (kits CH3810, TR3823, and GL3815; Randox Laboratories Ltd., United Kingdom) and free fatty acids (kit 434-91717; Wako Pure Chemical Industries Ltd, Osaka, Japan) were measured by spectroscopy. Insulin (kit INSKR020; Crystal Chem Inc, Downers Grove, USA) was measured by ELISA.

\section{Faecal lipid measurements}

Faeces were collected at weeks 0,8 , and 16 ; frozen at $-80^{\circ} \mathrm{C}$; and pulverized. For each condition, faeces from 8 mice, harvested during a 24-hour period, was pooled. Total lipids were extracted from $100 \mathrm{mg}$ of dried faeces as described (Folch et al., 1957). Total lipid levels from several independent extractions were estimated by traditional gravimetric analysis: $500 \mu \mathrm{l}$ of total lipids in chloroform was dried by evaporation and weighed.

The amount of faecal fat energy that was excreted, expressed in kcal/animal/day, was calculated in the lyophilized total fat that was excreted and collected throughout the experiment, assuming that $1 \mathrm{~g}$ lipids equals $9 \mathrm{kcal}$. 


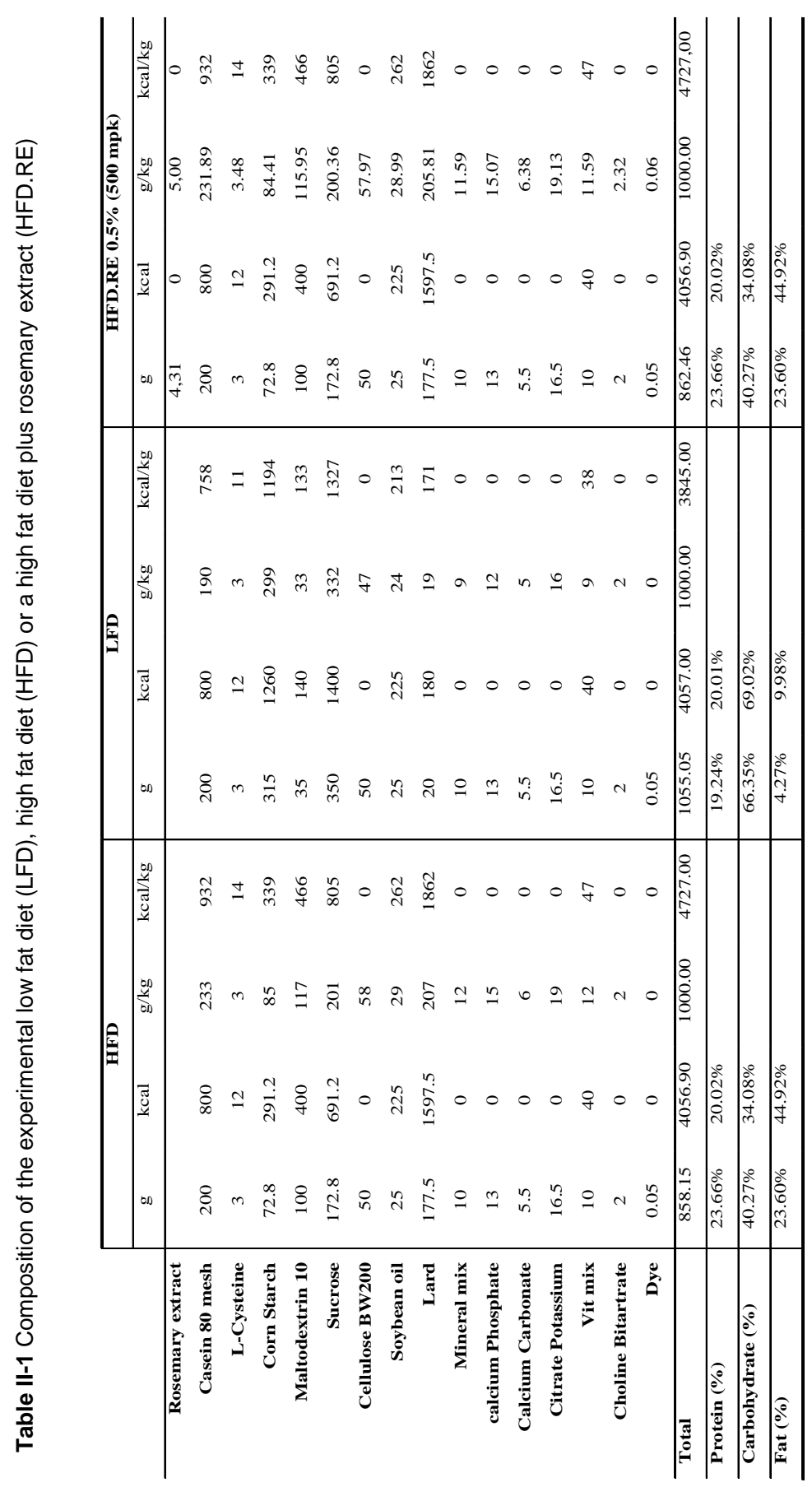




\section{Pancreatic lipase activity assay}

Human pancreatic lipase was purchased from Lee Biosolutions Inc. (St. Louis, MO, USA). Orlistat (tetrahydrolipstatin, a pancreatic lipase inhibitor) was purchased from Sigma Chemical Co. (St. Louis, MO, USA). Other chemicals were reagent-grade. The pancreatic lipase was diluted in DMSO to obtain a final activity of $0.1 \mathrm{U} / \mu$ l. Orlistat was tested at 2 concentrations in DMSO.

Lipase activity was measured using the ENZYLINETM Lipase Colour Assay kit (Biomérieux, France) according to the manufacturer's instructions. Briefly, pancreatic lipase, substrate, and the test sample were mixed gently and incubated for 5 minutes at $37^{\circ} \mathrm{C}$. Activator reagent was added, and the mixtures were incubated again for 6 minutes at $37^{\circ} \mathrm{C}$. The recorded rate of increase in absorbance at $550 \mathrm{~nm}$, due to the formation of quinone diimine dye, reflected pancreatic lipase activity.

\section{PPARy assay}

PPAR $\gamma$ activation was measured in a cell-based luciferase assay. COS-7 cells, cultured in DMEM that was supplemented with $10 \%$ FCS, were transiently transfected with a fusion protein GAL4/PPAR $\gamma$, and a DNA construct that harbored the gene reporter. The plasmid pGal5-TK-pGL3 was obtained by inserting 5 copies of the Gal4 (a yeast transcription factor) DNA-binding site upstream of the thymidine kinase promoter in pTK-pGL3.

The plasmid pGal4-hPPAR $\gamma$ was constructed by PCR-amplifying the hPPAR $\gamma$ DEF domain (aa 318-505). The resulting amplicons were cloned into pBD-Gal4 (Stratagene, La Jolla, USA), and the chimera was subsequently subcloned into pCDNA3.

After transfection, the COS-7 cells were incubated for 24 hours with RE to assess its capacity to activate PPAR $\gamma$. DMSO was used as the reference control, and rosiglitazone was used as a positive control. The activation of PPAR $\gamma$ by RE induced the expression of luciferase and a consequent increase in luminescence.

After 24 hours, the cells were collected, and luciferase assay was performed per the manufacturer's instructions (SteadyGlow, Promega). Luminescence was measured on a Tecan Ultra spectrophotometer (Tecan, Austria). All experiments were performed in quadruplicate. Relative luciferase activity of a sample was calculated as the ratio of mean luciferase activity in the test cells to that in the control cells, and PPAR $\gamma$ ligand-binding 
activity was expressed as the ratio of relative luciferase activity to that of the reference control.

\section{Analysis of results}

The animals were randomized based on total body weight by principal component analysis (PCA) (GENFIT, France), resulting in groups of animals between which no statistical difference was observed for any parameter.

The data from the in vivo and in vitro studies were expressed as mean \pm standard deviation $(\mathrm{x} \pm \mathrm{SD})$. One-way analysis of variance (ANOVA one-way Bonferroni) and student $t$-test were performed to compare groups using Sigma Plot 11.0 (2008) (Systat Software, Inc.). Statistical significance was considered at $\mathrm{p}<0.05$.

In the in vivo study, gains in the HFD.RE group were expressed as a percentage compared with the HFD and LFD control groups, calculated as:

Parameter $(\%)=[($ HFD - HFD.RE $) /($ HFD - LFD $)] \times 100$

In the in vitro studies, changes were expressed relative to their respective controls.

\section{Results}

\section{Effect of rosemary extract on body and organ weight and food intake in mice fed a high-fat diet}

Body weight between the HFD and LFD groups began to differ significantly after the first week of treatment. In HFD.RE animals, body weight differed significantly after the Day 80 (Figure II-1) compared with HFD mice, and weight gain peaked at 69\% $(\mathrm{p}<0.01)$ at the end of the study (Table II-2). This effect was associated with a 79\% ( $\mathrm{p}<0.001)$ less of an increase in epididymal fat mass; liver weight was unaffected by the treatment. No significant changes in food or energy intake were observed between groups (Table II-2). 


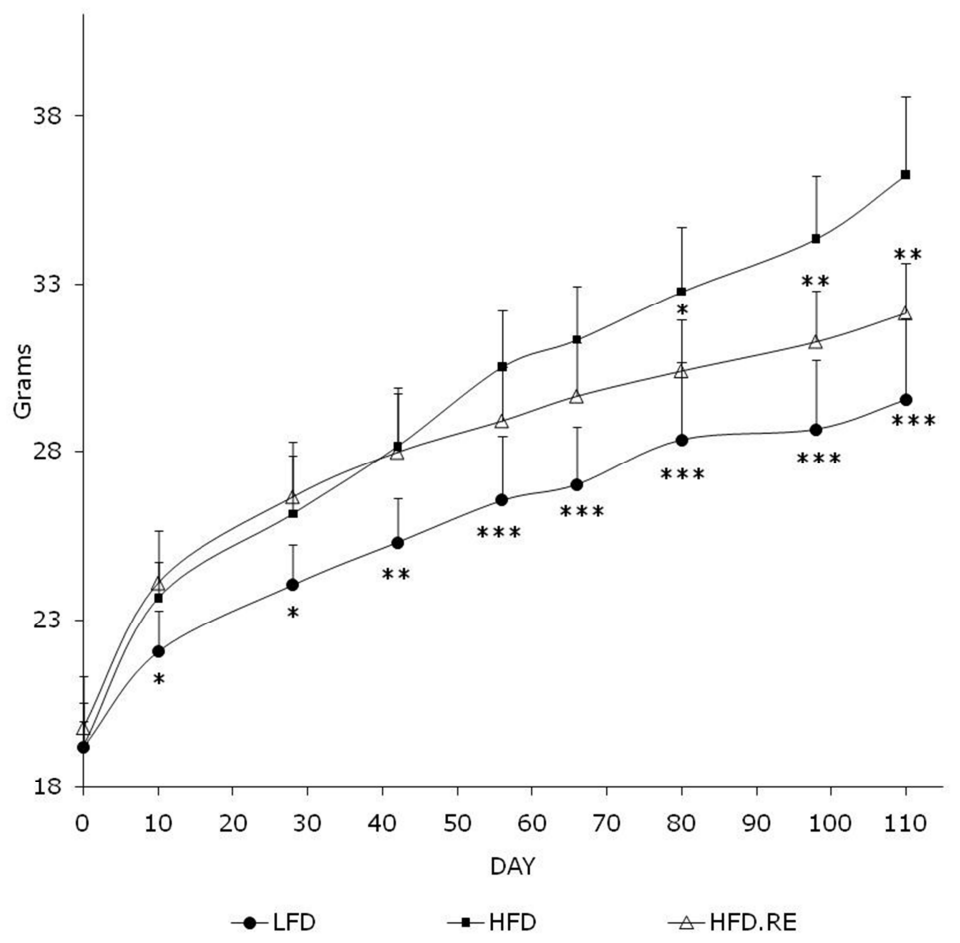

Figure II-1. Effects of rosemary extract standardized to $20 \%$ carnosic acid on body weight after 16 weeks. LFD = low-fat diet, HFD = high-fat diet, HFD.RE = high-fat diet supplemented with rosemary extract at a concentration equivalent to $500 \mathrm{mpk}$. Results are presented as means $\pm S D$. Significantly different from HFD control (ANOVA one-way Bonferroni): ${ }^{*} p<0.05 ;{ }^{* *} p<0.01 ;{ }^{* * *} p<0.001$

Table II-2. Effects of chronic administration of rosemary extract standardized to $20 \%$ carnosic acid on nutritional and weight parameters in mice fed a low fat diet (LFD), a high fat diet (HFD) or a high fat diet plus rosemary extract (HFD.RE) after 16 weeks.

\begin{tabular}{llllll}
\hline $\begin{array}{l}\text { Animal } \\
\text { group }\end{array}$ & $\begin{array}{c}\text { Mean Food } \\
\text { intake } \\
\text { (g/animal/day) }\end{array}$ & $\begin{array}{c}\text { Mean Energy } \\
\text { intake } \\
\text { (kcal/animal/day) }\end{array}$ & $\begin{array}{c}\text { Mean weight } \\
\text { gain (g) }\end{array}$ & $\begin{array}{c}\text { Liver weight } \\
\text { (g) }\end{array}$ & $\begin{array}{c}\text { Epididymal fat } \\
\text { weight (g) }\end{array}$ \\
\hline LFD & $3.40 \pm 0.28$ & $14.75 \pm 1.28$ & $10.33 \pm 2.18^{* * * *}$ & $0.99 \pm 0.10$ & $0.45 \pm 0.26^{* * *}$ \\
HFD & $3.09 \pm 0.19$ & $16.13 \pm 0.52$ & $17.01 \pm 1.94$ & $1.12 \pm 0.13$ & $1.52 \pm 0.48$ \\
HFD.RE & $3.01 \pm 0.10$ & $15.00 \pm 0.32$ & $12.37 \pm 1.59^{* *}$ & $1.14 \pm 0.15$ & $0.67 \pm 0.15^{* * *}$ \\
\hline
\end{tabular}

Results are presented as means $\pm S D$. Significantly different from HFD control (ANOVA one-way Bonferroni): ${ }^{* *} p<0.001 ;{ }^{* *} p<0.001$ 


\section{Effects of rosemary extract on serum biochemical parameters}

At 16 weeks of treatment, total fasting glycaemia, total cholesterol, and free fatty acid levels rose significantly in the HFD group compared with LFD animals. HFD.RE mice experienced $72 \%(\mathrm{p}<0.01)$ less of an increase in plasma glucose levels and 68\% $(\mathrm{p}<0.001)$ less of a rise in total cholesterol compared with HFD mice. No significant effects were observed in free fatty acid or triglyceride levels in HFD.RE mice compared with the HFD group (Table II-3).

Fasting insulinemia was also monitored; insulin levels remained low during the entire experiment, and no significant differences were observed between groups (data not shown).

Table II-3. Effects of chronic administration of rosemary extract standardized to $20 \%$ carnosic acid on plasma lipid and glucose levels in mice fed a low fat diet (LFD), a high fat diet (HFD) or a high fat diet plus rosemary extract (HFD.RE) after 16 weeks.

\begin{tabular}{lllll}
\hline Animal group & \multicolumn{1}{c}{$\begin{array}{c}\text { Total Cholesterol } \\
(\mathbf{m g} / \mathbf{d l})\end{array}$} & $\begin{array}{c}\text { Triglycerides } \\
(\mathbf{m g} / \mathbf{d l})\end{array}$ & $\begin{array}{c}\text { Free fatty acids } \\
(\mathbf{m m o l} / \mathbf{l})\end{array}$ & $\begin{array}{c}\text { Glucose } \\
(\mathbf{m g} / \mathbf{d l})\end{array}$ \\
\hline LFD & $107.66 \pm 4.80 * * *$ & $89.14 \pm 12.59 *$ & $1.46 \pm 0.22$ & $128.60 \pm 18.25 * * *$ \\
HFD & $147.58 \pm 13.63$ & $129.73 \pm 37.46$ & $1.45 \pm 0.11$ & $197.81 \pm 49.26$ \\
HFD.RE & $120.50 \pm 15.46^{* * *}$ & $102.11 \pm 25.68$ & $1.47 \pm 0.28$ & $148.00 \pm 11.33^{* *}$ \\
\hline
\end{tabular}

Results are presented as means \pm SD. Significantly different from HFD control (ANOVA one-way Bonferroni): ${ }^{\star} p<0.05$; ${ }^{* *} p<0.01 ;{ }^{* * *} p<0.001$

\section{Effect of rosemary extract on faecal fat excretion}

HFD animals had higher faecal fat excretion values $(7.63 \pm 1.27 \mathrm{mg} / 100 \mathrm{mg})$ compared with LFD mice $(2.74 \pm 0.10 \mathrm{mg} / 100 \mathrm{mg}, \mathrm{p}<0.001)$ after 16 weeks. Moreover, RE-treated mice experienced a significant 1.2 -fold increase $(\mathrm{p}<0.01)$ in total faecal content compared with HFD animals (Figure II-2).

Throughout the experiment, there was no significant difference in fat energy intake between the HFD and HFD.RE groups. However, faecal fat energy excretion rose 1.3-fold $(\mathrm{p}<0.05)$ in RE-treated mice $(0.270 \pm 0.038 \mathrm{kcal} /$ animal/day $)$ versus the HFD group $(0.208 \pm 0.035 \mathrm{kcal} / \mathrm{animal} / \mathrm{day})$. Faecal fat energy excretion differed between the LFD group $(0.076 \pm 0.003 \mathrm{kcal} / \mathrm{animal} / \mathrm{day}, \mathrm{p}<0.001)$ and HFD mice (Figure II-3). 


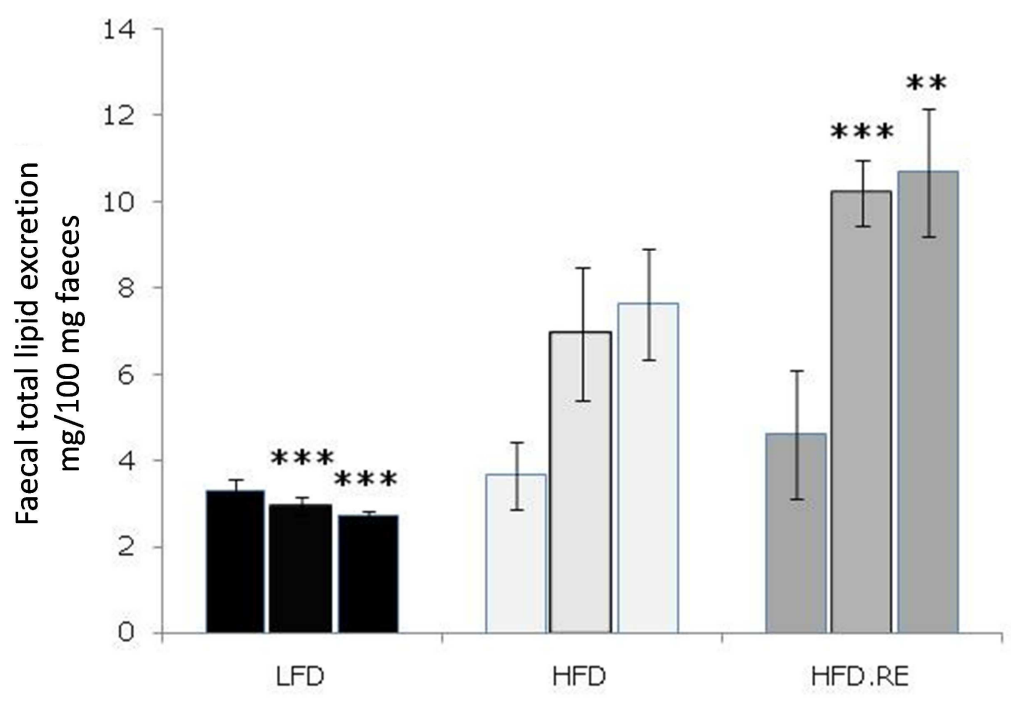

Figure II-2. Effects of rosemary extract standardized to $20 \%$ carnosic acid on total faecal lipid content at weeks 0,8 , and 16. LFD = low-fat diet, HFD = high-fat diet, HFD.RE = high-fat diet supplemented with rosemary extract at a concentration equivalent to $500 \mathrm{mpk}$. Results are presented as means $\pm S D$ of pooled data $(n=6) \pm S D$ (except for LFD, $n=3$ ). Significantly different from HFD control (ANOVA one-way Bonferroni): ${ }^{* *} p<0.01 ;{ }^{* *} p<0.001$.

\section{In vitro analysis of the mechanism of rosemary extract}

As shown in Figure II-4, $100 \mu \mathrm{g} / \mathrm{ml}$ RE ( $\mathrm{p}<0.001$ ) inhibited pancreatic lipase activity by 70\% compared with Orlistat. RE also activated PPAR $\gamma 1.66$-fold $(\mathrm{p}<0.001)$ in a dosedependent manner compared with the blank control at $30 \mu \mathrm{g} / \mathrm{ml}$ (Figure II-5), whereas activation in the positive control, rosiglitazone, was 4.35-fold $(\mathrm{p}<0.001)$ that in the blank control at $10 \mathrm{nM}$. Therefore, $30 \mu \mathrm{g} / \mathrm{ml} \mathrm{RE}$ is able to activate PPAR $\gamma$ by $19.70 \%$ as compared to the positive control. 


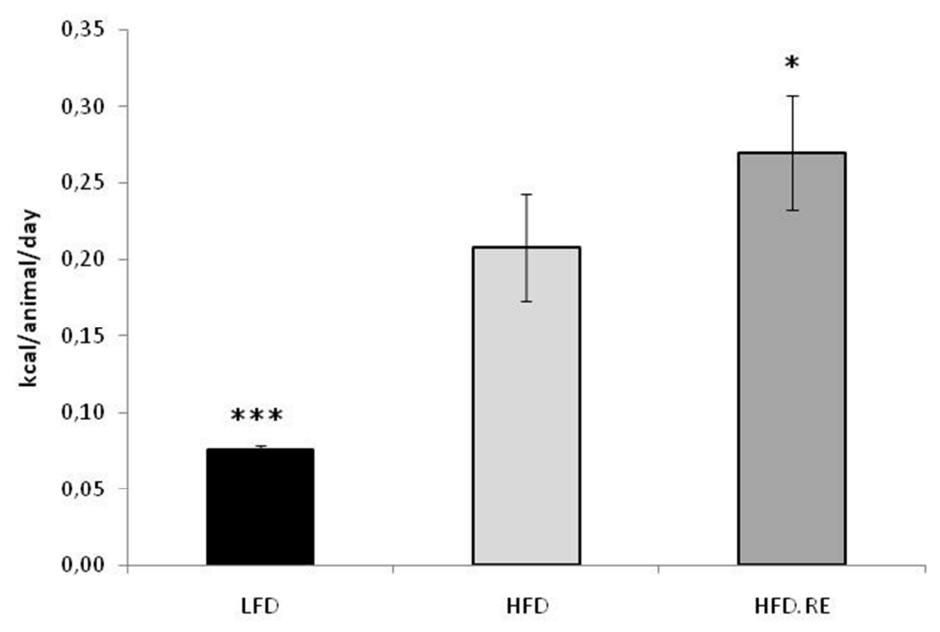

Figure II-3. Effects of rosemary extract standardized to $20 \%$ carnosic acid on total faecal energy excretion over 16 weeks. LFD = low-fat diet, HFD = high-fat diet, HFD.RE = high-fat diet supplemented with rosemary extract at a concentration equivalent to $500 \mathrm{mpk}$. Results are presented as means $\pm S D$ of pooled data $(n=6) \pm S D$ (except for LFD, $n=3$ ). Significantly different from HFD control (Student $t$-test): ${ }^{*} p<0.05 ;{ }^{* * *} p<0.001$.

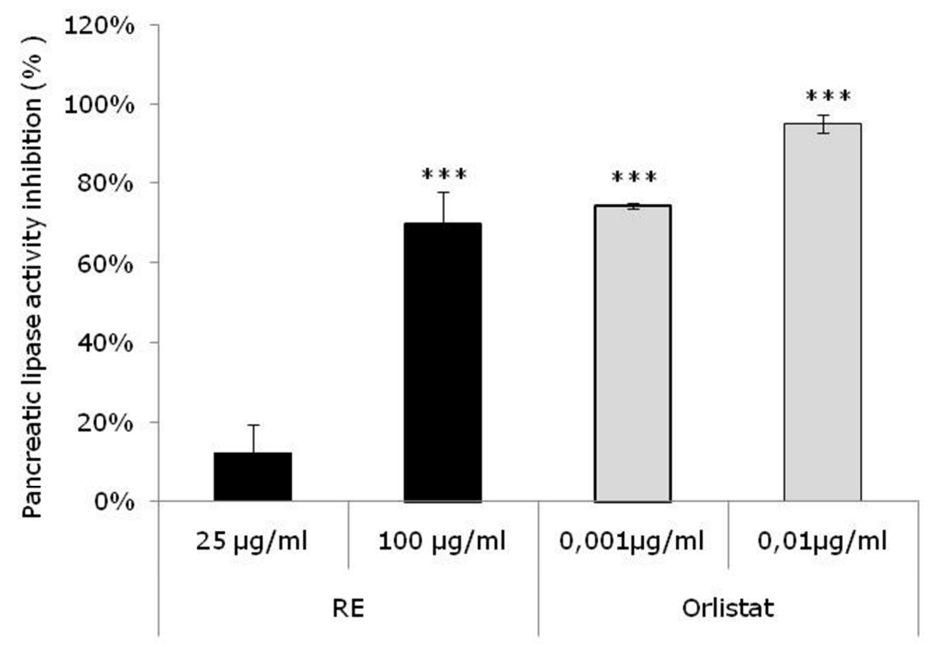

Figure II-4. Effects of rosemary extract standardized to $20 \%$ carnosic acid on pancreatic lipase inhibition in vitro. RE=rosemary extract. Results are expressed as percentage of inhibition and presented as means $\pm S D$ of 3 independent experiments. Significantly different from the blank control (Student $t$-test): ${ }^{* * *} \mathrm{p}<0.001$. 


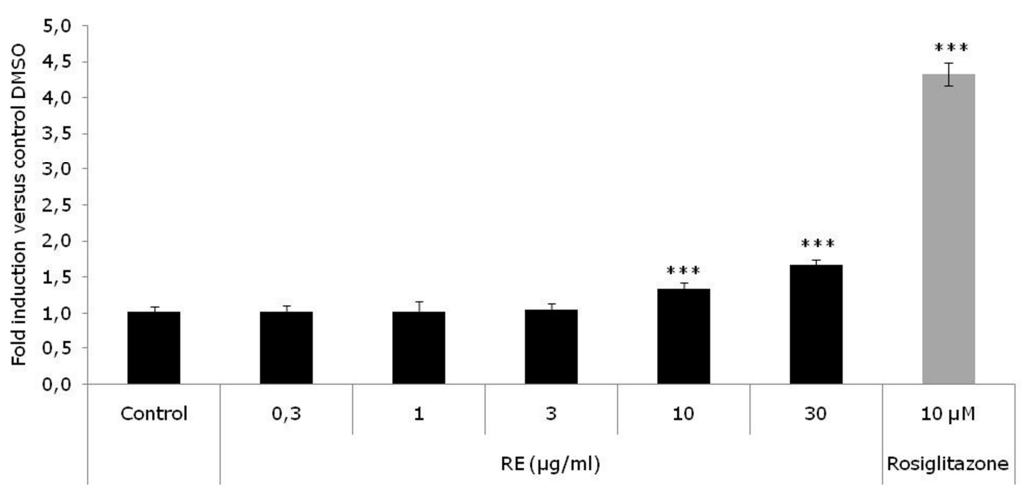

Figure II-5. Effects of rosemary extract standardized to $20 \%$ carnosic acid on PPARy activation in vitro. $\mathrm{RE}=$ rosemary extract. Results are expressed as percentage of inhibition and presented as means $\pm S D$ of 3 independent experiments. Significantly different from the blank control (Student $t$-test): ${ }^{* * *} p<0.001$.

\section{Discussion}

The production of rosemary extracts, estimated to exceed 100 tonnes annually, has risen considerably in recent years due to its widespread use in the food, beverage, flavour, food supplements, and cosmetic applications (Panda H., 2009;Etter, 2004;Aguilar et al., 2008;alSereiti et al., 1999;Ibarra et al., 2010). Consequently, technologies to develop standardized extracts from rosemary have evolved tremendously with regard to quality and reproducibility. Recently, we demonstrated the importance of standardization in determining the biological activity of plant extracts. Further, depending on content, we have observed that the antioxidant activities of various preparations of rosemary extract vary (Ibarra et al., 2010).

Rosemary exerts various biological activities with which preventive nutritional strategies against metabolic disorders, such as obesity, dyslipidaemia, and diabetes, can be developed (Ninomiya et al., 2004;Rau et al., 2006;Takahashi et al., 2009;Harach et al., 2010;Wang et al., 2011). Nevertheless, individual studies have examined specific extracts, the chemical description of which is not always available. Thus, it can be difficult to extrapolate the health benefits of a unique rosemary extract to another solely on the basis of published data.

In a previous study, we identified RE as the most potent antioxidative extract in an $e x$ vivo LDL oxidation model (Ibarra et al., 2010), prompting us to determine whether it affects other metabolic parameters in a high-fat diet mouse model. In this study, the 
administration of a $44.92 \%$ fat diet to 6-week-old C57BL/6J mice for 16 weeks resulted in significant increases in body weight, epididymal fat mass, glycaemia, and cholesterol, compared with a low-fat diet, confirming previous reports (Surwit et al., 1995;Black et al., 1998).

Treatment of mice with $500 \mathrm{mpk}$ of RE reduced the gains in weight that were induced by the high-fat diet without affecting food intake or fat energy intake. It also lowered epididymal fat tissue weight significantly compared with HFD mice. In addition, total faecal lipid content increased in HFD.RE mice compared with the HFD group, which correlates with the amount of total faecal fat energy that was excreted. Based on our study and other reports (Harach et al., 2010;Ninomiya et al., 2004), limiting lipid absorption in the intestine is a potential mechanism by which RE prevents weight gain.

This hypothesis is strongly supported by evidence of the in vitro inhibitory effect of RE on pancreatic lipase activity, a key enzyme in the digestion and absorption of fat. Moreover, similar effects have been reported recently with an ethanolic extract of rosemary that contains rosmarinic, carnosol, and carnosic acids, wherein the treatment of 15-weekold DIO mice with $200 \mathrm{mpk}$ of extract limited the weight gain that was induced by a 50day high-fat diet and increased the lipid faecal content 2.2-fold. Ninomiya et al. (2004) noted that after 2 weeks of treatment with $20 \mathrm{mpk}$ of carnosic acid alone, the weight of ddY mice fell by $7.6 \%$ compared with the control group. Thus, in our experiment, the effects of $\mathrm{RE}$ on faecal fat excretion and, consequently, faecal fat energy excretion partially explain the observed reductions in body weight.

In addition to its effects on physiological measures, RE significantly reduced elevated cholesterol levels that were induced by the high-fat diet. Although these effects were not observed by Harach et al. (2010) or Ninomiya et al. (2004), they were noted in humans with Orlistat (Micic et al., 1999;Muls et al., 2001;Erdmann et al., 2004) and in animal models with other plant-based pancreatic lipase inhibitors (Han et al., 2005;Sheng et al., 2006). Dietary cholesterol absorption has been proposed to be associated with fat digestion; Young et al. (Sheng et al., 2006) have shown that minimal triacylglycerol hydrolysis is sufficient to increase cholesterol transport significantly from lipid emulsions to intestinal cells. Consequently, pancreatic lipase inhibition has been proposed to be a target against which lipid malabsorption can be triggered to control triglyceride and cholesterol levels (Sheng et al., 2006). 
In this study, fasting glycaemia was reduced in animals in the HFD.RE group compared with the HFD control group. Few studies have evaluated the effect of rosemary on diabetes. Antihyperglycaemic effects can be induced by an ethanolic rosemary extract in the alloxan diabetic rat model (Bakirel et al., 2008) and by a water rosemary extract in a mouse model (Erenmemisoglu et al., 1997), whereas no such effect has been observed in the DIO mouse model with an extract that contains rosmarinic acid, carnosol, and carnosic acid (Harach et al., 2010). Based on these data, it appears that the antihyperglycaemic activity and preventive effects against T2DM of an extract depend on its composition and the animal model in which it is tested.

Recently, it was reported that the glucose-lowering effect of rosemary is attributed to PPAR $\gamma$ activation, in which carnosic acid and carnosol were proposed be the active compounds (Rau et al., 2006). Therefore, we examined the in vitro effects of RE on PPAR $\gamma$ activation, hypothesizing that the glucose-lowering effects are mediated through this mechanism.

In our study on C57BL/6J mice, we used an effective dose of RE-500 mpk-which contains 100 mpk of carnosic acid. The EFSA Panel on Food Additives has estimated the dietary exposure for adults and pre-school children (aged 1.5 to 4.5 years) to carnosol plus carnosic acid to be 0.04 and $0.11 \mathrm{mpk}$, respectively (Aguilar et al., 2008). Thus, considering the normal dietary exposure of carnosic acid, we used a pharmacological dose of RE.

In addition, the Panel also notes that the margin between the no observable adverse effect level (NOAEL) of carnosol plus carnosic acid, as calculated in 90-day rat studies, is equivalent to $20-60 \mathrm{mpk}$, and the mean intake of carnosic acid-rich rosemary extracts is estimated to be $500-1500 \mathrm{mg} /$ day in adults and $182-546 \mathrm{mg} /$ day in pre-school children (Aguilar et al., 2008). Therefore, future randomized clinical trials that aim to confirm the efficacy of RE in humans should consider these values to establish an effective and safe dose.

In conclusion, we have demonstrated that a carnosic-standardized rosemary extract limits weight gain and improves plasma lipid and glucose levels in a high-fat diet mouse model. These data confirm its potential for use in preventive strategies against metabolic disorders and encourage the initiation of further studies to recapitulate the physiological activity of RE in humans. 


\section{Acknowledgments}

Naturex is involved in the research/development and marketing/sales of rosemary extracts as ingredients for the food, cosmetic, and nutraceutical industries. Therefore, Naturex has a commercial interest in this publication. Naturalpha was paid by Naturex to perform and report the scientific work that formed the basis of this publication. Naturalpha and Naturex declare that the data in this report represent a true and faithful representation of the work that has been performed.

The financial assistance from Naturex is gratefully acknowledged.

Alvin Ibarra and Christophe Ripoll designed the protocol. Julien Cases and Marc Roller developed the sample of rosemary. The study was conducted under the supervision of Aurélie Coussaert. Amparo Chiralt-Boix analysed the data and reviewed the manuscript.

\section{References}

Aguilar,F., H.Autrup, S.Barlow, L.Castle, W.Dekant, K.H.Engel, N.Gontard, D.Gott, S.Grilli, R.Gürtler, R.Chr.Larsen, C.Leclercq, J.C.Leblanc, F.X.Malcata, W.Mennes, M.R.Milana, I.Pratt, I.Rietjens, P.Tobback, and F.Toldra. 2008. Use of rosemary exracts as a food additive. Scientific opinion of yhe panel on food additives, flavourings, processing aids and materials in contact with food. The EFSA journal 721:1-29.

al-Sereiti,M.R., K.M.Abu-Amer, and P.Sen. 1999. Pharmacology of rosemary (Rosmarinus officinalis Linn.) and its therapeutic potentials. Indian J. Exp. Biol. 37:124-130.

Anderson,J.W., andE.C.Konz. 2001. Obesity and disease management: effects of weight loss on comorbid conditions. Obes. Res. 9 Suppl 4:326S-334S.

Baena Diez,J.M., J.L.del Val Garcia, P.J.Tomas, J.L.Martinez Martinez, P.R.Martin, T.Gonzalez, I, E.M.Raido Quintana, S.M.Pomares, B.A.Altes, P.B.Alvarez, F.P.Pinol, E.M.Rovira, and C.M.Oller. 2005. [Cardiovascular disease epidemiology and risk factors in primary care]. Rev. Esp. Cardiol. 58:367-373.

Bakirel,T., U.Bakirel, O.U.Keles, S.G.Ulgen, and H.Yardibi. 2008. In vivo assessment of antidiabetic and antioxidant activities of rosemary (Rosmarinus officinalis) in alloxan-diabetic rabbits. J. Ethnopharmacol. 116:64-73.

Balunas,M.J., andA.D.Kinghorn. 2005. Drug discovery from medicinal plants. Life Sci. 78:431-441. 
Black,B.L., J.Croom, E.J.Eisen, A.E.Petro, C.L.Edwards, and R.S.Surwit. 1998. Differential effects of fat and sucrose on body composition in A/J and C57BL/6 mice. Metabolism 47:1354-1359.

Czernichow,S., L.Mennen, S.Bertrais, P.Preziosi, S.Hercberg, and J.M.Oppert. 2002. Relationships between changes in weight and changes in cardiovascular risk factors in middle-aged French subjects: effect of dieting. Int. J. Obes. Relat Metab Disord. 26:1138-1143.

Erdmann,J., F.Lippl, G.Klose, and V.Schusdziarra. 2004. Cholesterol lowering effect of dietary weight loss and orlistat treatment--efficacy and limitations. Aliment. Pharmacol. Ther. 19:1173-1179.

Erenmemisoglu,A., R.Saraymen, and S.Ustun. 1997. Effect of a Rosmarinus officinalis leave extract on plasma glucose levels in normoglycaemic and diabetic mice. Pharmazie 52:645-646.

Etter,S.C. 2004. Rosmarinus officinalis as an antioxidant. Journal of herbs, spices \& medicinal plants 11:121-159.

Folch,J., M.Lees, And G.H.Sloane Stanley. 1957. A simple method for the isolation and purification of total lipides from animal tissues. J. Biol. Chem. 226:497-509.

Furukawa,S., T.Fujita, M.Shimabukuro, M.Iwaki, Y.Yamada, Y.Nakajima, O.Nakayama, M.Makishima, M.Matsuda, and I.Shimomura. 2004. Increased oxidative stress in obesity and its impact on metabolic syndrome. J. Clin. Invest 114:1752-1761.

Gregor,M.F., andG.S.Hotamisligil. 2010. Inflammatory Mechanisms in Obesity. Annu. Rev. Immunol. doi: 10.1146/annurev-immunol-031210-101322.

Han,L.K., Y.N.Zheng, M.Yoshikawa, H.Okuda, and Y.Kimura. 2005. Anti-obesity effects of chikusetsusaponins isolated from Panax japonicus rhizomes. BMC. Complement Altern. Med. 5:9.

Harach,T., O.Aprikian, I.Monnard, J.Moulin, M.Membrez, J.C.Beolor, T.Raab, K.Mace, and C.Darimont. 2010. Rosemary (Rosmarinus officinalis L.) leaf extract limits weight gain and liver steatosis in mice fed a high-fat diet. Planta Med. 76:566-571.

Ibarra,A., J.Cases, A.Bily, K.He, N.Bai, M.Roller, A.Coussaert, and C.Ripoll. 2010. Importance of extract standardization and in vitro/ex vivo assay selection for the evaluation of antioxidant activity of botanicals: a case study on three Rosmarinus officinalis L. extracts. J. Med. Food 13:1167-1175.

Jouad,H., M.Haloui, H.Rhiouani, H.J.El, and M.Eddouks. 2001. Ethnobotanical survey of medicinal plants used for the treatment of diabetes, cardiac and renal diseases in 
the North centre region of Morocco (Fez-Boulemane). J. Ethnopharmacol. 77:175182.

Mengoni,E.S., G.Vichera, L.A.Rigano, M.L.Rodriguez-Puebla, S.R.Galliano, E.E.Cafferata, O.H.Pivetta, S.Moreno, and A.A.Vojnov. 2010. Suppression of COX-2, IL-1beta and TNF-alpha expression and leukocyte infiltration in inflamed skin by bioactive compounds from Rosmarinus officinalis L. Fitoterapia . doi: 10.1016/j.fitote.2010.11.023.

Micic,D., T.Ivkovic-Lazar, R.Dragojevic, J.Jorga, E.Stokic, and Z.Hajdukovic. 1999. Orlistat, a gastrointestinal lipase inhibitor, in therapy of obesity with concomitant hyperlipidemia. Med. Pregl. 52:323-333.

Muls,E., J.Kolanowski, A.Scheen, and G.L.Van. 2001. The effects of orlistat on weight and on serum lipids in obese patients with hypercholesterolemia: a randomized, double-blind, placebo-controlled, multicentre study. Int. J. Obes. Relat Metab Disord. 25:1713-1721.

Ninomiya,K., H.Matsuda, H.Shimoda, N.Nishida, N.Kasajima, T.Yoshino, T.Morikawa, and M.Yoshikawa. 2004. Carnosic acid, a new class of lipid absorption inhibitor from sage. Bioorganic \& Medicinal Chemistry Letters 14:1943-1946.

Panda H. 2009. Cultivation of Rosmarinus officinalis. p. 22-28. In National Institute of Industrial Research (ed.) Aromatic plants cultivation, processing and uses. Asia Pacific Business Press Inc., New Delhi.

Posadas,S.J., V.Caz, C.Largo, B.De la Gandara, B.Matallanas, G.Reglero, and M.E.De. 2009. Protective effect of supercritical fluid rosemary extract, Rosmarinus officinalis, on antioxidants of major organs of aged rats. Exp. Gerontol. 44:383389.

Raskin,I., D.M.Ribnicky, S.Komarnytsky, N.Ilic, A.Poulev, N.Borisjuk, A.Brinker, D.A.Moreno, C.Ripoll, N.Yakoby, J.M.O'Neal, T.Cornwell, I.Pastor, and B.Fridlender. 2002. Plants and human health in the twenty-first century. Trends Biotechnol. 20:522-531.

Rau,O., M.Wurglics, A.Paulke, J.Zitzkowski, N.Meindl, A.Bock, T.Dingermann, M.AbdelTawab, and M.Schubert-Zsilavecz. 2006. Carnosic Acid and Carnosol, Phenolic Diterpene Compounds of the Labiate Herbs Rosemary and Sage, are Activators of the Human Peroxisome Proliferator-Activated Receptor Gamma. Planta Med 72:881-887.

Sheng,L., Z.Qian, S.Zheng, and L.Xi. 2006. Mechanism of hypolipidemic effect of crocin in rats: crocin inhibits pancreatic lipase. Eur. J. Pharmacol. 543:116-122. 
Surwit,R.S., M.N.Feinglos, J.Rodin, A.Sutherland, A.E.Petro, E.C.Opara, C.M.Kuhn, and M.Rebuffe-Scrive. 1995. Differential effects of fat and sucrose on the development of obesity and diabetes in $\mathrm{C} 57 \mathrm{BL} / 6 \mathrm{~J}$ and $\mathrm{A} / \mathrm{J}$ mice. Metabolism 44:645-651.

Takahashi,T., T.Tabuchi, Y.Tamaki, K.Kosaka, Y.Takikawa, and T.Satoh. 2009. Carnosic acid and carnosol inhibit adipocyte differentiation in mouse 3T3-L1 cells through induction of phase 2 enzymes and activation of glutathione metabolism. Biochem. Biophys. Res. Commun. 382:549-554.

Unwin,N., D.Gan, and D.Whiting. 2010. The IDF Diabetes Atlas: providing evidence, raising awareness and promoting action. Diabetes Res. Clin. Pract. 87:2-3.

Wang,T., Y.Takikawa, T.Satoh, Y.Yoshioka, K.Kosaka, Y.Tatemichi, and K.Suzuki. 2011. Carnosic acid prevents obesity and hepatic steatosis in ob/ob mice. Hepatol. Res. 41:87-92.

Ye,J. 2008. Botanical treatments for diabetes and obesity. Endocr. Metab Immune. Disord. Drug Targets. 8:77.

Yu,Y.M., C.H.Lin, H.C.Chan, and H.D.Tsai. 2009. Carnosic acid reduces cytokine-induced adhesion molecules expression and monocyte adhesion to endothelial cells. Eur. J. Nutr. 48:101-106. 


\title{
CHAPTER III
}

\section{IRIDOIDS FROM Fraxinus excelsior L. WITH ADIPOCYTE DIFFERENTIATION-INHIBITORY AND PPAR $\alpha$ ACTIVATION ACTIVITY}

\author{
Naisheng Bai, ${ }^{\dagger}$ Kan He, ${ }^{* \dagger}$ Alvin Ibarra, ${ }^{\dagger}$ Antoine Bily, ${ }^{\dagger}$ Marc Roller, \\ Xiaozhuo Chen, ${ }^{\S}$ and Ralph Rühl ${ }^{\perp, \|, \nabla}$ \\ ${ }^{\dagger}$ Naturex Inc., 375 Huyler St., South Hackensack, New Jersey 07606, USA \\ ${ }^{\ddagger}$ Naturex SA, BP 1218 site d'Agroparc, 84911 Avignon Cedex 9, France \\ ${ }^{\S}$ Department of Biomedical Sciences and Edison Biotechnology Institute, Ohio University, \\ Athens, Ohio 45701, USA \\ $\perp$,Department of Biochemistry and Molecular Biology, Medical and Health Science Center, \\ University of Debrecen, Hungary; Apoptosis and Genomics Research Center \\ ||Hungarian Academy of Sciences, Debrecen, Hungary \\ ${ }^{\nabla}$ Paprika-Bioanalytics BT, Debrecen, Hungary
}

J. Nat. Prod. 2010, 73:2-6. 


\section{Abstract}

Two new secoiridoid glucosides, excelside A (1) and B (2), were isolated from the seeds of Fraxinus excelsior. Their structures were elucidated as $(2 S, 4 S, 3 E)$-methyl 3ethylidene-4-(2-methoxy-2-oxoethyl)-2-[(6-O- $\beta$-D-glucopyranosyl- $\beta$-D-

glucopyranosyl)oxy]-3,4-dihydro-2H-pyran-5-carboxylate and (2S,4S,3E)-methyl 3ethylidene-4-\{2-[2-(4-hydroxyphenyl)ethyl]oxy-2-oxoethyl\}-2-[(6- $O$ - $\beta$-D-glucopyranosyl$\beta$-D-glucopyranosyl)oxy]-3,4-dihydro-2 $H$-pyran-5-carboxylate, respectively, on the basis of NMR and MS data. Eight known compounds were identified as nuzhenide (3), GI3 (4), GI5 (5), ligstroside (6), oleoside 11-methyl ester (7), oleoside dimethyl ester (8), 1 ,"'-O- $\beta$ D-glucosylformoside (9), and salidroside (10). Compounds 1-9 inhibited adipocyte differentiation in 3T3-L1 cells. Dilutions of the aqueous extract of F. excelsior (1:10 000) as well as compounds $2,3,4,5$, and 8 activated the peroxisome proliferator-mediated receptor- $\alpha(\operatorname{PPAR} \alpha)$ reporter cell system in the range of $10^{-4} \mathrm{M}$, compared to $10^{-7}-10^{8} \mathrm{M}$ for the synthetic PPAR $\alpha$ activiator, WY14,643. Both biological activity profiles support the hypothesis that inhibition of adipocyte differentiation and PPAR $\alpha$-mediated mechanisms might be relevant pathways for the antidiabetic activity of $F$. excelsior extract.
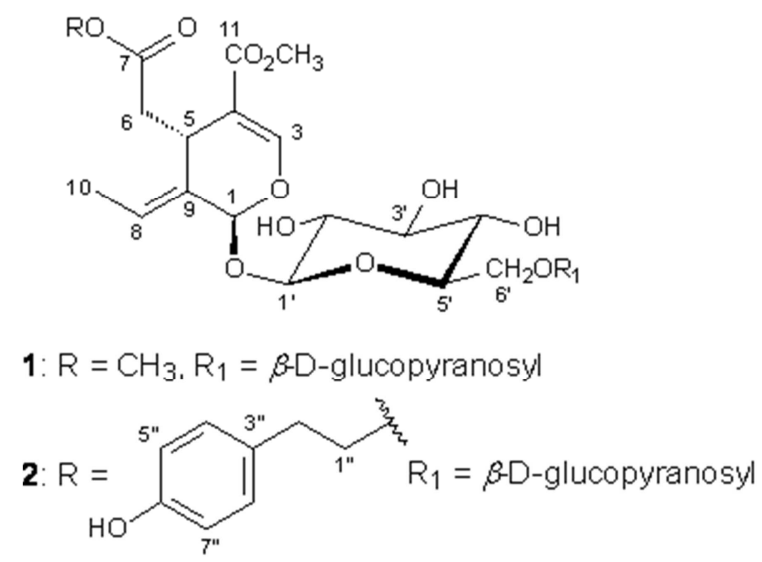


\section{Introduction}

The plant Fraxinus excelsior L. (Oleaceae) is known as "common ash" or "European ash" in temperate Asia and Europe (Hemmer et al., 2000;Eddouks et al., 2002). The plant is also widely distributed throughout the southeast of Morocco (Tafilalet), where it is locally known as "Lissan Ettir" and its seeds as "l'ssane l'ousfour". This region is a rich source of ethnobotanicals and an area which phytotherapy has been well developed (Eddouks et al., 2002; Maghrani et al., 2004;Eddouks et al., 2005). Aqueous seed extract of F. excelsior (FE) has been shown to be highly potent in the reduction of blood glucose levels without significantly affecting insulin levels (Eddouks et al., 2005;Eddouks and Maghrani, 2004;Maghrani et al., 2004). The Phlorizin-like effect of inhibiting renal glucose reabsorption is a potential mechanism for the hypoglycemic effect of FE (Eddouks and Maghrani, 2004). Previous investigations on the chemical composition of FE led to the characterization of several compound classes including secoiridoid glucosides, coumarins, flavonoids, phenylethanoids, benzoquinones, indole derivatives, and simple phenolic compounds (Iossifova etal., 1997;Kostova and Iossifova, 2007;Egan et al., 2004;Damtoft et al., 1992). However, bioactivity studies have not been reported.

During prescreening, FE was found to activate PPAR $\alpha$ and mildly inhibited adipocyte differentiation in 3T3-L1 preadipocytes. PPAR $\alpha$ - or PPAR $\gamma$-mediated pathways have been associated with protection against diabetes (Shulman and Mangelsdorf, 2005;Lee et al., 2003;Evans et al., 2004). Various synthetic PPAR $\alpha / \gamma$-selective agents have been reported to have potent antidiabetic activity (Lee et al., 2003;Bays and Stein, 2003). The focus of this study was to isolate and characterize the potential active principle(s) of FE and evaluate their biological activity in adipocyte (3T3-L1 cells) differentiation and PPAR $\alpha$ reporter assays. Sequential combination of normal, reversed-phase, and gel permeation column chromatography led to the isolation of nine secoiridoids including the new excelsides A (1) and B (2), the known nuzhenide (3) (Servili et al., 1999), GI3 (4) (LaLonde et al., 1976), GI5 (5) (Egan et al., 2004;Tanahashi et al., 1996), ligstroside (6) (Takenaka et al., 2000), oleoside-11-methyl ester (7) (Sugiyama et al., 1993), oleoside dimethyl ester (8) (Shen et al., 1996), and 1"', $O$ - $\beta$-D-glucopyranosylformoside (9) (Tanahashi et al., 1992), and the phenylethanoid salidroside (10) (Tolonen et al., 2003; Nishimura et al., 1984). Herein, we report the structures of $\mathbf{1}$ and $\mathbf{2}$, the inhibitory effects of 
the iridoids 1-9 on adipocyte differentiation in 3T3-L1 cells, and the activation of PPAR $\alpha$ by $\mathbf{2}, \mathbf{3 - 5}$, and $\mathbf{8}$, as potential mechanisms underlying the reported antidiabetic activity of FE.

\section{Results and discussion}

Excelside A (1) was obtained as an amorphous powder. Its molecular formula, $\mathrm{C}_{24} \mathrm{H}_{36} \mathrm{O}_{16}$, was established on the basis of its HRFABMS (m/z $603.1890[\mathrm{M}+\mathrm{Na}]^{+}$, calcd for $\mathrm{C}_{24} \mathrm{H}_{36} \mathrm{O}_{16} \mathrm{Na}, 603.1901$ ) and was supported by NMR data. The IR spectrum of $\mathbf{1}$ showed hydroxy absorption at 3401 and carbonyl absorptions at 1734 and $1717 \mathrm{~cm}^{-1}$. The

${ }^{1} \mathrm{H}$ and ${ }^{13} \mathrm{C}$ NMR data indicated that $\mathbf{1}$ was an oleoside-type secoiridoid glucoside based on proton signals at $\delta 7.51(s, \mathrm{H}-3), 5.94(s, \mathrm{H}-1), 6.09(\mathrm{q}, J=7.2 \mathrm{~Hz}, \mathrm{H}-8), 1.72(\mathrm{~d}, J=7.2$ $\left.\mathrm{Hz}, \mathrm{H}_{3}-10\right)$, and $4.80\left(\mathrm{~d}, J=7.6 \mathrm{~Hz}, \mathrm{H}-1^{\prime}\right)$, as well as the corresponding ${ }^{13} \mathrm{C}$ NMR signals at $\delta_{C} 155.2$ (C-3), 94.8 (C-1), 124.7 (C-8), 13.6 (C-10), and 100.6 (C-1'). The ${ }^{1} \mathrm{H}$ NMR signals at $\delta 3.62$ and 3.70 and corresponding ${ }^{13} \mathrm{C}$ NMR (gHMQC) resonances at $\delta_{C} 51.9$ and 52.3 were ascribed to two methoxy groups. The two methoxy groups showed correlations with C-7 $\left(\delta_{C} 173.7\right)$ and $\mathrm{C}-11\left(\delta_{C} 168.7\right)$ in the gHMBC spectrum, respectively, indicating that 1 possesses a 7,11-oleoside dimethyl ester unit (Shen et al., 1996;Boros and Stermitz, 1991). The additional ${ }^{13} \mathrm{C}$ NMR signals were ascribable to a $\beta$-glucopyranosyl moiety $\left(\delta_{C}\right.$ 105.2, 75.2, 77.7, 71.6, 77.8, and 62.7) attached to C-6' of the oleoside moiety, as evidenced by a 7.5 ppm dowfield shift of C-6' and upfield shifts of C-3' and C-5' of 0.8 and $3.2 \mathrm{ppm}$, respectively, compared to compound 8. The HMBC cross-peaks between $\mathrm{H}$ 1 '" at $\delta 4.36$ and C-6' at $\delta_{C} 70.1$, as well as H-6' $\left(\delta 4.16\right.$ and 3.76) and C-1"', $\left(\delta_{C} 105.2\right)$, supported these conclusions. The 10-methyl group attached to the $\Delta^{8,9}$-olefinic bond was determined to have an E-configuration by the ROESY spectrum, showing a strong correlation between H-10 $(\delta$ 1.72) and H-5 $(\delta 3.98)$. A ROESY correlation between the signals of $\mathrm{H}-1(\delta 5.94)$ and $\mathrm{H}-6(\delta$ 2.52) indicated that $\mathrm{H}-1$ is $\alpha$-oriented. The Dconfiguration of the glucopyranosyl was confirmed via acid hydrolysis (see Experimental Section). Hence, the structure of 1 was determined to be (2S,4S,3E)-methyl 3-ethylidene-4(2-methoxy-2-oxoethyl)-2-[(6- $O$ - $\beta$-D-glucopyranosyl- $\beta$-D-glucopyranosyl)oxy]-3,4dihydro- $2 \mathrm{H}$-pyran-5-carboxylate, for which the name excelside $\mathrm{A}$ is suggested. The ${ }^{1} \mathrm{H}$ and ${ }^{13} \mathrm{C}$ NMR data assignments are given in Table III-1. 
Excelside B (2) was isolated as a white, amorphous powder. Its molecular formula was established as $\mathrm{C}_{31} \mathrm{H}_{42} \mathrm{O}_{17}$ by HRFABMS (m/z $687.2506[\mathrm{M}+\mathrm{H}]^{+}$, calcd for $\mathrm{C}_{31} \mathrm{H}_{43} \mathrm{O}_{17}$, 687.2500) and supported by NMR data. The IR spectrum showed a hydroxy absorption at 3400 and carbonyl absorptions at 1701 and $1636 \mathrm{~cm}^{-1}$. The ${ }^{1} \mathrm{H}$ NMR spectrum displayed typical signals of an oleoside moiety at $\delta 7.51$ ( $s, \mathrm{H}-3), 5.95(s, \mathrm{H}-1), 6.06$ (q, H-8), 1.62 (d, $\mathrm{H}_{3}-10$ ), and 4.82 (d, H-1'). The corresponding ${ }^{13} \mathrm{C}$ NMR data are shown in Table III- 1 . The observed phenylethanoid signals as well as an AA'BB' spin system in the aromatic ring at $\delta 6.72(2 \mathrm{H}, \mathrm{d}, J=8.4 \mathrm{~Hz})$ and $\delta 7.04(2 \mathrm{H}, \mathrm{d}, J=8.4 \mathrm{~Hz})$ suggested para-disubstitution. The long-range ${ }^{1} \mathrm{H}-^{13} \mathrm{C}$ correlations (gHMBC) between $\mathrm{H}-1 "$ at $\delta 4.27$ and $\mathrm{C}-7$ at $\delta_{C} 173.4$ suggested that the phenylethyloxy moiety was attached at C-7, which related the structure of 2 to ligstroside (6) (Takenaka et al., 2000). Six additional ${ }^{13} \mathrm{C}$ NMR signals in 2 were assigned to a $\beta$-glucopyranosyl moiety ( $\delta$ 105.2, 75.1, 77.8, 71.4, 77.6, and 62.7). Its attachment at C-6' was confirmed by the observed glycosidation chemical shift effects: a 7.5 ppm downfield shift of C-6' and upfield shifts of 0.8 and 3.1 ppm of C-3' and C-5', respectively, compared to compound 6. A gHMBC correlation between the anomeric $\mathrm{H}-$ 1 ', $\left(\delta\right.$ 4.31) and C-6' $\left(\delta_{C} 70.1\right)$ confirmed thise assignment. The position of the methoxy group was assigned at $\mathrm{C}$-11 due to the observed long-range correlations of the $O$-methyl hydrogens $(\delta 3.70)$ and C-11 $\left(\delta_{C}\right.$ 168.7) in the gHMBC spectrum. Acid hydrolysis of 2 yielded D-glucose (see Experimental Section). Thus, compound 2 was designated as (2S,4S,3E)-methyl 3-ethylidene-4-\{2-[2-(4-hydroxyphenyl)ethyl]oxy-2-oxoethyl $\}-2-[(6-O$ $\beta$-D-glucopyranosyl- $\beta$-D-glucopyranosyl)oxy]-3,4-dihydro-2 $H$-pyran-5-carboxylate, $\quad$ for which the name excelside $\mathrm{B}$ is suggested. The ${ }^{1} \mathrm{H}$ and ${ }^{13} \mathrm{C}$ NMR data are given in Table III1.

In order to evaluate their antidiabetes and antiadipogenesis activities, compounds 1-9 and FE were evaluated for their glucose transport (GLUT4) stimulatory (GTS) and differentiation inhibitory effects in 3T3-L1 preadipocytes, respectively. GLUT4 is the major insulin-dependent transporter responsible for the uptake of glucose from the bloodstream into muscle and fat tissue, so as to decrease the glucose concentration in the blood. No GTS activity was observed for 1-9 and FE in the glucose uptake activity assay, which excludes the possibility of GLUT4 being a mediator for the effect of secoiridoids in FE on plasma glucose levels. However, 1-9 inhibited adipocyte differentiation in 3T3-L1 preadipocytes as summarized in Table III-2. While compound $\mathbf{5}$ showed significant 
adipogensis-inhibitory activity, compounds $\mathbf{2}, \mathbf{8}$, and $\mathbf{9}$ promoted adipogenesis at low concentrations and inhibited it at higher concentrations. These observations provide a preliminary basis for the observed decreasing fat gain of FE in mice.

Table III-1. NMR Data (400 MHz, methanol- $d_{4}$ ) of Excelsides A (1) and B (2)

\begin{tabular}{|c|c|c|c|c|c|c|}
\hline & \multicolumn{3}{|c|}{1} & \multicolumn{3}{|c|}{2} \\
\hline no. & $\delta(J$ in $\mathrm{Hz})$ & $\delta_{\mathrm{C}}$, mult. & $\begin{array}{l}\text { HMBC } \\
\text { (H to C) }\end{array}$ & $\delta(J$ in $\mathrm{Hz})$ & $\delta_{\mathrm{C}}$, mult. & $\begin{array}{l}\text { HMBC } \\
\text { (H to } \mathrm{C})\end{array}$ \\
\hline 1 & $5.94 \mathrm{~s}$ & $94.8 \mathrm{~d}$ & $8,1^{\prime}$ & $5.95 \mathrm{~s}$ & $94.7 \mathrm{~d}$ & $8,1^{\prime}$ \\
\hline $\begin{array}{l}3 \\
4\end{array}$ & $7.51 \mathrm{~s}$ & $\begin{array}{l}155.2 \mathrm{~d} \\
1093 \mathrm{~s}\end{array}$ & $1,4,5,11$ & $7.51 \mathrm{~s}$ & $155.2 \mathrm{~d}$ & $1,4,5,11$ \\
\hline 5 & $3.98 \mathrm{dd}(9.6,4.4)$ & $31.9 \mathrm{~d}$ & $\begin{array}{l}1,3,4,6,7 \\
8,9,11\end{array}$ & $3.96 \mathrm{dd}(9.6,4.4)$ & $32.0 \mathrm{~d}$ & 7,11 \\
\hline 6 & $\begin{array}{l}2.76 \mathrm{dd}(14.0,4.4) \\
2.52 \mathrm{dd}(14.0,9.6)\end{array}$ & $41.1 \mathrm{t}$ & $\begin{array}{l}4,5,7,9 \\
4,5,7,9\end{array}$ & $\begin{array}{l}2.73 \mathrm{dd}(14.0,4.4) \\
2.52 \mathrm{dd}(14.0,9.6)\end{array}$ & $41.3 \mathrm{t}$ & $\begin{array}{l}7 \\
7\end{array}$ \\
\hline 7 & & $173.7 \mathrm{~s}$ & & & $173.4 \mathrm{~s}$ & \\
\hline $\begin{array}{l}8 \\
9\end{array}$ & $6.09 \mathrm{q}(7.2)$ & $\begin{array}{l}124.7 \mathrm{~d} \\
130.4 \mathrm{~s}\end{array}$ & $1,5,10$ & $6.06 \mathrm{q}(7.2)$ & $\begin{array}{l}124.8 \mathrm{~d} \\
130.1 \mathrm{~s}\end{array}$ & $1,5,9,10$ \\
\hline $\begin{array}{l}10 \\
11\end{array}$ & $1.72 \mathrm{~d}(7.2)$ & $\begin{array}{l}13.6 \mathrm{q} \\
168.7 \mathrm{~s}\end{array}$ & 8,9 & $1.62 \mathrm{~d}(7.2)$ & $\begin{array}{l}13.6 \mathrm{q} \\
168.7 \mathrm{~s}\end{array}$ & 8,9 \\
\hline $\mathrm{OCH}_{3}$ & $3.70 \mathrm{~s}$ & $52.3 \mathrm{q}$ & 11 & $3.70 \mathrm{~s}$ & $51.9 \mathrm{q}$ & 11 \\
\hline $\mathrm{OCH}_{3}$ & $3.62 \mathrm{~s}$ & $51.9 \mathrm{q}$ & 7 & & & \\
\hline $1^{\prime}$ & $4.80 \mathrm{~d}(7.6)$ & $100.6 \mathrm{~d}$ & 1 & $4.82 \mathrm{~d}(7.6)$ & $100.4 \mathrm{~d}$ & $1,2^{\prime}$ \\
\hline $2^{\prime}$ & $3.30 \mathrm{~m}$ & $77.8 \mathrm{~d}$ & & $3.37 \mathrm{~m}$ & $77.8 \mathrm{~d}$ & \\
\hline $3^{\prime}$ & $3.52 \mathrm{~m}$ & $77.6 \mathrm{~d}$ & & $3.53 \mathrm{~m}$ & $77.5 \mathrm{~d}$ & \\
\hline $4^{\prime}$ & $3.40 \mathrm{~m}$ & $71.5 \mathrm{~d}$ & & $3.39 \mathrm{~m}$ & $71.5 \mathrm{~d}$ & \\
\hline $5^{\prime}$ & $3.32 \mathrm{~m}$ & $74.7 \mathrm{~d}$ & & $3.34 \mathrm{~m}$ & $74.7 \mathrm{~d}$ & \\
\hline $6^{\prime}$ & $\begin{array}{l}4.16 \mathrm{dd}(12.0,2.0) \\
3.76 \mathrm{dd}(12.0,6.8)\end{array}$ & $70.1 \mathrm{t}$ & $1^{\prime \prime \prime}$ & $\begin{array}{l}4.16 \mathrm{~d}(12.0,1.6) \\
3.75 \mathrm{dd}(12.0,6.4)\end{array}$ & $70.1 \mathrm{t}$ & $5^{\prime}, 1^{\prime \prime \prime}$ \\
\hline $1^{\prime \prime}$ & & & & $\begin{array}{l}4.27 \mathrm{~m} \\
4.07 \mathrm{~m}\end{array}$ & $67.0 \mathrm{t}$ & $\begin{array}{l}7,2^{\prime \prime}, 3^{\prime \prime} \\
7,2^{\prime \prime}, 3^{\prime \prime}\end{array}$ \\
\hline $\begin{array}{l}2^{\prime \prime} \\
3^{\prime \prime}\end{array}$ & & & & $2.82 \mathrm{t}(6.8)$ & $\begin{array}{l}35.2 \mathrm{t} \\
130.3 \mathrm{~s}\end{array}$ & \\
\hline $4^{\prime \prime}$ & & & & $7.04 \mathrm{~d}(8.4)$ & $131.1 \mathrm{~d}$ & $2^{\prime \prime}, 3^{\prime \prime}, 6^{\prime \prime}$ \\
\hline $5^{\prime \prime}$ & & & & $6.72 \mathrm{~d}(8.4)$ & $116.4 \mathrm{~d}$ & $3^{\prime \prime}, 4^{\prime \prime}, 6^{\prime \prime}$ \\
\hline $6^{\prime \prime}$ & & & & & $157.0 \mathrm{~s}$ & \\
\hline $7^{\prime \prime}$ & & & & $6.72 \mathrm{~d}(8.4)$ & $116.4 \mathrm{~d}$ & \\
\hline $8^{\prime \prime}$ & & & & $7.04 \mathrm{~d}(8.4)$ & $131.1 \mathrm{~d}$ & \\
\hline $1^{\prime \prime \prime}$ & $4.36 \mathrm{~d}(7.6)$ & $105.2 \mathrm{~d}$ & $6^{\prime}$ & $4.31 \mathrm{~d}(7.6)$ & $105.2 \mathrm{~d}$ & $6^{\prime}$ \\
\hline $2^{\prime \prime \prime}$ & $3.18 \mathrm{~m}$ & $75.2 \mathrm{~d}$ & & $3.17 \mathrm{~m}$ & $75.1 \mathrm{~d}$ & \\
\hline $3^{\prime \prime \prime}$ & $3.39 \mathrm{~m}$ & $77.7 \mathrm{~d}$ & & $3.41 \mathrm{~m}$ & $77.8 \mathrm{~d}$ & \\
\hline $4^{\prime \prime \prime}$ & $3.27 \mathrm{~m}$ & $71.6 \mathrm{~d}$ & & $3.26 \mathrm{~m}$ & $71.4 \mathrm{~d}$ & \\
\hline $5^{\prime \prime \prime}$ & $3.25 \mathrm{~m}$ & $77.8 \mathrm{~d}$ & & $3.16 \mathrm{~m}$ & $77.6 \mathrm{~d}$ & \\
\hline $6^{\prime \prime \prime}$ & $\begin{array}{l}3.85 \mathrm{brd}(11.6) \\
3.66 \mathrm{~m}\end{array}$ & $62.7 \mathrm{t}$ & & $\begin{array}{l}3.82 \mathrm{dd}(12.0,2.4) \\
3.62 \mathrm{dd}(12.0,5.6)\end{array}$ & $62.7 \mathrm{t}$ & \\
\hline
\end{tabular}


The biological effects of $\mathbf{2 - 5}$ and $\mathbf{8}$ were also evaluated on the PPAR $\alpha$ reporter cell lines. PPAR $\alpha$ pathways are known to be involved in lipid homeostasis and inflammation 25-26 (Kliewer et al., 1997; Szeles et al., 2007;Kostadinova et al., 2005). PPAR $\alpha$ is a main target of fibrate drugs for therapy of hyperlipidemia and hyperglycemia (Evans et al., 2004). In the present study, the synthetic and selective PPAR $\alpha$ activator WY14,643 was used as positive control, exhibiting a concentration-dependent activation (Table III-3). Compounds 2-5 and 8 were partly active at a concentration of $10^{-4} \mathrm{M}$, compared to $10^{-7}-10^{-8}$ M for WY14,643.. These preliminary biological profiles suggest that inhibition of adipocyte differentiation and PPAR $\alpha$-mediated pathways might be relevant mechanisms that can explain the antidiabetic activity of $F$. excelsior extract.

Table III-2. Inhibitory Activity of the F. excelsior Iridoids on Adipocyte Differentiation

\begin{tabular}{c|cccc}
\hline \multirow{3}{*}{ Compound } & \multicolumn{4}{|c}{ Concentration $(\mathrm{mg} / \mathrm{mL})$} \\
\cline { 2 - 5 } & 0.05 & 0.2 & 0.5 & 1.0 \\
\hline $\mathbf{2}$ & $-16.7 \pm 1.1^{a}$ & $-30.8 \pm 2.9$ & $-22.7 \pm 2.5$ & $-24.3 \pm 3.9$ \\
$\mathbf{3}$ & $-15.2 \pm 1.5$ & $-28.3 \pm 1.8$ & $-27.9 \pm 2.1$ & $-38.2 \pm 4.0$ \\
$\mathbf{4}$ & $2.3 \pm 0.4$ & $-8.3 \pm 1.0$ & $-10.4 \pm 1.7$ & $-2.1 \pm 1.1$ \\
$\mathbf{5}$ & $-4.7 \pm 2.1$ & $-31.7 \pm 4.2$ & $-57.7 \pm 5.5$ & -100 \\
\cline { 2 - 5 } & & Concentration $(\mathrm{mg} / \mathrm{mL})$ & \\
\cline { 2 - 5 } $\mathbf{1}$ & 0.01 & 0.05 & 0.1 & 0.5 \\
$\mathbf{6}$ & $102.5 \pm 12.2$ & $30.9 \pm 5.9$ & $-16.6 \pm 2.1$ & $\mathrm{ND}$ \\
$\mathbf{7}$ & $-9.3 \pm 2.2$ & $-76.4 \pm 18.7$ & $-9.8 \pm 3.9$ & $\mathrm{ND}$ \\
$\mathbf{8}$ & $78.2 \pm 9.1$ & $-7.3 \pm 10.1$ & $-81.0 \pm 9.5$ & $\mathrm{ND}$ \\
$\mathbf{9}$ & $77.6 \pm 7.4$ & $-17.1 \pm 3.6$ & $-49.7 \pm 7.2$ & $\mathrm{ND}$
\end{tabular}

${ }^{a}$ The inhibitory activity was measured using the glucose uptake assay. A negative value indicates an inhibitory activity to adipocyte differentiation. A value of -50 indicates a measured glucose uptake value $50 \%$ lower than that of the MDItreated (fully differentiated) samples, which was arbitrarily set at zero. A value of -100 indicates a measurement equivalent the value measured by the non-MDI-treated (no differentiation) samples. A positive value indicates an adipocyte differentiation promoting activity. One hundred means a measurement $100 \%$ higher than the value measured in the samples treated by MDI (MDI is a combination of IBMX, dexamethasone, and insulin). ${ }^{b} \mathrm{ND}=$ not determined due to excessive cell death. 
Table III-3. PPAR $\alpha$ Activation Potential of the F. excelsior Iridoids in Reporter Cell Lines

\begin{tabular}{c|cc}
\hline Compounds/ Extract & Concentration $(\mathrm{M})$ & relative activation in \% \\
\hline DMSO & & 1 \\
WY14,643 & $10^{-5}$ & 100 \\
& $10^{-6}$ & $62.8 \pm 35.2$ \\
& $10^{-7}$ & $36.7 \pm 15.7$ \\
& $10^{-8}$ & $17.3 \pm 13.1$ \\
$\mathbf{2}$ & $10^{-9}$ & $13.0 \pm 11.0$ \\
$\mathbf{3}$ & $10^{-4}$ & $24.8 \pm 9.6$ \\
$\mathbf{4}$ & $10^{-4}$ & $12.2 \pm 11.7$ \\
$\mathbf{5}$ & $10^{-4}$ & $21.0 \pm 15.7$ \\
$\mathbf{8}$ & $10^{-4}$ & $14.2 \pm 13.8$ \\
$\mathbf{F E}$ & $10^{-4}$ & $27.9 \pm 9.9$ \\
\hline
\end{tabular}

\section{Experimental section}

\section{General Experimental Procedures}

Optical rotations were measured with a Perkin-Elmer 241 polarimeter. FT-IR was performed on a Perkin-Elmer spectrum BX system (Perkin-Elmer Instruments, Norwalk, CT). UV spectra were acquired on a Shimadzu UV-1700 UV-visible spectrophotometer. The ${ }^{1} \mathrm{H}$ and ${ }^{13} \mathrm{C}$ NMR spectra were recorded on an Inova-400 $\left({ }^{1} \mathrm{H}\right.$ at $\left.400 \mathrm{MHz}\right)$ instrument (Varian Inc., Palo Alto, CA) with methanol- $d_{4}$ (reference $3.30 \mathrm{ppm}$ ) and $\mathrm{D}_{2} \mathrm{O}$ as the solvent (Aldrich Chemical Co., Allentown, PA). The 2D correlation spectra were obtained using standard gradient pulse sequences of Varian VNMR software and performed on 4-nuclei PFG autoswitchable or PFG indirect detection probes. HRFABMS was run on a JEOL HX110 double focusing mass spectrometer. Both negative and positive ESIMS were obtained on an LCQ ion trap (Thermo-Finnigan, San Jose, CA). GC-MS analysis was carried out on an Agilent HP 6890 Series gas chromatograph system and Agilent HP 5973 mass spectrometer (Santa Clara, CA) with an Rxi-1ms capillary GC column $(60 \mathrm{~m} \times 0.25 \mathrm{~mm}$ i.d. $\times 1.0 \mu \mathrm{m})$. HPLC analysis was performed on an Agilent 1100 LC Series using a Prodigy ODS3 column $(5 \mu \mathrm{m}, 4.6 \mathrm{~mm}$ i.d. $\times 25 \mathrm{~cm})$ with a flow rate of $1.0 \mathrm{~mL} / \mathrm{min}$. Solvent system consisted of $0.1 \% \mathrm{TFA} / \mathrm{H}_{2} \mathrm{O}(\mathrm{A})$ and $\mathrm{MeCN}(\mathrm{B})$ in the following manner: $0-5 \mathrm{~min}, 0-20 \%$ B; 5-15 min, $20-30 \%$ B; $15-25$ min, 30-100\% B. At the end of the run, $100 \%$ of MeCN was 
allowed to flush the column for $10 \mathrm{~min}$, and an additional $10 \mathrm{~min}$ of post-run time was set to allow for equilibration of the column with the starting eluant. The UV detector was operating at $238 \mathrm{~nm}$, and the column temperature was ambient.

3T3-L1 fibroblasts were purchased from American Type Culture Collection (ATCC, Rockville, MD). Dulbecco's modified Eagle's medium (DMEM) and Dulbecco's PBS (DPBS) were from Gibco Life Technologies (Grand Island, NY). Fetal bovine serum (FBS) was from Atlanta Biologicals (Norcross, GA). Insulin (IS), 3-isobutyl-1-methylxanthine (IBMX), and dexamethasone (DEX) were from Sigma Chemical (St. Louis, MO). 2Deoxy-D- $\left[{ }^{3} \mathrm{H}\right]$ glucose and XK 50 columns were from Amersham Pharmacia Biotech (Piscataway, NJ). Chemicals for plasmid preparation and PPAR activity testing were purchased from Sigma-Aldrich KFT (Budapest, Hungary), Certex KFT (Budapest, Hungary), Promega (Bioscience KFT, Budapest, Hungary), or Spectrum 3D (Debrecen, Hungary).

\section{Plant Material}

The seeds of $F$. excelsior were collected in Morocco. A voucher specimen (J02/02/A7) was deposited in the Herbarium of Naturex, Inc.

\section{Extraction and Isolation}

Air-dried and powered seeds $(2.5 \mathrm{~kg})$ of $F$. excelsior were extracted with $\mathrm{H}_{2} \mathrm{O}(2 \times 15$ L) at $95{ }^{\circ} \mathrm{C}$ for $2 \mathrm{~h}$. The combined extract was concentrated and dried into powder (500 g). The powder was re-extracted with $\mathrm{MeOH}(2 \times 3.5 \mathrm{~L})$, and the $\mathrm{MeOH}$ was evaporated in vасио. The obtained extract (54 g solid) was reconstituted in $0.5 \mathrm{~L}$ of $\mathrm{H}_{2} \mathrm{O}$ and was loaded on a C-18 (1 L) (Sigma Chemical Co., St. Louis, MO) column $(8.0 \mathrm{~cm}$ i.d. $\times 70 \mathrm{~cm})$ eluted with $\mathrm{H}_{2} \mathrm{O}(5 \mathrm{~L})$ and $10 \% \mathrm{MeOH} / \mathrm{H}_{2} \mathrm{O}(3 \mathrm{~L})$. Fractions with similar HPLC chromatograms were combined and concentrated in vacuo. The combined water fractions $(21 \mathrm{~g}$ solid) were separated over silica gel (Sorbent Technologies, Inc.) by column chromatography (500 g, $3.5 \mathrm{~cm} \times 60 \mathrm{~cm})$, eluting with a step gradient consisting of $\mathrm{CH}_{3} \mathrm{Cl} / \mathrm{MeOH}(10: 1,8: 1,5: 1$, $3: 1,2: 1)$. In each gradient step, $1.5 \mathrm{~L}$ of eluent was used and $0.5 \mathrm{~L}$ was collected as one fraction. A total of 15 fractions were collected and labeled as $\mathrm{W}$-fractions. These fractions were subjected to column chromatography over MCI gel CHP-20P (Mitsubishi Kasei Co.) 
$(100 \mathrm{~mL}, 2.5 \mathrm{~cm} \times 40 \mathrm{~cm})$ and/or Sephadex LH-20 $(100 \mathrm{~mL}, 2.5 \mathrm{~cm} \times 40 \mathrm{~cm})$, eluting with a $\mathrm{H}_{2} \mathrm{O} / \mathrm{MeOH}$ (4:6) system to yield 3 (210 $\mathrm{mg}$ from fraction $\mathrm{W}-9, t_{\mathrm{R}}=12.6 \mathrm{~min}$ in HPLC), $6\left(46 \mathrm{mg}\right.$ from $\left.\mathrm{W}-2, t_{\mathrm{R}}=19.3 \mathrm{~min}\right), 7\left(28 \mathrm{mg}\right.$ from $\left.\mathrm{W}-11, t_{\mathrm{R}}=9.4 \mathrm{~min}\right), 8(41 \mathrm{mg}$ from W$\left.10, t_{\mathrm{R}}=12.7 \mathrm{~min}\right), \mathbf{9}\left(21 \mathrm{mg}\right.$ from $\left.\mathrm{W}-8, t_{\mathrm{R}}=13.4 \mathrm{~min}\right)$, and $\mathbf{1 0}\left(22 \mathrm{mg}\right.$ from $\mathrm{W}-4, t_{\mathrm{R}}=8.1$ min). In a similar manner to that above, the $10 \% \mathrm{MeOH} / \mathrm{H}_{2} \mathrm{O}$ eluates (12 $\mathrm{g}$ solid) from the C-18 column were chromatographed over a silica gel column using $\mathrm{CH}_{3} \mathrm{Cl} / \mathrm{MeOH}$ (10:1, $8: 1,5: 1,3: 1,2: 1)$ as solvent system and collecting a total of $15 \mathrm{M}$-fractions. These fractions were chromatographed over MCI gel CHP-20P and/or Sephadex LH-20 to yield 1 (16 mg from fraction $\left.\mathrm{M}-8, t_{\mathrm{R}}=10.4 \mathrm{~min}\right), 2$ (33 mg from M-6, $\left.t_{\mathrm{R}}=15.6 \mathrm{~min}\right), 4$ (238 mg from M$\left.3, t_{\mathrm{R}}=17.9 \mathrm{~min}\right)$, and 5 (36 $\mathrm{mg}$ from $\left.\mathrm{M}-5, t_{\mathrm{R}}=20.4 \mathrm{~min}\right)$.

Excelside A (1): amorphous, white powder; $[\alpha]_{\mathrm{D}}^{25}-106.1$ (c 0.18, MeOH); UV (MeOH) $\lambda$ $\max (\log \Sigma) 232(4.61) \mathrm{nm} ; \mathrm{IR}(\mathrm{KBr}) \mathrm{V}_{\max } 3401,1734,1717,1626 \mathrm{~cm}^{-1} ;{ }^{1} \mathrm{H}$ and ${ }^{13} \mathrm{C} \mathrm{NMR}$

data, see Table III-1; HRFABMS m/z $603.1890[\mathrm{M}+\mathrm{Na}]^{+}$(calcd. for $\mathrm{C}_{24} \mathrm{H}_{36} \mathrm{O}_{16} \mathrm{Na}$, 603.1901).

Excelside $B(2)$ : amorphous, white powder; $[\alpha]_{\mathrm{D}}^{25}-115.6$ (c $\left.0.16, \mathrm{MeOH}\right)$; UV (MeOH) $\lambda$ $\max (\log \Xi) 230$ (4.33), 275 (4.02), 283 (0.56) nm; IR (KBr) V $\mathrm{vax}_{\max }$ 3400, 1701, 1636, 1518 $\mathrm{cm}^{-1} ;{ }^{1} \mathrm{H}$ and ${ }^{13} \mathrm{C}$ NMR data, see Table III-1; HRFABMS m/z $687.2506[\mathrm{M}+\mathrm{H}]^{+}$(calcd. for $\left.\mathrm{C}_{31} \mathrm{H}_{43} \mathrm{O}_{17}, 687.2500\right)$.

\section{Acid Hydrolysis of Compounds 1 and 2 and Sugar Analysis}

Solutions of compounds 1 and 2 (2.0 mg each) in $1 \mathrm{~N} \mathrm{HCI} \mathrm{(1} \mathrm{mL)} \mathrm{were} \mathrm{separately}$ stirred at $85{ }^{\circ} \mathrm{C}$ for $3 \mathrm{~h}$. The solution was evaporated under a stream of $\mathrm{N}_{2}$. The residue was dissolved in $0.1 \mathrm{~mL}$ of Tri-Sil Z (N-trimethylsilylimidazole/pyridine, 1:4, Pierce Biotechnology, Rockford, IL), and the mixture was allowed to react at $60{ }^{\circ} \mathrm{C}$ for $15 \mathrm{~min}$. After drying under a stream of $\mathrm{N}_{2}$, the residue was dissolved in $1 \mathrm{~mL}$ of $\mathrm{H}_{2} \mathrm{O}$ and partitioned with $1 \mathrm{~mL}$ of $\mathrm{CH}_{2} \mathrm{CI}_{2}$. The $\mathrm{CH}_{2} \mathrm{CI}_{2}$ layer was analyzed by GC-MS (Rxi-1ms GC column, temperatures for inlet injection, $200{ }^{\circ} \mathrm{C}$; temperature gradient system for the oven, $120{ }^{\circ} \mathrm{C}$ for $1 \mathrm{~min}$ and then raised to $280{ }^{\circ} \mathrm{C}$ at rate of $40{ }^{\circ} \mathrm{C} / \mathrm{min}$ ). D-Glucose was 
identified for $\mathbf{1}$ and $\mathbf{2}$ by comparison with retention time of authentic D-glucose $\left(t_{\mathrm{R}}=9.72\right.$ min) after treatment in the same manner with Tri-Sil Z.

\section{Cell Culture and Adipocyte Differentiation}

For differentiation assays, 3T3-L1 cells were maintained in Dulbecco's Modified Eagle's medium (DMEM) and supplemented with $10 \% \mathrm{FBS}$ at $37^{\circ} \mathrm{C}$ in a $10 \% \mathrm{CO}_{2}$ cell incubator. Preadipocyte 3T3-L1 cells were grown in 12-well plates until 2 days postconfluence. The differentiation was induced as previously described (Liu et al., 2001; Liu et al., 2005) by addition of $1 \mathrm{mg} / \mathrm{L}$ insulin (IS), $0.5 \mathrm{mmol} / \mathrm{L}$ 3-isobutyl-1-methylxanthine (IBMX), and $0.25 \mathrm{mmol} / \mathrm{L}$ dexamethasone (DEX). Two days after induction, the IS/IBMX/DEX-containing medium was replaced with medium containing $1 \mathrm{mg} / \mathrm{L}$ IS. The medium was subsequently replaced again with fresh culture medium (DMEM supplemented with $10 \%$ FBS) after 2 days and then every other day thereafter. To determine the roles of compounds in adipocyte differentiation, different concentrations of individual compound were added to the medium along with IS/IBMX/DEX (BE/IS/IBMX/DEX). The compound-treated cells were assayed for their glucose uptake activity 9-12 days after the initiation of induction.

\section{Glucose Uptake Activity Assay}

Glucose uptake activity was analyzed by measuring the uptake of 2-deoxy-D$\left[{ }^{3} \mathrm{H}\right]$ glucose as described previously (Liu et al., 2001;Liu et al., 2005). Briefly, confluent 3T3-L1 adipocytes grown in 12-well plates were washed twice with serum-free DMEM and incubated with $1 \mathrm{~mL}$ of the same medium at $37^{\circ} \mathrm{C}$ for $2 \mathrm{~h}$. The cells were washed 3 times with Krebs-Ringer-Hepes (KRP) buffer and incubated with $0.9 \mathrm{~mL}$ KRP buffer at $37{ }^{\circ} \mathrm{C}$ for $30 \mathrm{~min}$. Insulin, FE, or compounds were then added and adipocytes incubated at $37{ }^{\circ} \mathrm{C}$ for $15 \mathrm{~min}$. Glucose uptake was initiated by the addition of $0.1 \mathrm{~mL}$ of KRP buffer and $37 \mathrm{MBq} / \mathrm{L}$ 2-deoxy-D-[ $\left.{ }^{3} \mathrm{H}\right]$-glucose and $1 \mathrm{mmol} / \mathrm{L}$ glucose as final concentrations. After 10 min, glucose uptake was terminated by washing the cells 3 times with cold PBS. The cells were lysed with $0.7 \mathrm{~mL}$ of $1 \%$ Triton $\mathrm{X}-100$ at $37{ }^{\circ} \mathrm{C}$ for $20 \mathrm{~min}$. The radioactivity retained by the cell lysates was determined by a scintillation counter. Assays were repeated at least once $(n=2)$, and data were analyzed by comparison of experimental 
samples of the same treatment conditions as a group with negative control (untreated) samples, positive (insulin-treated) samples, or experimental samples with different treatment conditions. If values were below that of the negative control, they were interpreted as due to inhibitory activity.

\section{Adipocyte Differentiation Assay}

Undifferentiated 3T3-L1 preadipocytes were induced to differentiate into adipocytes as described above. The degree of the differentiation of the cells induced by different agents was evaluated by microscopic observation of lipid accumulation, as well as by their glucose uptake activities at the end of the induction. The glucose uptake assay was chosen and performed here for determination of the degree of adipocyte differentiation on the basis of the observation that differentiated adipocytes can be induced by insulin to take up glucose, whereas undifferentiated preadipocytes cannot (Liu et al., 2001;Liu et al., 2005). In addition, a near-linear relationship was found between the glucose uptake activity of differentiated adipocytes and the triglyceride contents of cells (unpublished data). Glucose uptake and adipocyte differentiation inhibition assays for each compound or fraction were performed at least twice $(n=2)$. The result was normalized and expressed as percentage by considering the activities of positive $(1 \mathrm{nmol} / \mathrm{mL}$ of insulin) and negative control $(\mathrm{MeOH})$ as $100 \%$ and $0 \%$, respectively. Results were reported as mean \pm standard error of means (SEM). Data were analyzed by comparing compound-treated samples with untreated negative control samples or with insulin-treated positive samples using one-way ANOVA with Turkey's post hoc test. Significance level was set at $p \leq 0.05$.

\section{PPAR Reporter Cell Lines. Preparation of Plasmids}

MH100-TK-LUC was utilized as luciferase reporter gene, and $\beta$-galactosidase gene was used as internal control. PPAR $\alpha$ and $\operatorname{RXR} \alpha$ constructs and $\beta$-galactosidase vector were transfected with MH100-TK-LUC. In order to equalize the DNA amount, the $\mathrm{VDR}^{-1}$ vector plasmid was used. All the plasmids contain the ampicillin resistance gene, which are controlled by SV40 promotor, and all plasmids originate from the Nuclear Hormone Receptor Research group of the Department of Biochemistry and Molecular Biology, Debrecen, Hungary. DNA was transformed into Escherichia coli DH5- $\alpha$ cells using heat 
shock transformation. The plasmids were replicated in DH5- $\alpha$ E. coli grown in LuriaBertani (LB) medium supplemented with ampicillin $(25 \mathrm{ng} / \mathrm{mL})$. Plasmid extraction was conducted via Wizard Prep Mini Column purification kit.

\section{Cell culture and transient transfection.}

Human embryonic kidney (HEK) cells were cultured in DMEM supplemented with $10 \%$ fetal bovine serum (FBS), 1\% penicillin streptomycin, and $2 \mathrm{mM} \mathrm{L-glutamin.} \mathrm{For}$ experiments, $2 \times 10^{6}$ cells were grown in T-75 flasks at $37{ }^{\circ} \mathrm{C}$ with $5 \% \mathrm{CO}_{2}$. In 24-well plates, 80.000 cells were seeded per well to obtain $70-80 \%$ confluency, $24 \mathrm{~h}$ before transfection. Polyethylenimine (PEI)-based transfection was performed. The protocol was applied for a 24-well plate transfection. Plasmid DNA $(1 \mu \mathrm{g})$ was diluted into $50 \mu \mathrm{L}$ of 150 $\mathrm{mM} \mathrm{NaCl}$ per well. PEI solution $(2 \mu \mathrm{L})$ was diluted into $50 \mu \mathrm{l}$ of $150 \mathrm{mM} \mathrm{NaCl}$ for each well. PEI solution was gently added to the DNA solution, and after mixing, it was incubated at room temperature for 15 to $30 \mathrm{~min}$ to permit the formation of PEI/DNA complex. DMEM supplemented with 10\% fetal bovine serum (FBS), $1 \%$ penicillin streptomycin, and $2 \mathrm{mM} \mathrm{L}$-glutamin was taken out from the transfection plate, and PEI/DNA complex was gently added for each well. The wells were filled with unsupplemented DMEM. The cells were transfected for $4 \mathrm{~h}$, and after changing the medium with supplemented (medium including derivatives) DMEM, the cells were incubated for 2 days to allow luciferase protein expression. After $48 \mathrm{~h}$, cells were rinsed by $1 \%$ PBS and lysed with reporter lysis buffer. Plates were shaken for $2 \mathrm{~h}$ and kept at $-80{ }^{\circ} \mathrm{C}$ for $1 \mathrm{~h}$. The luciferase activity of cell lysates was measured with $50 \mu 1$ of luciferase assay kit by luminometer (Wallac 1420 Victor, Perform Hungaria KFT, Budapest, Hungary). The results were normalized against $\beta$-gal as control.

While FE was diluted 1:10 000 in $\mathrm{H}_{2} \mathrm{O}$, compounds 2- 5, and 8 were dissolved in DMSO at $10^{-4} \mathrm{M}$ and applied to the cell culture medium (supplemented DMEM). The cell culture experiments were conducted 3 times independently and normalized to 100, corresponding to WY14, $643 \times 10^{-5} \mathrm{M}$, a PPAR $\alpha$ agonist used as positive control. The activation of PPAR $\alpha$ by FE, the isolated compounds, and positive control resulted in the expression of luciferase and consequent increment of the luminescent signals, which were measured by spectrophotometry. Results were expressed as the relative activation of 
PPAR $\alpha$ proportional to the luminescent signal emitted by the control conditions (DMSO). Results are expressed as mean $\pm \mathrm{SD}$.

\section{Acknowledgments}

The authors wish to thank J. Kim, Y. Cao, and Y. Liu, Edison Biotechnology Institute and Department of Biological Sciences, Ohio University, for their help in performing the antidiabetic and adiposity bioassays. We would also like to thank Dr. Guido F. Pauli, the University of Illinois at Chicago, for valuable suggestions and linguistic improvement of the manuscript.

\section{Supporting information available}

${ }^{1} \mathrm{H}$ and ${ }^{13} \mathrm{C}$ NMR, COSY, HMQC, HMBC, and ROESY spectra of $\mathbf{1}$ and $2 .{ }^{13} \mathrm{C}$ NMR data for compounds $\mathbf{6}$ and $\mathbf{8}$. This material is available free of charge via the Internet at http://pubs.acs.org.

\section{References}

Bays,H., andE.A.Stein. 2003. Pharmacotherapy for dyslipidaemia--current therapies and future agents. Expert. Opin. Pharmacother. 4:1901-1938.

Boros, C. A.; Stermitz, F. R., Iridoids. An Updated Review, Part II. J Nat Prod 1991, 54, (5), 1173-1246.

Damtoft,S., H.Franzyk, and S.R.Jensen. 1992. Excelsioside, a secoiridoid glucoside from Fraxinus excelsior 56. Phytochemistry 31:4197-4201.

Eddouks,M., andM.Maghrani. 2004. Phlorizin-like effect of Fraxinus excelsior in normal and diabetic rats. J Ethnopharmacol. 94:149-154.

Eddouks,M., M.Maghrani, A.Lemhadri, M.Ouahidi, and H.Jouad. 2002. Ethnopharmacological survey of medicinal plants used for the treatment of diabetes mellitus, hypertension and cardiac diseases in the south-east region of Morocco (Tafilalet). Journal of Ethnopharmacology 82:97-103.

Eddouks,M., M.Maghrani, N.A.Zeggwagh, M.Haloui, and J.B.Michel. 2005. Fraxinus excelsior L. evokes a hypotensive action in normal and spontaneously hypertensive rats. Journal of Ethnopharmacology 99:49-54. 
Egan,P., P.Middleton, M.Shoeb, M.Byres, Y.Kumarasamy, M.Middleton, L.Nahar, A.Delazar, and S.Sarker. 2004. GI 5, a dimer of oleoside, from Fraxinus excelsior (Oleaceae). Biochemical Systematics and Ecology 32.

Evans,R.M., G.D.Barish, and Y.X.Wang. 2004. PPARs and the complex journey to obesity. Nat. Med. 10:355-361.

Hemmer,W., M.Focke, F.Wantke, M.Gotz, R.Jarisch, S.Jager, and M.Gotz. 2000. Ash (Fraxinus excelsior)-pollen allergy in central Europe: specific role of pollen panallergens and the major allergen of ash pollen, Fra e 1. Allergy 55:923-930.

Iossifova, T.; Kostova, I.; Evstatieva, L. N., Secoiridoids and hydroxycoumarins in Bulgarian Fraxinus species. Biochemical Systematics and Ecology 1997, 25, (3), 271-274.

Kliewer,S.A., S.S.Sundseth, S.A.Jones, P.J.Brown, G.B.Wisely, C.S.Koble, P.Devchand, W.Wahli, T.M.Willson, J.M.Lenhard, and J.M.Lehmann. 1997. Fatty acids and eicosanoids regulate gene expression through direct interactions with peroxisome proliferator-activated receptors alpha and gamma. Proc. Natl. Acad. Sci. U. S. A 94:4318-4323.

Kostadinova,R., W.Wahli, and L.Michalik. 2005. PPARs in diseases: control mechanisms of inflammation. Curr. Med. Chem. 12:2995-3009.

Kostova,I., andT.Iossifova. 2007. Chemical components of Fraxinus species. Fitoterapia 78:85-106.

LaLonde,R., C.Wong, and A.Tsai. 1976. Polyglucosidic Metabolites of Oleaceae. The Chain Sequence of Oleoside Aglucon, Tyrosol, and Glucose Units in Three Metabolites from Fraxinus americana. Journal of the American Chemical Society 98:3007-3013.

Lee,C.H., P.Olson, and R.M.Evans. 2003. Minireview: lipid metabolism, metabolic diseases, and peroxisome proliferator-activated receptors. Endocrinology 144:2201-2207.

Liu,F., J.Kim, Y.Li, X.Liu, J.Li, and X.Chen. 2001. An extract of Lagerstroemia speciosa L. has insulin-like glucose uptake-stimulatory and adipocyte differentiationinhibitory activities in 3T3-L1 cells. J. Nutr. 131:2242-2247.

Liu,X., J.K.Kim, Y.Li, J.Li, F.Liu, and X.Chen. 2005. Tannic acid stimulates glucose transport and inhibits adipocyte differentiation in 3T3-L1 cells. J. Nutr. 135:165171. 
Maghrani,M., N.Zeggwagh, A.Lemhadri, M.El Amraoui, J.Michel, and M.Eddouks. 2004. Study of the hypoglycaemic activity of Fraxinus excelsior and Silybum marianum in an animal model of type 1 diabetes mellitus. J Ethnopharmacol. 91.

Nishimura, H.; Nonaka, G.; Nishioka, I., Tannins and Related Compounds. XVIII. A Gallotannin and Two Ellagitannins Containing a p-Hydroxyphenethyl Alcohol 1O-?-D-Glucoside (Salidroside) Core from Quercus stenophylla MAKINO. Chem Pharm Bull (Tokyo) 1984, 32, (5), 1735-1740.

Servili,M., M.Baldioli, R.Selvaggini, A.Macchioni, and G.Montedoro. 1999. Phenolic compounds of olive fruit: one- and two-dimensional nuclear magnetic resonance characterization of Nuzhenide and its distribution in the constitutive parts of fruit. J. Agric. Food Chem. 47:12-18.

Shen, Y. C.; Lin, S. L.; Chein, C. C, Jaspolyside, a secoiridoid glycoside from Jasminum polyanthum. Phytochemistry 1996, 42, (6), 1629-1631.

Shulman,A.I., andD.J.Mangelsdorf. 2005. Retinoid $\mathrm{x}$ receptor heterodimers in the metabolic syndrome. N. Engl. J. Med. 353:604-615.

Sugiyama, M.; Machida, K.; Matsuda, N.; Kikuchi, M., A secoiridoid glycoside from Osmanthus asiaticus. Phytochemistry 1993, 34, (4), 1169-1170.

Szeles,L., D.Torocsik, and L.Nagy. 2007. PPARgamma in immunity and inflammation: cell types and diseases. Biochim. Biophys. Acta 1771:1014-1030.

Tanahashi, T.; Takenaka, Y.; Nagakura, N., Two dimeric secoiridoid glucosides from Jasminum polyanthum. Phytochemistry 1996, 41, (5), 1341-1345.

Tanahashi, T.; Watanabe, H.; Itoh, A.; Nagakura, N.; Inoue, K.; Ono, M.; Fujita, T.; Morita, M.; Cheng, C. C., Five secoiridoid glucosides from Fraxinus formosana. Phytochemistry 1992, 32, (1), 133-136.

Takenaka,Y., T.Tanahashi, M.Shintaku, T.Sakai, N.Nagakura, and d.Pari. 2000. Secoiridoid glucosides from Fraxinus americana. Phytochemistry 55:275-284.

Tolonen,A., M.Pakonen, A.Hohtola, and J.Jalonen. 2003. Phenylpropanoid glycosides from Rhodiola rosea. Chem. Pharm. Bull. (Tokyo) 51:467-470. 


\title{
CHAPTER IV
}

\section{Fraxinus excelsior L. SEED EXTRACT FRAXIPURE ${ }^{\text {TM }}$ LIMITS WEIGHT GAINS AND HYPERGLYCEMIA IN HIGH-FAT DIET-INDUCED OBESE MICE}

\author{
Alvin Ibarra ${ }^{\mathrm{a}}$, Naisheng Bai ${ }^{\mathrm{a}}$, Kan $\mathrm{He}^{\mathrm{a}}$, Antoine Bily ${ }^{\mathrm{a}}$, Julien Cases ${ }^{\mathrm{b}}$, \\ Marc Roller ${ }^{\mathrm{b}}$, Shengmin Sang ${ }^{\mathrm{c}}$
}

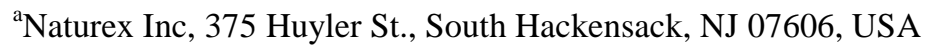

${ }^{\mathrm{b}}$ Naturex SA, Site d'Agroparc BP 1218, 84911 Avignon Cedex 9, France

${ }^{\mathrm{c}}$ Center for Excellence in Post-Harvest Technologies, North Carolina

Agricultural and Technical State University, North Carolina Research

Campus, 500 Laureate Way, Kannapolis, NC 28081, USA

Phytomedicine. 2010, doi:10.1016/j.phymed.2010.09.010. 


\section{Abstract}

Purpose: The aim of this study was to determine whether a Fraxinus excelsior L. seed extract, FraxiPure ${ }^{\mathrm{TM}}(0.5 \%$ in the diet), limits weight gain and hyperglycemia in mice. In a previous report, we identified several secoiridoids in FraxiPure ${ }^{\mathrm{TM}}$, some of which activated peroxisome proliferator-activated receptor alpha (PPAR $\alpha)$ in vitro and inhibited the differentiation of 3T3-L1 preadipocyte cells. In a separate study, FraxiPure ${ }^{\mathrm{TM}}$ reduced glycemia in healthy volunteers, following an oral glucose tolerance test. These findings suggest that FraxiPure ${ }^{\mathrm{TM}}$ has antiobesity and antihyperglycemia effects.

Materials and methods: FraxiPure ${ }^{\mathrm{TM}}$ was tested in mice that were fed a high-fat diet over 16 weeks and compared with low-fat and high-fat diet controls. Weight gain, omental and retroperitoneal fat, fasting blood glucose, and fasting blood insulin were measured.

Results: FraxiPure ${ }^{\mathrm{TM}}$ reduced gains in body weight by $32.30 \%(p<0.05)$, omental fat by $17.92 \%$, and retroperitoneal fat by $17.78 \%$. FraxiPure ${ }^{\mathrm{TM}}$ also lowered fasting blood glucose levels by $76.52 \%(p<0.001)$ and plasma insulin levels by $53.43 \%(p<0.05)$ after 16 weeks. Moreover, FraxiPure ${ }^{\mathrm{TM}}$ lowered liver weight gains by $63.62 \%(p<0.05)$ and the incidence of fatty livers by $66.67 \%$.

Conclusions: Our novel results demonstrate the antiobesity effects of chronic administration of an F. excelsior seed extract and confirm its ability to regulate glycemia and insulinemia. In addition, this extract, which is rich in secoiridoid glucosides, protects against obesity-related liver steatosis.

Keywords: Fraxinus excelsior, secoiridoids, PPAR $\alpha$, body weight, blood glucose, insulin. 


\section{Introduction}

The common ash (Fraxinus excelsior L., Oleaceae) is a tree that grows naturally in temperate regions across Europe and Asia (Pliûra and Heuertz, 2003; Eddouks et al., 2005) and exists throughout southeastern Morocco (Eddouks et al., 2002). Several reports have demonstrated that ash seeds have been used traditionally as food and condiments (Hedrick, 1919; Kunkel, 1984; Sinclair, 1998; Vergne, 2001; Boisver, 2003; Eddouks and Maghrani, 2004; Maghrani et al., 2004; Eddouks et al., 2005) and administered to improve several health conditions (Parsa, 1959; Eddouks and Maghrani, 2004).

In Europe, there is evidence that these seeds have been collected since the Middle Ages (Vermeeren and Gumbert, 2008). The aqueous seed extract of the ash tree is recognized as an effective hypoglycemic and antidiabetic agent by traditional healers in Morocco (Eddouks et al., 2005). Moreover, ash seed extract has hypoglycemic and antidiabetic effects in normal and streptozotocin-induced diabetic rats (Eddouks and Maghrani, 2004; Maghrani et al., 2004).

In a previous study, we developed a well-standardized extract of $F$. excelsior seeds (FraxiPure ${ }^{\mathrm{TM}}$, Naturex Inc.) (Visen et al., 2009), in which a glucose screen $(50 \mathrm{~g})$ was used to assess the effects of FraxiPure ${ }^{\mathrm{TM}}$ on plasma glucose and insulin levels. The intervention was double-blinded, randomized, crossover design that tested FraxiPure ${ }^{\mathrm{TM}}(1.0 \mathrm{~g})$ versus matching placebo ( $1.0 \mathrm{~g}$ of wheat bran) in 16 healthy volunteers. FraxiPure ${ }^{\mathrm{TM}}$ significantly reduced the glycemic area under the curve (Visen et al., 2009).

In a separate study, we identified (1) salidroside, a phenolic compound, and 9 secoiridoid glucosides in FraxiPure ${ }^{\mathrm{TM}}$ : (2) oleoside-11-methylester, (3) nuzhenide, (4) 1"'$O$ - $\beta$-D-glucosylformoside, (5) excelside B, (6) Gl3, (7) Gl5, (8) excelside A, (9) ligstroside, and (10) oleoside dimethyl ester (Bai et al., 2010). In an in vitro study, we demonstrated that compounds 2-9 inhibited adipocyte differentiation in 3T3-L1 cells (Bai et al. 2010). Further, FraxiPure ${ }^{\mathrm{TM}}$ (at 1:10,000) and secoiridoids 3, 6- 8, and $\mathbf{1 0}$ activated a peroxisome proliferator-activated receptor alpha (PPAR $\alpha$ ) reporter cell system in the range of $10^{-4} \mathrm{M}$, comparable with $10^{-8} \mathrm{M}$ WY 14,643, a specific PPAR $\alpha$ agonist that has robust hypolipidemic effects (Chou et al., 2002). This evidence suggests that FraxiPure ${ }^{\mathrm{TM}}$ has antiobesity properties. 
Based on these findings, the purpose of this study was to examine the antiobesity and antihyperglycemia effects of FraxiPure ${ }^{\mathrm{TM}}$ and evaluate its safety in a low-fat/high-fat mouse model.

\section{Materials and Methods}

\section{F. excelsior seed extract}

F. excelsior seeds were collected from rural communities in Morocco and deposited into the herbarium (voucher specimen \# J02/02/A7; Reference \# RB3524) at Naturex Maroc, Technopole Nouasser BP 42, Casablanca 20240, Morocco. Extracts of the sample were generated through an established industrial process at Naturex France (FraxiPure ${ }^{\mathrm{TM}}$, Reference: EA149251, Naturex SA, Site d'Agroparc BP 1218, 84911 Avignon Cedex 9, France) (Visen et al., 2009).

\section{Chromatographic analysis}

HPLC analysis was performed on an Agilent 1100 LC Series that was equipped with a quaternary pump, a 4-channel online degasser, an autosampler, a column oven, and a photodiode array detector. Chromatography was performed using a Prodigy ODS3 column $(5 \mu \mathrm{m}, 4.6 \mathrm{~mm} \mathrm{ID} \times 25 \mathrm{~cm})$ at a flow rate of $1.0 \mathrm{ml} / \mathrm{min}$. The solvent system consisted of $0.1 \% \mathrm{TFA} / \mathrm{H}_{2} \mathrm{O}(\mathrm{A})$ and $\mathrm{MeCN}(\mathrm{B})$ as follows: 0-5 min, 0-20\% B (v/v); 5-15 min, 20-30\% $\mathrm{B}$; and $15-25 \mathrm{~min}, 30-100 \% \mathrm{~B}$.

At the end of the run, the column was flushed with $100 \% \mathrm{MeCN}$ for $10 \mathrm{~min}$, and the column was equilibrated with the starting eluent for an additional 10 min of post-run time. The UV detector was operated at $238 \mathrm{~nm}$, and the column temperature was ambient. Figure IV-1 shows the chromatogram, and Table IV-1 lists the compounds that were identified in FraxiPure $^{\mathrm{TM}}$ (Bai et al., 2010). 


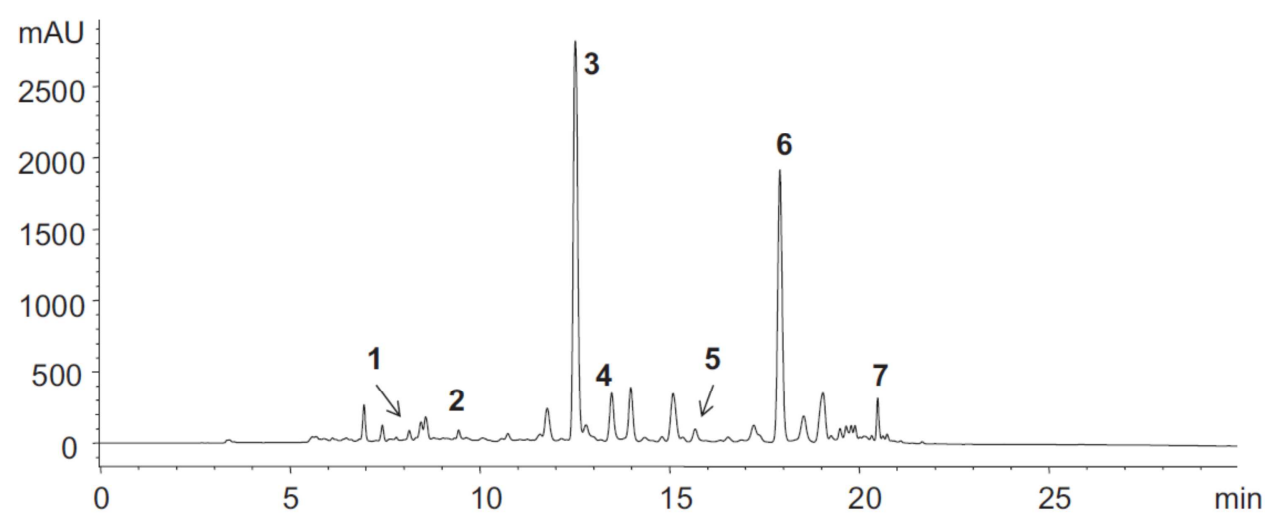

Figure IV-1. HPLC chromatogram of $F$. excelsior seed extract (FraxiPure ${ }^{\mathrm{TM}}$ ). The peaks were assigned based on the isolation of each compound, and the structure of the compound was determined by NMR and MS. (1) Salidroside, (2) Oleoside-11-methylester, (3) Nuzhenide, (4) 1'"'-O- $\beta$-D-glucosylformoside, (5) Excelside B, (6) Gl3, and (7) Gl5. Peaks of other identified secoiridoid glucosides, present in only trace amounts, are not shown: (8) Excelside A, (9) Ligstroside, and (10) Oleoside dimethyl ester (see Table IV-1).

\section{Animals and diets}

Male C57BL/6J mice (aged 5 weeks) were purchased from Jackson Laboratories (Bar Harbor, ME, USA). Fifty mice were randomly assigned to 1 of 3 groups:

- $\quad$ Negative control group on a low-fat diet (LFD) (10\% of energy from fat) $(n=20)$;

- $\quad$ Control group on a high-fat diet (HFD) (60\% of energy from fat) $(n=20)$;

- $\quad$ High-fat diet, containing $0.5 \%$ FraxiPure $^{\mathrm{TM}}$ (FED) (60\% of energy from fat) $(n=10)$.

Diets of equally sized pellets were prepared by Research Diets Inc. (New Brunswick, NJ, USA). The mice were housed at room temperature on a 12-h light/12-h dark cycle. Animals subsisted on the experimental diets for 16 weeks with free access to their respective chow and water. Average food and fluid intake and body weight were measured. The entire study was performed in accordance with international guidelines regarding animal experiments (Robert et al., 2004). 
Table IV-1: Profile of phenolic and secoiridoid compounds in F. excelsior seed extract FraxiPure ${ }^{\mathrm{TM}}$.

\begin{tabular}{|c|c|c|c|c|}
\hline & Compound & IUPAC name & Structure & Content (\%) \\
\hline 1 & Salidroside & $\beta$-D-Glucopyranoside, 2-(4-hydroxyphenyl)ethyl & & 0.20 \\
\hline 2 & Oleoside-11-methyl ester & $\begin{array}{l}\text { (2S,3E,4S) } 2 \mathrm{H} \text {-Pyran-4-acetic acid, 3-ethylidene-2-( } \beta \text {-D- } \\
\text { glucopyranosyloxy)-3,4-dihydro-5-methoxycarbonyl }\end{array}$ & & 0.19 \\
\hline 3 & Nuzhenide & $\begin{array}{l}\beta \text {-D-Glucopyranoside, 2-(4-hydroxyphenyl)ethyl, } \\
\text { 6-[(2S,3E,4S)-3-ethylidene-2-( } \beta \text {-D-glucopyranosyloxy)- } \\
\text { 3,4-dihydro-5-(methoxycarbonyl)-2H-pyran-4-acetate] }\end{array}$ & & 11.42 \\
\hline 4 & $1^{\prime \prime \prime}-O-\beta$-D-Glucosylformoside & $\begin{array}{l}\text { (2S,3E,4S) } 2 \mathrm{H} \text {-Pyran-4-acetic acid-3-ethylidene-2-( } \beta \text {-D- } \\
\text { glucopyranosyloxy)-3,4-dihydro-5-(methoxycarbonyl) } \\
4 \text {-[2-( } \beta \text {-D-glucopyranosyloxy)-ethyl]phenyl ester }\end{array}$ & & 1.35 \\
\hline 5 & Excelside B & $\begin{array}{l}\text { (2S, 3E, } 4 S) 2 H \text {-Pyran-4-acetic acid-3-ethylidene-2-[(6-O- } \\
\beta \text {-D-glucopyranosyl- } \beta \text {-D-glucopyranosyl) } \\
\text { oxy]-3,4-dihydro-5-(methoxycarbonyl) } \\
\text { 2-(4-hydroxyphenyl) ethyl ester }\end{array}$ & & 0.41 \\
\hline 6 & G13 & $\begin{array}{l}\text { (2S,3E,4S) } 2 H \text {-Pyran-4-acetic acid, 3-ethylidene-2-( } \beta \text {-D- } \\
\text { glucopyranosyloxy)-3,4-dihydro-5-(methoxycarbonyl)-, } \\
\text { 4-[2-[[6-O-[[3-ethylidene-2-( } \beta \text {-D-glucopyranosyloxy)-3,4- } \\
\text { dihydro-5-(methoxycarbonyl)- (2S,3E,4S) } \\
2 H \text {-pyran-4-yl]acetyl]- } \beta \text {-D- } \\
\text { glucopyranosyl] } \\
\text { gexy]ethyl]phenyl ester }\end{array}$ & & 6.15 \\
\hline 7 & G15 & $\begin{array}{l}\text { (2S,3E,4S) 2H-Pyran-4-acetic acid, 3-ethylidene-2-( } \beta \text {-D- } \\
\text { glucopyranosyloxy)-3,4-dihydro-5-(methoxycarbonyl)-, } \\
\text { 4-[2-[II(2S,3E,4S)-3-ethylidene-2-( } \beta \text {-D- } \\
\text { glucopyranosyloxy)-3,4-dihydro-5-(methoxycarbonyl)- } \\
\text { 2H-pyran-4-yl]acetyl] oxy]ethyl] } \\
\text { phenyl ester }\end{array}$ & & 0.63 \\
\hline 8 & Excelside A & $\begin{array}{l}\text { (2S, 3E, 4S) } 2 \mathrm{H} \text {-Pyran-4-acetic acid-3-ethylidene-2-[(6-O- } \\
\beta \text {-D-glucopyranosyl- } \beta \text {-D-glucopyranosyl) } \\
\text { oxy]-3,4-dihydro-5-(methoxycarbonyl) methyl ester }\end{array}$ & & Trace \\
\hline 9 & Ligstroside & $\begin{array}{l}\text { (2S,3E,4S) } 2 \text { H-Pyran-4-acetic acid-3-ethylidene-2-( } \beta \text {-D- } \\
\text { glucopyranosyloxy)-3,4-dihydro-5-(methoxycarbonyl) } \\
\text { 2-(4-hydroxyphenyl)ethyl ester }\end{array}$ & & Trace \\
\hline 10 & Oleoside dimethyl ester & $\begin{array}{l}\text { (2S,3E,4S)-2H-Pyran-4-acetic acid-3-ethylidene-2-( } \beta \text {-D- } \\
\text { glucopyranosyloxy)-3,4-dihydro-5-(methoxycarbonyl) } \\
\text { methyl ester }\end{array}$ & & Trace \\
\hline & Total & & & 20.35 \\
\hline
\end{tabular}

\section{Tissue harvesting}

Mice were food-deprived for $8 \mathrm{~h}$ and sacrificed by $\mathrm{CO}_{2}$ inhalation after 16 weeks of treatment. Whole blood was obtained by cardiac puncture. Liver, omental fat, and retroperitoneal fat were harvested, rinsed, and weighed. Plasma was isolated by centrifugation at $700 \times \mathrm{g}$ for $15 \mathrm{~min}$. A liver was considered fatty, based on altered coloration; the percentage of fatty livers was recorded in each group. All samples were stored at $-80^{\circ} \mathrm{C}$. 


\section{Fasting blood glucose}

Fasting blood glucose was measured at $0,5,8,10,12,14$, and 16 weeks of treatment. Food was removed $8 \mathrm{~h}$ prior to the blood glucose measurements, and the cage bedding was changed to minimize the interference from coprophagy. Blood was collected from the tail vein, and glucose levels were measured with a One Touch ${ }^{\circledR}$ Ultra $^{\circledR} 2$ glucose monitor (LifeScan Inc., Milpitas, CA, USA).

\section{Biochemical analysis of plasma samples}

Fasting plasma insulin levels and plasma alanine transaminase (ALT) levels were measured at Week 16 of the treatment after sacrifice. Insulin levels were measured by ELISA (Millipore, Billerica, MA, USA), per the manufacturer's protocol. ALT levels were measured spectrophotometrically with a commercial kit (Catachem Inc., Bridgeport, CT, USA).

\section{Statistical analysis}

Results are reported as the mean \pm standard error to the mean (SEM). Statistical differences between HFD and FED mice compared with LFD animals were determined by one-way ANOVA with Tukey's post hoc test (GraphPad software, San Diego, CA, USA).

\section{Results}

All animals tolerated their respective diets; no adverse effects were observed, the animals behaved normally, and similar average food and water intake was reported for the three groups (data not shown). The FraxiPure ${ }^{\mathrm{TM}}$ diet improved physiological and biochemical parameters in mice - i.e., body weight, fat gain in various organs, fasting glucose, and insulin - compared with HFD control animals and the LFD negative control group, the morbid and healthy references, respectively. In addition, FraxiPure ${ }^{\mathrm{TM}}$ prevented the development of high-fat diet-induced liver damage. 


\section{Changes in body weight, omental fat, and retroperitoneal fat gain}

Body weight gain was monitored weekly for 16 weeks in all groups (Figure IV-2A). LFD animals grew steadily, plateauing at Week 9 (27.29 $\pm 0.53 \mathrm{~g})$. In contrast, HFD mice grew regularly throughout the entire study (16 weeks), outpacing LFD animals from Week $3(25.26 \pm 0.49 \mathrm{~g} v s 23.00 \pm 0.42 \mathrm{~g}-p<0.05)$ through Week $16(42.25 \pm 1.03 \mathrm{~g} v s .28 .84 \pm 0.64-$ $p<0.05)$.
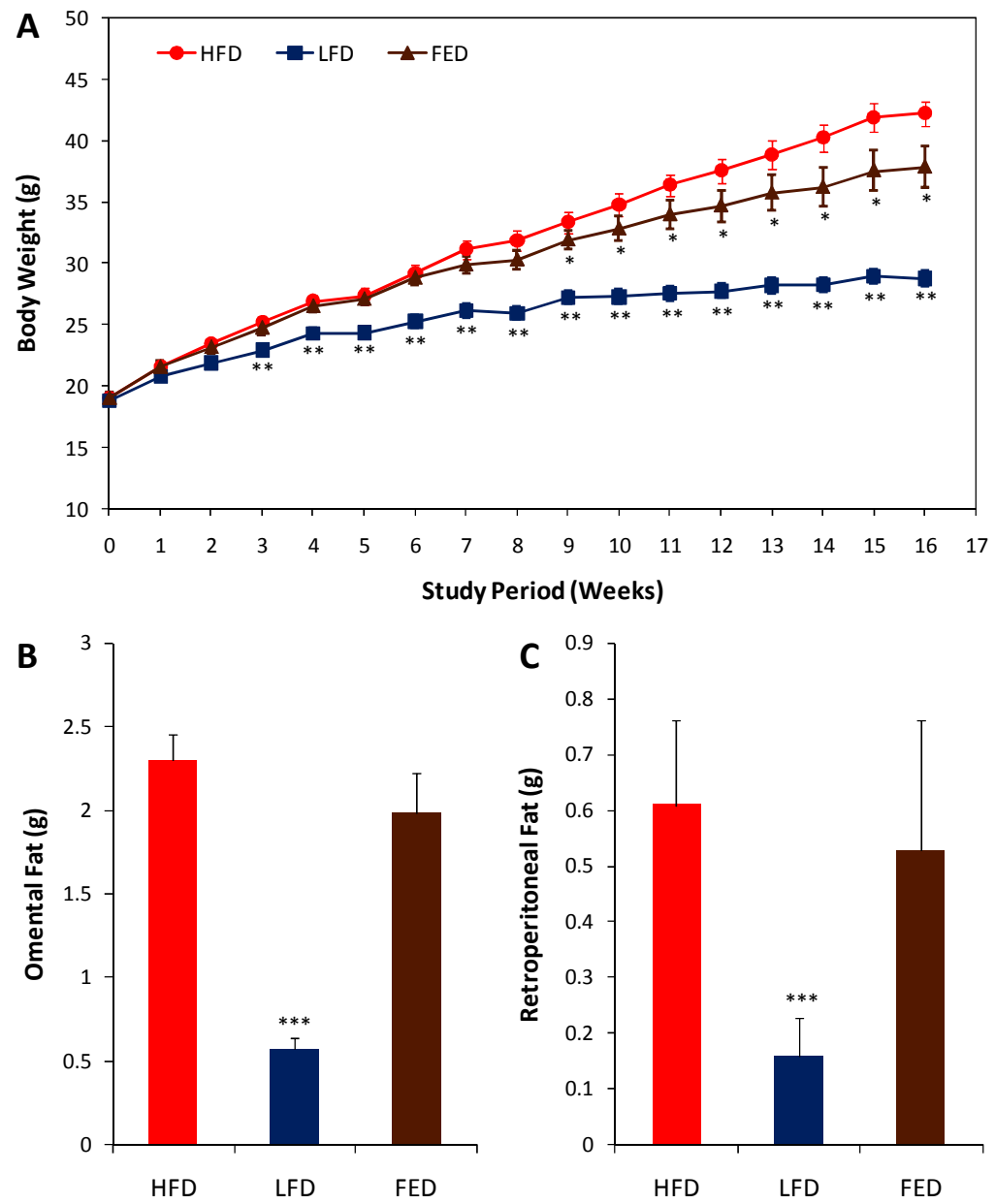

Figure IV-2. (A) Changes in body weight in high-fat diet (HFD), low-fat diet (LFD), and high-fat diet + $0.5 \%$ FraxiPure $^{\mathrm{TM}}$ (FED) animals over 16 weeks. (B) Changes in omental fat in HFD, LFD, and FED mice. (C) Changes in retroperitoneal fat in HFD, LFD, and FED mice. Values are mean \pm SEM for LFD and HFD $(n=20)$ and FED $(n=10)$. Significance is indicated as $\left({ }^{*}\right)$ at $p<0.05,\left({ }^{* *}\right) p<0.001$, and $\left(^{* * *}\right)$ $p<0.0001$ compared with the HFD control group, using the LFD negative control group as the common reference. 
Fat status was monitored with regard to the omental fat (Figure IV-2B) and retroperineal fat (Figure IV-2C) that were harvested from the three groups at the end of the study. In the LFD group, the omental fat and retroperineal fat weighed $0.57 \pm 0.07 \mathrm{~g}$ and $0.16 \pm 0.03 \mathrm{~g}$, respectively, after 16 weeks. In the HFD group, omental and retroperineal fat rose $304 \%(2.30 \pm 0.15 \mathrm{~g}$ vs $0.57 \pm 0.07 \mathrm{~g}-p<0.001)$ and $286 \%(0.61 \pm 0.13 \mathrm{~g}$ vs. $0.16 \pm 0.08 \mathrm{~g}$ - $p<0.001)$, respectively, compared with LFD animals.

In FED-treated animals, fat in the omental and retroperineal muscles gained $17.92 \%$ $(1.99 \pm 0.23 \mathrm{~g}$ vs. $2.30 \pm 0.15 \mathrm{~g})$ and $17.78 \%(0.53 \pm 0.06 \mathrm{~g}$ vs. $0.61 \pm 0.13 \mathrm{~g})$ less weight, respectively, compared with HFD mice at the end of the study. These results, however, were not statistically significant.

\section{Changes in fasting blood glucose and fasting plasma insulin}

Fasting blood glucose levels were recorded throughout the entire experiment, as reported in Figure IV-3A. Figure IV-3B shows the levels of fasting plasma insulin at the end of the study, Week 16.

Animals in the LFD group had normal glycemia levels during the 16-week treatment $(120.15 \pm 5.16 \mathrm{mg} / \mathrm{dl}$ at Week 0 , and $100.20 \pm 5.33 \mathrm{mg} / \mathrm{dl}$ at Week 16). In contrast, HFD animals increased fasting blood glucose levels progressively from the beginning of the study (122.15 $\pm 3.90 \mathrm{mg} / \mathrm{dl})$ until Week $16(176.85 \pm 7.43 \mathrm{mg} / \mathrm{dl})$.

In the FED-treated group, fasting blood glucose rose $76.52 \%$ less $(118.20 \pm 9.09 \mathrm{md} / \mathrm{dl}$ $p<0.001)$ compared with HFD mice at the end of the study. Moreover, at Week 16, FraxiPure $^{\mathrm{TM}}$ reduced fasting plasma insulin levels by $53.43 \%$ in the FED-treated group compared with HFD mice $(1.29 \pm 0.29 \mathrm{ng} / \mathrm{ml} v s .2 .38 \pm 0.29 \mathrm{ng} / \mathrm{ml}-p<0.05)$. 

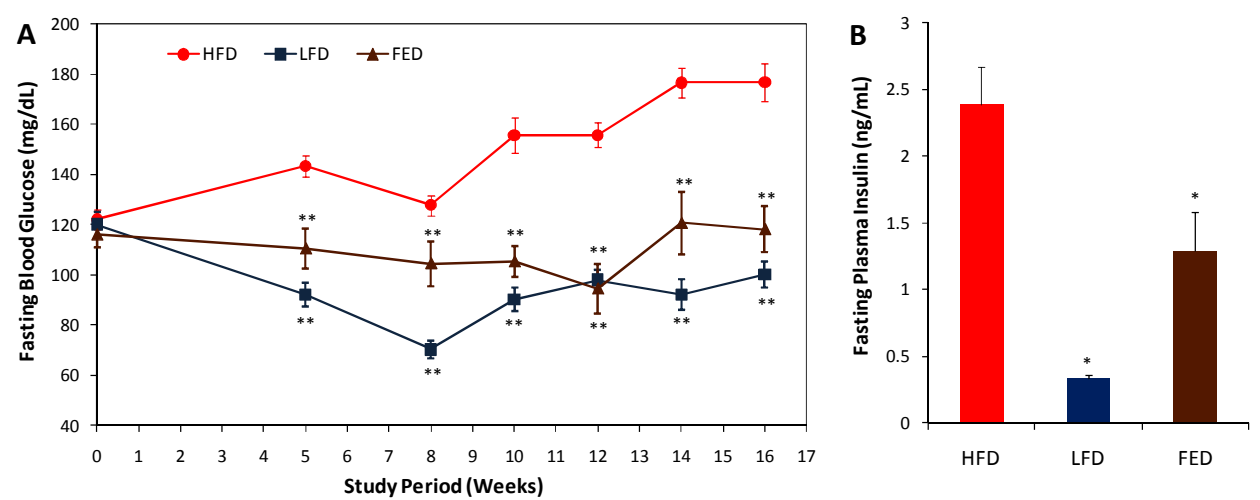

Figure IV-3. (A) Changes in fasting blood glucose levels in high-fat diet (HFD), low fat-diet (LFD), and high-fat diet $+0.5 \%$ FraxiPure $^{\mathrm{TM}}$ (FED) animals during the 16-week study. (B) Changes in fasting plasma insulin levels in HFD, LFD, and FED mice. Values are mean \pm SEM for LFD and HFD $(n=20)$ and FED $(n=10)$. Significance is indicated as $\left({ }^{*}\right)$ at $p<0.05$ and $\left({ }^{* *}\right) p<0.001$ compared with the HFD control group, using the LFD negative control group as the common reference.

\section{Changes in liver weight, incidence of fatty liver, and plasma ALT levels}

After 16 weeks of treatment, the average liver weight (Figure IV-4A) reached $0.96 \pm 0.05 \mathrm{~g}$ in the LFD group and increased $40.43 \%$ more in the HFD group $(1.35 \pm 0.09 \mathrm{~g}$ $\mathrm{p}<0.05)$. In the FED-treated group, the average liver weight increased $63.62 \%$ less compared with HFD animals $(1.10 \pm 0.03 \mathrm{~g}-\mathrm{p}<0.05)$.

Fatty livers (Figure IV-4B) developed in 1 of the 20 mice in the LFD group at Week 16. This rate was 300\% higher in the HFD group (4 of 20) and $66.67 \%$ lower in the FEDtreated group (1 of 10) compared with HFD animals.

In addition, plasma ALT levels (Figure IV-4C) in LFD animals were $22.64 \pm 3.54 \mathrm{U} / \mathrm{L}$ at the end of the study, increasing $236 \%$ in the HFD group $(76.20 \pm 9.06 \mathrm{U} / \mathrm{L}-\mathrm{p}<0.0001)$. FED

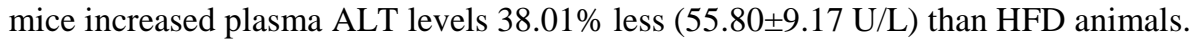



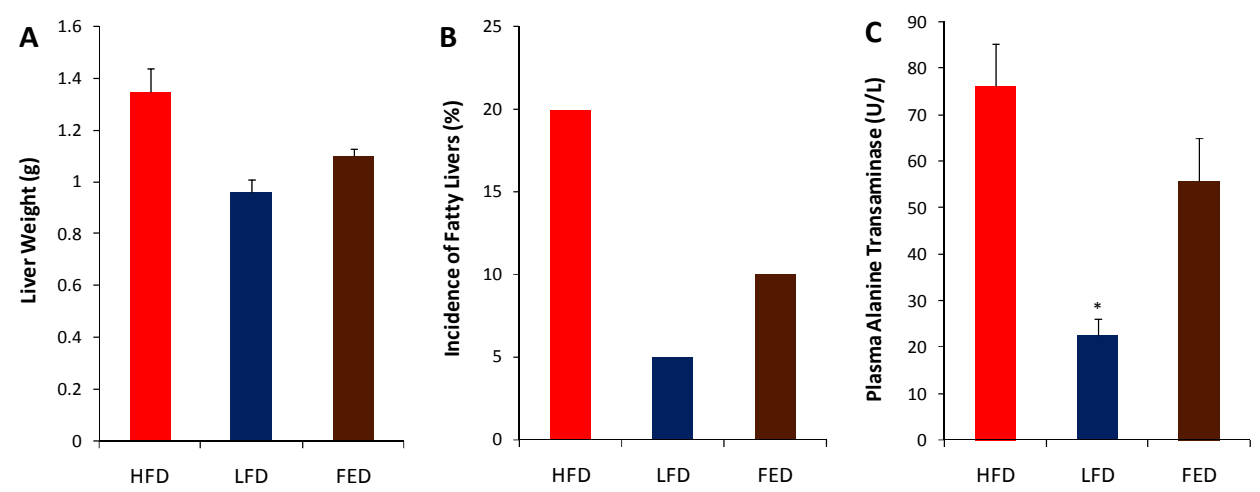

Figure IV-4. (A) Changes in liver weight in high-fat diet (HFD), low-fat diet (LFD), and high-fat diet + $0.5 \%$ FraxiPure $^{\mathrm{TM}}$ (FED) animals after the 16-week study. (B) Changes in fatty liver rates in HFD, LFD, and FED mice. (C) Changes in fatty plasmatic ALT levels in HFD, LFD, and FED mice. Values are mean \pm SEM for LFD and HFD $(n=20)$ and FED $(n=10)$. Values are mean \pm SME for HFD and LFD $(n=20)$ and FED $(n=10)$. Significance is indicated as $\left(^{*}\right)$ at $p<0.05$ compared with the HFD control group.

\section{Discussion}

Many naturally occurring phytonutrients have beneficial effects on health (Steffen, 2009). In addition, several phytonutrients have received positive attention, based on their relative safety and the accumulation of evidence of their antiobesity and antihyperglycemia effects in animals and humans; these properties exist in specific flavonoids (Hwang et al., 2005), chlorogenic acid from green coffee bean (Dellalibera et al., 2006), and carnosic acid in rosemary (Takahashi et al., 2009) and have recently been proposed for secoiridoids from F. excelsior (Bai et al. 2010).

Our results demonstrate the substantial physiological and biochemical health benefits of a $F$. excelsior seed extract in obese mice that are fed a high-fat diet.

The differential weight gain patterns that we observed, despite similar average daily intake throughout the study, confirmed the validity of our calorie-controlled obese mouse model. Although HFD mice grew steadily throughout the study, doubling in weight, the low-calorie diet in the LFD group significantly lowered gains in weight after Week 3. Mice that were supplemented with FraxiPure ${ }^{\mathrm{TM}}$ in the FED group grew similarly to HFD animals; at Week 9, FED began to experience significant reductions in weight gain, like LFD healthy mice. 
These results complement work by Maghrani and colleagues (2004), who reported that administration of $F$. excelsior seed extract for 2 weeks $(20 \mathrm{mg} / \mathrm{Kg})$ reduced body weight in streptozotocin-induced diabetic rats but not in normal animals. Similarly, the HFD group experienced increases in adipose tissue weight compared with LFD animals over 16 weeks, while FED mice did not gain as much fat, based on omental fat, retroperitoneal fat, liver weight, and, consequently, the incidence of fatty livers, trending toward the lower levels that were observed in LFD animals.

We demonstrated recently that secoiridoid glucosides from $F$. excelsior seeds dosedependently activate PPAR $\alpha$ in vitro and inhibit preadipocyte differentiation in the 3T3-L1 cell model (Bai et al., 2010). $\operatorname{PPAR} \alpha$, a transcription factor that regulates energy homeostasis (Van Raalte et al., 2004), is highly expressed in liver, heart, muscle, and kidney, where it controls fatty acid uptake and $\beta$-oxidation (Sonoda et al., 1998; Staels and Fruchart, 2005) by modifying the expression of specific genes, such as acyl-CoA synthetase and fatty acid transport proteins (Schoonjans et al., 1995; Reddy and Hashimoto, 2001). PPAR $\alpha$ also increases the expression of lipoprotein lipase (LPL) and downregulates apo-C-III, an inhibitor of LPL (Staels et al., 1998).

Additionally, PPAR $\alpha$ ligands are used widely to lower serum triglycerides and increase high-density lipoprotein cholesterol in patients with obesity, dyslipidemia, atherosclerosis, and coronary heart disease (Staels and Fruchart, 2005). In our study, the decrease in fat levels in FED animals, correlating with evidence that secoiridoid glucosides from $F$. excelsior seed extracts activate PPAR $\alpha$ and inhibit preadipocyte differentiation (Bai et al., 2010), demonstrates that FraxiPure ${ }^{\mathrm{TM}}$, due specifically to secoiridoid glucosides, has antiobesity effects in vivo, likely by lowering the rate of adipocyte differentiation in growing animals and enhancing fat catabolism.

In addition to these observations, with regard to weight management, if we assume that obesity is associated with increased insulin resistance (Kruszynska and Olefsky, 1996), it becomes easier to understand how obesity contributes to reduced glucose uptake by muscle and liver cells (McGarry, 1992). Consequently, local glucose storage (as glycogen) decreases, effecting triacylglycerol accumulation in adipocytes and liver cells and resulting in steatosis through the esterification of free fatty acids that are supplied primarily from the diet, coupled with increased LPL activity (Rossi et al., 2010). A notable outcome of this 
phenomenon is the development of type 2 diabetes (Leahy, 2005), wherein insulin resistance is considered to be significantly worse than for nonobese diabetics (Seely and Olefsky, 1993).

A corollary to this model can be proffered from our observations. Although significant increases in fasting blood glucose and fasting plasma insulin levels were observed after 16 weeks in obese HFD animals compared with baseline values, despite their high-fat diet: (1) fasting blood glucose in the FED group did not differ significantly from the beginning of the study, when the mice were still healthy; and (2) fasting insulin levels in FED mice decreased significantly to those of LFD animals. These observations demonstrate that FraxiPure $^{\mathrm{TM}}$ has antihyperglycemia activity that is accompanied by improvements in insulin levels in FED mice, precluding the negative outcomes of obesity with regard to fasting glucose and insulin levels in HFD animals (Jeffcoat, 2007). As a chief consequence, the mechanisms of fat accumulation in adipocytes of FED animals are impaired and insulin resistance is improved.

These results also support previous findings of animal studies by Eddouks and Maghrani (2004) and Maghrani et al. (2004), who observed that acute intravenous administration of $10 \mathrm{mg} / \mathrm{kg} / \mathrm{h} \mathrm{F}$. excelsior seed extract reduced blood glucose levels in normal rats for $4 \mathrm{~h}$ and in streptozotozin-induced diabetic rats after chronic oral consumption of $20 \mathrm{mg} / \mathrm{kg} / \mathrm{day}$ for 14 days.

These results were galvanized when we observed a significant decrease in postprandial glycemia with humans who were administrated FraxiPure ${ }^{\mathrm{TM}}$ acutely (Visen et al., 2009). Moreover, Eddouks and Maghrani, Maghrani et al., and our group failed to note any increase in plasma insulin. Thus, the antihyperglycemia activity of $F$. excelsior seed extracts has been proposed to be caused by extrapancreatic phenomena - a hypothesis that we discussed with regard to our findings on PPAR $\alpha$ activation (Bai et al., 2010).

To promptly evaluate liver safety, we implemented an evidence-based liver safety system, supported by changes in liver weight, fat accumulation (expressed as the rate of steatosis), and the release of ALT in plasma.

The upper limit of toxicity in this study, as monitored by steatosis rate and ALT release in the plasma, was established with data on animals in the HFD group. Compared with these results, mice that were fed a high-fat diet and administered FraxiPure ${ }^{\mathrm{TM}}$ for 16 weeks (FED) experienced significant improvements in fatty liver levels and decreases in ALT 
release in plasma. These findings indicate that $0.5 \%$ FraxiPure $^{\mathrm{TM}}$ does not induce any side effects in mice, as monitored principally by liver physiology and biochemistry. Moreover, FraxiPure $^{\mathrm{TM}}$ improved the healthy status of obese mice that were affected by a 16 -week high-fat diet (the FED group).

In conclusion, this study confirms the capacity of $F$. excelsior to control body weight and supports the existing evidence of its antihyperglycemic effects and ability to improve resistance to insulin. The positive effects on weight and blood glucose might be attributed to the secoiridoids in FraxiPure ${ }^{\mathrm{TM}}$, likely through the enhancement of fat metabolism through $\beta$-oxidation, the inhibition of adipocyte differentiation during animal growth, and limited fat accumulation.

Finally, our results suggest that this botanical extract is effective, safe, and well tolerated for long periods in obese mice that are fed a high-fat diet.

We propose that secoiridoids constitute an active component in $F$. excelsior seeds, limiting weight gains and hyperglycemia through PPAR $\alpha$ activation in vivo. To this end, our results encourage further study on the bioavailability of secoiridoids in FraxiPure ${ }^{\mathrm{TM}}$ and their mechanisms of regulation in vivo.

\section{Acknowledgments}

The financial assistance from Naturex is gratefully acknowledged.

\section{Author's disclosure statement}

Naturex is involved in the research/development and marketing/sales of FraxiPure ${ }^{\mathrm{TM}}$ as an ingredient for the food, nutraceutical, and cosmetic industries. Therefore, Naturex has a commercial interest in this publication. The Center for Excellence in Post-Harvest Technologies (CEPHT), the conducting laboratory, was paid by Naturex to perform and report the scientific work, which formed the basis of this publication; CEPHT and Naturex declare that the data in this publication represent a true and faithful representation of the work that was performed. 


\section{References}

Bai N., He K., Ibarra A., Bily A., Roller M., Chen X., Rühl R., 2010. Iridoids from Fraxinus excelsior with adipocyte differentiation-inhibitory and PPAR-alpha activation activity. Journal of Natural Products 73 (1), 2-6.

Boisver T. C., 2003. Plantes et remèdes naturels Genève.

Chou C.J., Haluzik M., Gregory C., Dietz K.R., Vinson C., Gavrilova O., Reitman M.L., 2002. WY14,643, a peroxisome proliferator-activated receptor alpha (PPARalpha ) agonist, improves hepatic and muscle steatosis and reverses insulin resistance in lipoatrophic A-ZIP/F-1 mice. Journal of Biological Chemistry 277 (27), 2448424489.

Dellalibera O., Lemaire B., Lafay S., 2006. Le Svetol®, un extrait de café vert décaféiné, induit une perte de poids et augmente le ratio masse maigre sur masse grasse chez des volontaires en surcharge pondérale. Phytothérapie Expérimentale 4 (4), 194197.

Eddouks M., Maghrani M., 2004. Phlorizin-like effect of Fraxinus excelsior in normal and diabetic rats. Journal of Ethnopharmacology 94 (1), 149-154.

Eddouks M., Maghrani M., Lemhadri A., Ouahidi M., Jouad H., 2002. Ethnopharmacological survey of medicinal plants used for the treatment of diabetes mellitus, hypertension and cardiac diseases in the south-east region of Morocco (Tafilalet). Journal of Ethnopharmacology 82(2-3), 97-103.

Eddouks M., Maghrani M., Zeggwagh N.A., Haloui M., Michel J.B., 2005. Fraxinus excelsior L. evokes a hypotensive action in normal and spontaneously hypertensive rats. Journal of Ethnopharmacology 99(1), 49-54.

Hedrick U.P., 1919. Sturtevant's Notes on Edible Plants, $1^{\text {st }}$ ed. State of New York Department of Agriculture, Albany.

Hwang J.T., Park I.J., Shin J.I., Lee Y.K., Lee S.K., Baik H.W., Ha J., Park O.J., 2005. Genistein, EGCG, and capsaicin inhibit adipocyte differentiation process via activating AMP-activated protein kinase. Biochemical and Biophysical Research Communications 338(2), 694-699.

Jeffcoat R., 2007. Obesity - A perspective based on the biochemical interrelationship of lipids and carbohydrates. Medical Hypotheses 68(5), 1159-1171.

Kruszynska Y.T., Olefsky J.M., 1996. Cellular and molecular mechanisms of non-insulin dependent diabetes mellitus. J Investig.Med 44(8), 413-428.

Kunkel G., 1984. Plants for Human Consumption, $1^{\text {st }}$ ed Koenigstein. 
Leahy J.L., 2005. Pathogenesis of Type 2 Diabetes Mellitus. Archives of Medical Research 36(3), 197-209.

Maghrani M., Zeggwagh N., Lemhadri A., El Amraoui M., Michel J., Eddouks M., 2004. Study of the hypoglycemic activity of Fraxinus excelsior and Silybum marianum in an animal model of type 1 diabetes mellitus. J Ethnopharmacol. 91(2-3), 309316.

Mcgarry J.D., 1992. What if Minkowski had been ageusic? An alternative angle on diabetes. Science 258(5083), 766-770.

Parsa A., 1959. Medicinal plants and drugs of plant origin in Iran III. In: Springer Netherland (Ed.).

Pliûra A., Heuertz M., 2003. Technical Guidelines for genetic conservation: Common ash (Fraxinus excelsior). European Forest Genetic Resources Programme 1(1).

Reddy J.K., Hashimoto T., 2001. Peroxisomal oxidation and peroxisome porliferatoractivated receptor alpha: An Adaptive Metabolic System. Annual Review of Nutrition 21(1), 193-230.

Robert V.C., Kenneth M.B., David J.W., 2004. The revision of the Declaration of Helsinki: past, present and future. British Journal of Clinical Pharmacology 57(6), 695-713.

Rossi A.S., Lombardo Y.B., Chicco A.G., 2010. Lipogenic enzyme activities and glucose uptake in fat tissue of dyslipemic, insulin-resistant rats: Effects of fish oil. Nutrition 26(2), 209-217.

Schoonjans K., Watanabe M., Suzuki H., Mahfoudi A., Krey G., Wahli W., Grimaldi P., Staels B., Yamamoto T., Auwerx J., 1995. Induction of the Acyl-Coenzyme A Synthetase Gene by Fibrates and Fatty Acids Is Mediated by a Peroxisome Proliferator Response Element in the C Promoter. Journal of Biological Chemistry 270(33), 19269-19276.

Seely B.L., Olefsky J.M., 1993. Potential Cellular and Genetic Mechanisms for Insulin Resistance in the Common Disorders of Diabetes and Obesity. In: Moller,D. (Ed.), Insulin Resistance and its clinical disorders. pp. 187-252.

Sinclair C.G., 1998. International Dictionary of Food \& Cooking, $1^{\text {st }}$ ed London.

Sonoda Y., Kasahara T., Mukaida N., Shimizu N., Tomoda M., Takeda T., 1998. Stimulation of interleukin-8 production by acidic polysaccharides from the root of Panax ginseng. Immunopharmacology 38(3), 287-294. 
Staels B., Dallongeville J., Auwerx J., Schoonjans K., Leitersdorf E., Fruchart J.C., 1998. Mechanism of Action of Fibrates on Lipid and Lipoprotein Metabolism. Circulation 98(19), 2088-2093.

Staels B., Fruchart J.C., 2005. Therapeutic Roles of Peroxisome Proliferator-Activated Receptor Agonists. Diabetes 54(8), 2460-2470.

Steffen L.M., 2009. Five or More Servings of Fruit and Vegetables Each Day for Better Health! In: Ronald,R.W. (Ed.), Complementary and Alternative Therapies and the Aging Population. Academic Press, San Diego, pp. 417-431.

Takahashi T., Tabuchi T., Tamaki Y., Kosaka K., Takikawa Y., Satoh T., 2009. Carnosic acid and carnosol inhibit adipocyte differentiation in mouse 3T3-L1 cells through induction of phase2 enzymes and activation of glutathione metabolism. Biochemical and Biophysical Research Communications 382(3), 549-554.

Van Raalte D.H., Li M., Pritchard P.H., Wasan K.M., 2004. Peroxisome proliferatoractivated receptor (PPAR)-alpha: a pharmacological target with a promising future. Pharm Res. 21(9), 1531-1538.

Vergne E., 2001. Moroccan Cafe: Casual Moroccan Cooking at Home. Silverback Books.

Vermeeren C., Gumbert B., 2008. "Ontellicke boomen" or "countless trees": reconstructing the late medieval vegetation surrounding the 16th century St Margaretha Convent, Leiden, The Netherlands. Veget Hist Archaeobot 17(1), 93-103.

Visen P., Saraswat B., Visen A., Roller M., Bily A., Mermet C., He K., Bai N., Lemaire B., Lafay S., Ibarra A., 2009. Acute effects of Fraxinus excelsior L. seed extract on postprandial glycemia and insulin secretion on healthy volunteers. Journal of Ethnopharmacology 126(2), 226-232. 


\title{
CHAPTER V
}

\section{ACUTE EFFECTS OF Fraxinus excelsior L. SEED EXTRACT ON POSTPRANDIAL GLYCEMIA AND INSULIN SECRETION ON HEALTHY VOLUNTEERS}

\author{
Pradeep Visen ${ }^{\mathrm{a}}$, Binduja Saraswat ${ }^{\mathrm{b}}$, Aastha Visen ${ }^{\mathrm{c}}$, Marc Roller ${ }^{\mathrm{d}}$, \\ Antoine Bily ${ }^{d}$, Claire Mermet ${ }^{\mathrm{d}}$, Kan $\mathrm{He}^{\mathrm{e}}$, Naisheng Bai ${ }^{\mathrm{e}}$, Benoit \\ Lemaire $^{\mathrm{d}}$, Sophie Lafay ${ }^{\mathrm{d}}$, Alvin Ibarra ${ }^{\mathrm{e}}$
}

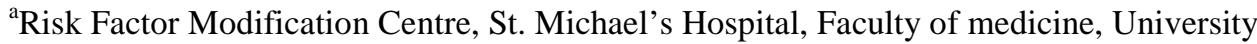
of Toronto, 70 richmond Street East, Main Floor, Toronto, Ontario, Canada M5C 1N8

${ }^{\mathrm{b}}$ Kumar Clinic and Diabetes Care Unit, Lucknow, India

${ }^{c}$ Lotus Nutraceutical, Canada

${ }^{\mathrm{d}}$ Naturex SA, BP 1218 site d'Agroparc, 84911 Avignon Cedex 9, France

${ }^{\mathrm{e}}$ Naturex Inc., 375 Huyler St., South Hackensack, New Jersey 07606, USA

J. of Ethnopharmacol. 2009, 126:226-232. 


\section{Abstract}

Aim of the Study: Fraxinus excelsior L. (Family: Oleaceae) seeds are consumed as a food, condiment, and folk medicine. The seeds are traditionally used as a potent hypoglycemic agent, but no clinical evidence exists in this regard. We assessed the clinical efficacy and safety of the seed extract (FraxiPure ${ }^{\mathrm{TM}}$, Naturex), containing $6.8 \%$ of nuzhenide and $5.8 \%$ of GI3 (w/w), on plasma glucose and insulin levels against glucose (50 g) induced postprandial glycemia.

Materials and methods: Preselected dose $(1.0 \mathrm{~g})$ was used in a double blind, randomized, crossover, placebo (wheat bran) controlled study on 16 healthy volunteers. Each treatment was given immediately after a fasting blood glucose sample ( $0 \mathrm{~min})$. Postprandial plasma glucose levels were estimated at 0, 15, 30, 45, 60, 90 and $120 \mathrm{~min}$; and postprandial plasma insulin at $0,30,60,90$ and $120 \mathrm{~min}$.

Results: The extract lowered the incremental postprandial plasma glucose concentration as compared to placebo at $45 \mathrm{~min}(P=0.06)$ and $120 \mathrm{~min}(P=0.07)$. It statistically $(P=0.02)$ reduced the glycemic area under the blood glucose curve. The seed, also, induced a significant $(P=0.002)$ secretion of insulin at 90 min after glucose administration. However, the insulinemic area under the blood insulin curve was not different than the placebo. No adverse events were reported.

Conclusions: Our findings confirm the hypoglycemic action of Fraxinus excelsior L. seed extract. These promising results, thus, encourage conducting long term clinical studies to evaluate the efficacy and safety of Fraxinus excelsior L. seed extract in healthy and diabetic volunteers and also to explore the possible mechanism(s) of action.

Keywords: Fraxinus excelsior L.; Postprandial blood glucose; Insulinemia; Secoiridoids; Nuzhenide; GI3 


\section{Introduction}

Plant derivatives with purported hypoglycemic properties have been used in folk medicine and traditional healing systems around the world (e.g., Native American, Indian, Jewish, Chinese, East Indian, Mexican) (Ungar et al., 1957; Yeh et al., 2003). But on the other hand, as indicated by Marles and Farnsworth, 1995, not all of the plants, based on anecdotal use, reported to be entirely safe, and they emphasize the need for carefully planned scientific research to identify those hypoglycemic plants with true therapeutic efficacy and safety. To provide evidence-based herbal medicine, we must standardize suitable clinical models and utilize randomized controlled trials (RCTs) to determine what herbs are efficacious for what diseases and standardized them according to their health use.

In this pursuit, the present study, utilizing our well standardized acute clinical model, was undertaken with the common ash, Fraxinus excelsior L. (Family: Oleaceae). It grows naturally in Europe, North Africa, and Asia from the shores of the Atlantic Ocean in the West to the Volga River in the East (Pliûra and Heuertz, 2003;Eddouks et al., 2005). Several reports reveal that the seeds of Fraxinus excelsior L. have been traditionally used as food, condiment, and folk medicine (Hedrick, 1919;Kunkel, 1984;Boisvert, 2003). The ash tree is known in Morocco as "Lissan Ettir", and its seeds as "L'ssane l'ousfour", one of the ingredients of the condiment "Ras el Hanout" used to prepare the famous tagines and other typical Moroccan plates (Sinclair, 1998;Vergne, 2001;Allen, 2007). In The Netherlands, there is evidence of the use of ash seeds since the medieval $16^{\text {th }}$ century (Vermeeren and Gumbert, 2008). In Iran, the ash seeds are employed as carminative and to destroy bladder stones (Parsa, 1959). Also, in Morocco the aqueous extract of the ash seeds is drunk in order to enhance several health conditions (Eddouks and Maghrani, 2004). This plant has been reported to have anti-oxidative (Meyer et al., 1995;Schempp et al., 2000;Middleton et al., 2005), anti-inflammatory (el-Ghazaly et al., 1992; von Kruedener et al., 1996), anti-rheumatic (von Kruedener et al., 1995;Gundermann and Muller, 2007), analgesic (Okpanyi et al., 1989), and antipyretic (Strehl et al., 1995) properties. The seeds of Fraxinus excelsior L. were recognized as potent hypoglycemic agents by several traditional healers using it for type 1 and type 2 diabetes mellitus (Eddouks et al., 2005). Eddouks and Maghrani (2004) and Maghrani et al. (2004) experimented on animals and reported hypoglycemic activity in normal rats and anti-diabetic properties, such as 
controlling streptozotocin (STZ) induced hyperglycemia, but no clinical evidence and scientific validation exist in this regard.

Therefore, in the current acute clinical study, for the first time an attempt has been made to confirm our hypothesis that Fraxinus excelsior L. seed extract will reduce postprandial glycemia in non-diabetic healthy individuals following glucose $(50 \mathrm{~g})$ intake. In order to determine the underlying mechanism, the serum insulin concentrations were also determined. We are thus; presenting the preliminary data on the acute clinical effect of the aqueous extract of the seeds of Fraxinus excelsior L. on healthy subjects against glucose induced postprandial glycemia.

\section{Material and Methods}

\section{Fraxinus excelsior $L$. seed extract}

\subsection{Raw material}

The seeds of Fraxinus excelsior L. were collected from many rural communities in Morocco and deposited at the herbarium (voucher specimen \# J02/02/A7; reference \# RB3524) of Naturex Maroc, Technopole Nouasser BP 42, Casablanca 20240, Morocco. First the samaras were harvested from the trees in the Atlas Mountains, and then the seeds were separated manually at home, a traditional practice in that region. After the collection, the seeds were analyzed in order to confirm their botanical origin. Analyses included macroscopic, microscopic and High Pressure Thin Layer Chromatography (HPTLC, CAMAG, Switzerland) techniques. These analyses were conducted by Mr. Elan Sudberg from Alkemists Pharmaceuticals, Inc. (Costa Mesa, CA, USA) using authenticated Fraxinus excelsior $\mathrm{L}$. seeds as a control. The sample used in our experiment corresponded to the seeds of Fraxinus excelsior $\mathrm{L}$.

\subsection{Extract preparation}

Fraxinus excelsior L. seed extract was obtained by an industrial process (FraxiPure ${ }^{\mathrm{TM}}$, batch \# 347/53/A7; reference \# 149251, Naturex SA, Site d'Agroparc BP 1218, 84911 Avignon Cedex 9, France) according to the traditional method used in Morocco (Eddouks and Maghrani, 2004;Maghrani et al., 2004;Eddouks et al., 2005). First the seeds were milled, and then the seed powder was extracted in water stirring for $2 \mathrm{~h}$ at $65{ }^{\circ} \mathrm{C}$. The ratio 
(Fraxinus excelsior L. seeds: solvent) was fixed, using only water as a solvent. After filtration, the clarified solution was concentrated under vacuum at $40{ }^{\circ} \mathrm{C}$ which was then mixed with Arabic gum and silicon dioxide as carriers and spry dried to obtain a fine powder. Moisture content in the extract was less than $8 \%$. The extract ratio was approximately 6:1 (Fraxinus excelsior L. seeds: extract powder), yielding $16.67 \%$ of dry Fraxinus excelsior L. seed extract.

\subsection{Chemical identification}

The molecular weight of nuzhenide ( $\beta$-D-Glucopyranoside, 2-(4-hydroxyphenyl)ethyl, 6-[(2S,3E,4S)-3-ethylidene-2-( $\beta$-D-glucopyranosyloxy)-3,4-dihydro-5-(methoxycarbonyl)2H-pyran-4-acetate]) and GI3 (2H-Pyran-4-acetic acid, 3-ethylidene-2-( $\beta$-Dglucopyranosyloxy)-3,4-dihydro-5-(methoxycarbonyl)-, 4-[2-[[6-O-[[3-ethylidene-2-( $\beta$-Dglucopyranosyloxy)-3,4-dihydro-5-(methoxycarbonyl)-2H-pyran-4-yl]acetyl]- $\beta$-Dglucopyranosyl]oxy]ethyl]phenyl ester, stereoisomer (9CI)), the main secoiridoids being standardized in Fraxinus excelsior L. seed extract, were identified by HPLC-MS and the chemical structures were determined by comparison of NMR data to those in literature (LaLonde et al., 1976). Figure V-1 shows the chromatogram of the extract and the chemical structure of the two compounds. An HPLC method was developed for the quantification of the secoiridoid contents. The HPLC system used was an Agilent 1100 (Palo Alto, CA, USA) equipped with a diode array detector. The stationary phase was a Prodigy ODS3 analytical column (250 x $4.6 \mathrm{~mm}$ i.d, 5 $\mu \mathrm{m}$, Phenomenex, Torrance, CA, USA) thermostated at $30{ }^{\circ} \mathrm{C}$. The flow rate was $1 \mathrm{ml} / \mathrm{min}$, and the elution was monitored at 238 $\mathrm{nm}$. The mobile phases were (A) water with $0.1 \%$ TFA and (B) acetonitrile. The solution of $80 \% \mathrm{~A}$ and $20 \% \mathrm{~B}$ was maintained for $5 \mathrm{~min}$ and then changed to $70 \% \mathrm{~A}$ and $30 \% \mathrm{~B}$ after 15 min total time; followed by a linear gradient of $100 \%$ B after 25 min total time, maintaining this composition for $10 \mathrm{~min}$; the system was then reequilibrated to the initial composition after 10 min. Peaks of nuzhenide and GI3 appeared at approximately 13 and $18 \mathrm{~min}$, respectively. The Fraxinus excelsior L. seed extract used in this clinical trial contained $6.8 \%$ of nuzhenide and $5.8 \%$ of GI3. 


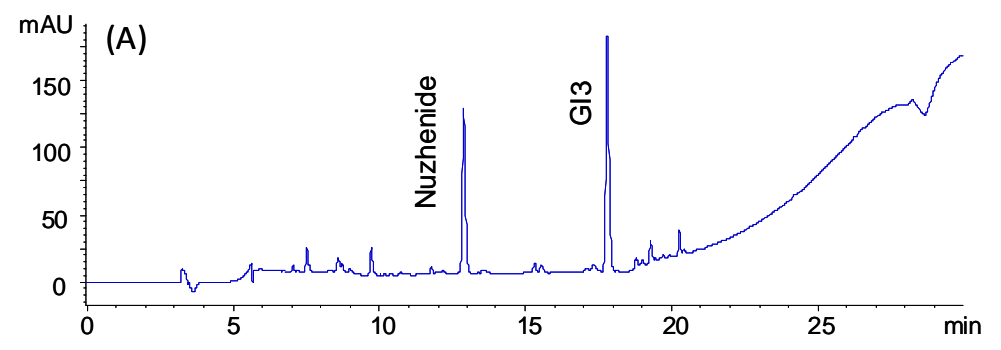

(B)

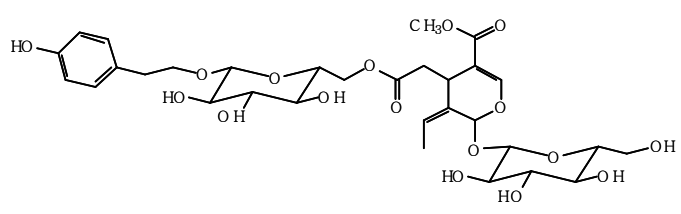

(C)

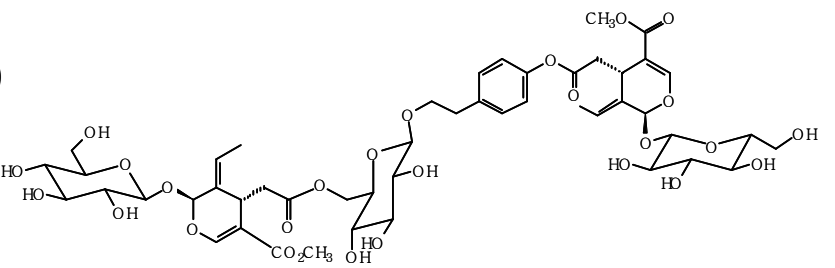

Figure V-1. (A) Chromatogram of Fraxinus excelsior L seed extract, (B) Nuzhenide and (C) GI3.

\section{Clinical trial}

\subsection{Test material}

The dose of Fraxinus excelsior L. seed extract in our acute clinical study was $1.0 \mathrm{~g}$ (powdered extract filled in two capsules of $500 \mathrm{mg}$ each).

\subsection{Placebo}

Wheat bran (Certified Hard Red Wheat Bran; lot 195) served as placebo which was also administered at the dose of $1.0 \mathrm{~g}$ for comparison. It is certified by American Association of Cereal Chemists (AACC). The main composition of wheat bran consists of protein-16.05\% (Nx6.31), fat- $4.34 \%$ (as triglycerides, total), total dietary fiber- $49.65 \%$, carbohydrates65.75\%, starch- 13.3\% (Modified Ewers method), besides vitamin $\mathrm{B}_{1}, \mathrm{~B}_{6}, \mathrm{~B}_{12}$, magnesium, potassium, phosphorus, manganese, calcium, copper, iron, sodium and zinc. It did not seem to 
improve blood glucose control or risk factors for coronary heart disease (CHD) in type 2 diabetes over 3 months (Jenkins et al., 2002).

\section{Study design}

The study was randomized, double blind, placebo-controlled and crossover designed. By this design subjects act as their own controls. Only the "blinder", an independent clinical research scientist, knew the identity of the treatments who performed and maintained the "blinding" of packages, labels, and randomization of the treatments while not having contact with individuals or data. Randomization was done using a random number table. Monitoring of all individual records, data sheets, sample handling, laboratory sample storage, and sample inventory for completeness and adherence to the protocol was conducted by the study monitor.

The trial was carried out at Kumar Clinic and Diabetes Care Centre, Lucknow, India. All the healthy subjects were recruited at this Centre.

\subsection{Inclusion criteria}

- Subjects were males or non-pregnant females aged 18-55 years, recruited from India.

- Given written consent to participate in the study.

- Healthy, fasting plasma glucose range: $4.0-5.5 \mathrm{mmol} / \mathrm{l}$.

- BMI $25-28 \mathrm{~kg} / \mathrm{m}^{2}$.

\subsection{Exclusion criteria}

- Diabetes.

- Hypertension.

- Any medication which might, in the opinion of investigator, be dangerous to the subject or will affect the results.

- Smokers.

- Heavy alcohol abuse.

- Renal, hepatic or inflammatory bowel disease, anemia or CVD.

- Blood donation within 2 months. 
- Subjects who cannot comply with the experimental procedures or do not follow safety guidelines.

- Women with anticipated pregnancy/pregnant/lactation.

- Use of any microsomal enzyme inhibiting/inducing drugs within 30 days and/or systemic medication including .OTC operation 14 days prior to day 1 of the study.

- Participation of any clinical trial within 6 weeks preceding day 1 of the study.

\subsection{Participant characteristics and study flow}

Prior to commencement of the study, the participants were invited to come to the Kumar Clinic and Diabetic Care Centre, Lucknow (India). They were then briefed with objective and procedures of the study in simple communicable language. All the volunteers were screened for inclusion/exclusion criteria and asked to understand and sign the informed consent form at each visit. During the screening session, they underwent multiple measurements such as blood pressure, height and weight. None of the participants reported use of natural health products or supplements with potential effects on glycemia with 3 weeks prior to the screening visit.

Sixteen healthy individuals (11 male; 5 female of Indian origin, age range: 20-55 y, BMI: $26 \pm 2.2 \mathrm{~kg} / \mathrm{m}^{2}$; fasting blood glucose: $4.4 \pm 0.09 \mathrm{mmol} / \mathrm{L}$ ) completed the study.

The test substance (Fraxinus excelsior L. seed extract, $1.0 \mathrm{~g}$ ) or the placebo (wheat bran, $1.0 \mathrm{~g}$ ) was administered orally on two separate occasions, with a gap of one week (washout period), in the form of two capsules (each having $500 \mathrm{mg}$ ) as a single dose prior to the glucose challenge $(50 \mathrm{~g}$ in $100 \mathrm{ml})$ for evaluation of glycemic response. The placebo matched with the test substance in all aspects except for active constituents for the purpose of blinding. Each of the 16 healthy subjects underwent randomization for each of the investigated treatment and all of their data were included in final analysis.

At each study visit, 10-12 overnight fasted volunteers first had their blood pressure, weight and height measured and subsequently rested in the seated position. Thereafter, individuals filled out forms detailing their pharmacological regimen including their previous visit and their diet (dinner) and activity (sleep, urination, morning routine) regimen for the previous 12-hours. 


\subsection{Compliance and symptoms}

The participants were asked to maintain their usual carbohydrate intake which excludes dieting or restricting intake and to maintain a constant level of physical activity and lifestyle patterns throughout the course of the study and avoid strenuous exercise the day before and the morning of the test. Moreover, they were advised to refrain from taking any herbal supplements or medicines. Volunteers were asked to have a simple diet 3 days prior to the test substance administration accompanied by 10-12 $\mathrm{h}$ of fasting before coming to the clinic between 7:30 and 10:30 am. The standardized amount of water and time for treatment consumption were strictly observed by all participants.

\subsection{Methodology}

The methods and treatment protocol for the present study have been well established for acute clinical screening at our Risk Factor Modification Centre (RFMC), St. Michael's Hospital, Toronto, Canada (Vuksan et al., 2000;Vuksan et al., 2001;Vuksan et al., 2008; Sievenpiper et al., 2003;Sievenpiper et al., 2004;Sievenpiper et al., 2006).

The consent form, questionnaires along with corresponding protocol were approved by Institutional Human Ethical Committee (IEC) of Kumar Clinic and Diabetes Care Centre vide letter \# LNC/FR/2008/19; dated February 15, 2008 following the guidelines of the Declaration of Helsinki and Tokyo for humans and AYUSH, Government of India.

\subsubsection{Estimation of blood glucose level.}

During the study, finger- prick blood samples were obtained at 0, 15, 30, 45, 60, 90 and 120 minutes. The test extract/placebo was given immediately with $100 \mathrm{ml}$ of water, after taking out the fasting blood sample at 0 min. This was followed by the ingestion of a glucose (D-glucose; Qualigens Co., Glaxo India) drink (50 g in $100 \mathrm{ml})$. At this moment the timer was started. This was asked to consume within 5-8 min. Additional finger-prick blood samples were taken at 15, 30, 45, 60, 90 and 120 min after the start of glucose drink. Glucose concentrations were determined in the capillary whole blood using Bayer's glucometer using Essentia glucotrip. The portable blood glucose monitor measures the glucose concentration in whole blood using a glucose dehydrogenase method based on bioamperometry, but is calibrated to yield plasma-like glucose values (Heacock et al., 
2005). This blood glucose monitor correlated well with our standard laboratory glucose analyzer (YSI 2300 Stat Plus, Yellow Springs Instruments, Yellow Springs, OH) used routinely at RFMC, St. Michael's Hospital, Canada. During the $2 \mathrm{~h}$ of the testing session, subjects remained seated, did not smoke, eat or drink. After the end of study, they were asked to fill up post test questionnaire. The entire time spent in the clinic was approximately 2.5 hours. Thereafter, they were offered a snack and then allowed to leave.

\subsubsection{Estimation of serum insulin level.}

Venous blood samples $(7-8 \mathrm{ml})$ were collected at $0,30,60,90$ and $120 \mathrm{~min}$ in test extract/placebo treated healthy subjects in serum separator tubes. The blood was allowed $15 \mathrm{~min}$ to clot, and then was centrifuged at $1500 \times \mathrm{g}$ for $10 \mathrm{~min}$. The resulting serum was then analyzed for insulin using an electrochemiluminescence immunoassay (ECLIA) at the prestigious analytical unit of Ranbaxy at Mumbai, India. The inter-assay CV was between $1.5-2.0 \%$.

\section{Statistical analysis}

The positive incremental area under the curve (i-AUC) for both placebo and Fraxinus excelsior L. seed extract treated groups were calculated for glycemic and insulinemic concentrations at different time intervals, ignoring areas below the initial value at time zero (Wolever et al., 1991). Significant differences between groups were calculated using a twotailed paired Student's $t$ test. Analyses were performed using XLSTAT 2008 software (Addinsoft ${ }^{\mathrm{TM}}$, USA). Statistical significance was set at $P<0.05$. All data are reported as mean \pm SEM.

\section{Results}

\section{Blood glucose level}

The graphic, from pair-wise comparison, of incremental glycemia showed a decrease in postprandial glucose levels by Fraxinus excelsior L. seed extract, during the length of experiment from $15(2.0 \pm 0.28 \mathrm{mmol} / \mathrm{l}$ vs. $1.7 \pm 0.21 \mathrm{mmol} / \mathrm{l}), 30(4.1 \pm 0.31 \mathrm{mmol} / \mathrm{l}$ vs $3.8 \pm 0.33 \mathrm{mmol} / \mathrm{l}), 45(4.2 \pm 0.41 \mathrm{mmol} / \mathrm{l}$ vs. $3.8 \pm 0.47 \mathrm{mmol} / \mathrm{l}), 60(3.5 \pm 0.46 \mathrm{mmol} / \mathrm{l}$ vs. $3.4 \pm 0.41), 90(1.9 \pm 0.38 \mathrm{mmol} / \mathrm{l}$ vs $1.7 \pm 0.31 \mathrm{mmol} / \mathrm{l})$ to $120(0.58 \pm 0.29 \mathrm{mmol} / \mathrm{l}$ vs. 
$0.21 \pm 0.28 \mathrm{mmol} / \mathrm{l}$ ) $\mathrm{min}$ as compared to matched wheat bran placebo (Figure V-2A). The extract almost reached statistical difference at $45 \mathrm{~min}(P=0.06)$ and $120 \mathrm{~min}(P=0.07)$.

Paired Student's $t$ test indicated that differences $(299.8 \pm 28.9 \mathrm{~min} \mathrm{mmol} / \mathrm{l}$ vs $273.3 \pm 25.3$ $\min \mathrm{mmol} / \mathrm{l}$ ) in the effect of treatment (Fraxinus excelsior L. seed extract vs. placebo) on mean glycemic area under the curve (AUC) were statistically significant $(P=0.02)$. The results are presented in Figure V-2B.
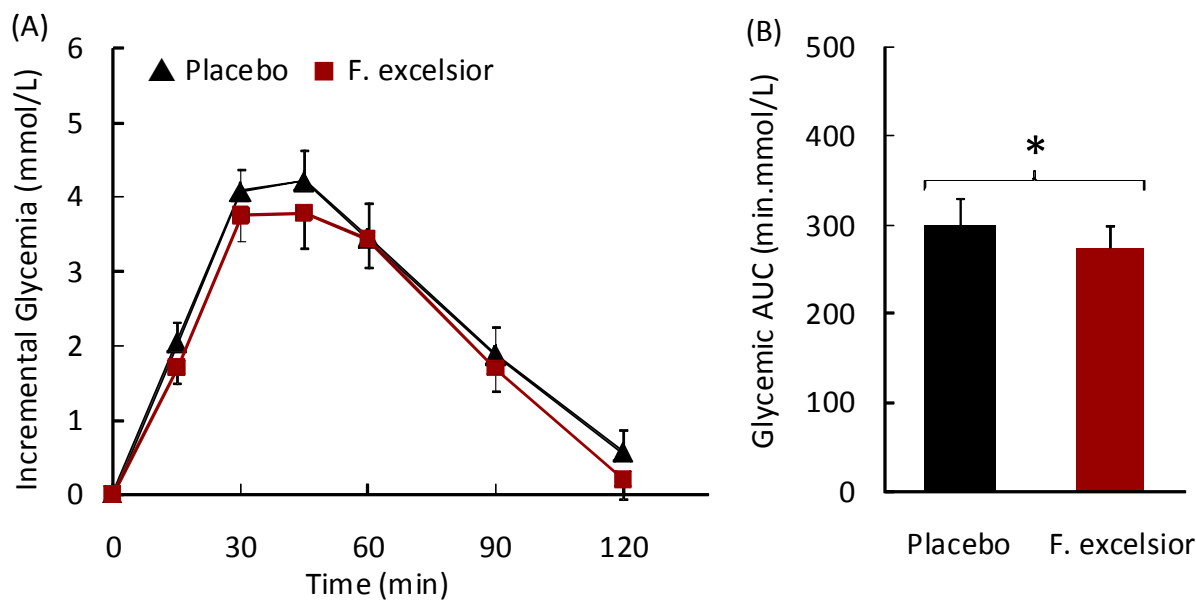

Figure V-2. Comparison between Fraxinus excelsior $\mathrm{L}$ seed extract $(1.0 \mathrm{~g})$ and matched wheat bran placebo $(1.0 \mathrm{~g})$ on glycemia in healthy volunteers administrated with $50 \mathrm{~g}$ of glucose. (A) Incremental glycemia at individual time points. (B) Glycemic area under the curve (AUC). Values are mean \pm SEM. ${ }^{*} P=0.02$, Student's $t$ test $(\mathrm{n}=16)$.

\section{Insulin level}

Fraxinus excelsior $\mathrm{L}$. seed extract $(55.5 \pm 4.6 \mathrm{mU} / \mathrm{l})$ induced a significant $(P=0.002)$ secretion of insulin at $90 \mathrm{~min}$ compared to placebo (43.5 $\pm 5.0 \mathrm{mU} / \mathrm{l})$ (Figure V-3A). No significant difference was noticed in the mean insulinemic AUC (0-120 min), in Fraxinus excelsior L. seed extract treated group $(6,041.6 \pm 340.5 \mathrm{~min} \mathrm{mU} / \mathrm{l})$ compared to placebo $(5,996.3 \pm 594.58$ min.mU/l) (Figure V-3B). 

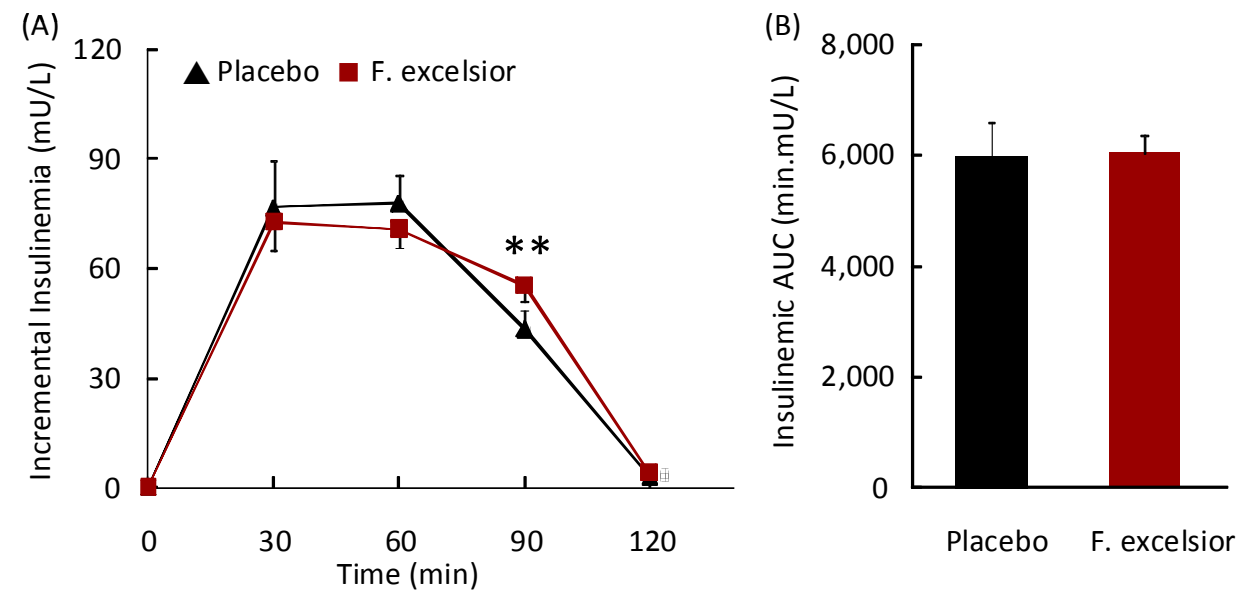

Figure V-3. Comparison between Fraxinus excelsior $\mathrm{L}$ seed extract $(1.0 \mathrm{~g})$ and matched wheat bran placebo $(1.0 \mathrm{~g})$ on insulin levels in healthy volunteers administrated with $50 \mathrm{~g}$ of glucose. (A) Incremental insulinemia at individual time points. (B) Insulinemic area under the curve (AUC). Values are mean \pm SEM. ${ }^{* \star} P=0.002$, Student's $t$ test $(n=16)$.

\section{Discussion}

In the present preliminary acute study with Fraxinus excelsior L. seeds, we have tested the aqueous extract in healthy subjects against glucose $(50 \mathrm{~g})$ induced postprandial hyperglycemia to know its efficacy and safety. A regular decreasing trend of postprandial glycemia was observed with Fraxinus excelsior L. seed extract $(1.0 \mathrm{~g})$ which almost reached statistical difference at $45 \mathrm{~min}(P=0.06)$ and $120 \mathrm{~min}(P=0.07)$ compared to placebo (wheat bran). This finding, thus, validates the hypoglycemic activity in normal animal studies observed by Eddouks and Maghrani (2004), and Maghrani et al. (2004).

The healthy volunteers were taken in order to avoid potential interaction with antidiabetic and other medications. Further, the acute approach also eliminates possible concerns regarding the untested safety of the extract. In our investigation, no adverse event or reaction was observed in the healthy volunteers at least for the dose and duration used. However, the effect should nevertheless, be confirmed in long term trial in healthy as well as diabetic patients. The animal studies are also indicative for such clinical study with Fraxinus excelsior $\mathrm{L}$. seed extract where more activity was observed in diabetic rats compared to normal (Eddouks and Maghrani, 2004). 
In this study, we found that the main compounds in Fraxinus excelsior L. seed extract are the secoiridoid glycoside nuzhenide (6.8\%) and the dimeric secoiridoid glycoside GI3 (5.8\%) (Figure V-1), which may be responsible for efficacy. Similar secoiridoid glycosides such as oleuropein, ligstroside, and excelsioside and GI5 - a molecule similar to GI3 - have also been isolated from Fraxinus excelsior L. leaves (Jensen and Nielsen, 1976;Damtoft et al., 1992;Egan et al., 2004). All these secoiridoids glycosides have been reported for hypoglycemic (Gonzalez et al., 1992;Al-Azzawie and Alhamdani, 2006) and anti-diabetic (Ahmed et al., 2003;Somova et al., 2003) properties.

The incremental glycemic curve for Fraxinus excelsior L. seed extract shows two different phases compared to the placebo (Figure V-2A). The first phase takes place during the initial $60 \mathrm{~min}$ of the experiment. During the first $15 \mathrm{~min}$ there is a slight reduction of glycemia in the Fraxinus excelsior L. seed extract group, this difference is more evident at $30 \mathrm{~min}$, and almost reaches statistical difference at $45 \mathrm{~min}(P=0.06)$. The two groups have similar glycemic values at $60 \mathrm{~min}$. The second phase takes place during the last hour of the experiment. At 90 min there is a slight reduction in glycemia in the Fraxinus excelsior L. seed extract group compared to the placebo, which almost reach statistical difference at 120 $\min (P=0.07)$. These two phases may underlay different mechanisms of action of Fraxinus excelsior L. seed extract in reducing postprandial glycemia.

A possible explanation for the first phase is that Fraxinus excelsior L. seed extract partially inhibits the absorption of glucose by blocking its uptake in the intestine. The partial inhibition of glucose uptake by other secondary metabolites of plants already have been reported for glycoside flavonoids (Johnston et al., 2005;Kottra and Daniel, 2007; Kwon et al., 2007). Flavonoids reduce the intestinal glucose absorption by limited inhibition of sodium-dependent co-transporter SGLT1 in the brush border membrane (Welsch et al., 1989;Kottra and Daniel, 2007) and the sodium-independent glucose transporter GLUT2 in the basolateral membrane (Kwon et al., 2007). In flavonoids, this inhibition is enhanced in the presence of glycosides (Johnston et al., 2005; Kottra and Daniel, 2007). Therefore, the reduction in glycemia during the first phase might be caused by the glycoside secoiridoids present in Fraxinus excelsior L. seed extract by blocking the intestinal glucose transporters. However, more research is needed in order to confirm this hypothesis. Other mechanisms can also be involved in the reduction of postprandial glycemia during the first phase and may have a longer effect. The literature describe that 
some glycoside secoiridoids lowers the hypoglycemic activity by reducing the peripheral uptake of glucose (Gonzalez et al., 1992).

Regarding the second phase, our preliminary mechanistic trial suggests that the postprandial hypoglycemic effect may be due to increased insulin secretion, compensated for the reduced release in the time period. Normal insulin secretion is biphasic, with an early burst of insulin release within the first $10 \mathrm{~min}$, followed by a progressively phase of insulin secretion that persists as long as the hyperglycemic state is present. As the first 60 min of oral glucose challenge is considered to be the representative of the early phase of insulin secretion (Vuksan et al., 2001), our data suggest that Fraxinus excelsior L. seed extract may be able to increase this phase, the loss of which is a primary defect in type 2 diabetes. We observed a significant $(P=0.002)$ increase in the insulin level at $90 \mathrm{~min}$ by Fraxinus excelsior $\mathrm{L}$. seed extract at the dose of $1.0 \mathrm{~g}$, after glucose administration compared to the placebo (Figure V-3), from where we saw a decline in postprandial plasma glucose level. Our study, thus, also offers stronger support for post-absorptive effects (60120 min of the oral glucose challenges) such as enhancement of insulin secretion (Vuksan et al., 2001). This might be caused by the action of the secoiridoids glycosides present in the Fraxinus excelsior L. seed extract. Compounds from the secoiridoid family have proven to stimulate glucose induced insulin secretion (Gonzalez et al., 1992;Al-Azzawie and Alhamdani, 2006;Zhang et al., 2006) and improve the insulin resistance (Somova et al., 2003). In order to exert insulin secretion, compounds found in Fraxinus excelsior L. seed extract or its metabolites must be bioavailable. There is no evidence in literature on the bioavailability of nuzhenide or GI3; but some studies suggested that secoiridoids with similar structures can be absorbed by the body (Edgecombe et al., 2000; Singh et al., 2008). For example, an in vitro study showed that part of oleuropein, the main secoiridoid glycoside found in olives, is hydrolyzed in gastric conditions and another portion is degraded by the colonic microflora (Corona et al., 2006). The authors reported paracellular absorption and/or an active transport mechanism via SGLT1 (Edgecombe et al., 2000). Resulting metabolites could then be subjected to classic Phase I/II biotransformation before reaching general circulation (Corona et al., 2006). As there is no information on bioavailability of nuzhenide or GI3, we can suppose that their mechanism of absorption is close to the absorption of oleuropein. However, more research is needed in order to determine the type of metabolites, their pharmacokinetic mechanisms and to understand the 
possible insulin stimulation mechanisms of secoiridoids from Fraxinus excelsior L. seeds in humans.

In type 2 diabetes, in early phase, the insulin resistance is overcome by a compensatory response from the pancreatic beta cells and euglycemia is maintained. In our study, the stimulation of insulin secretion at 90 min seems to be a direct action of the plant extract on the pancreatic islet cells (Zhang et al., 2006) which returned to normalcy at the end of study (120 minutes). This may reduce insulin resistance and improve insulin sensitivity in such cases. Further, since there is no significant difference in mean insulinemic AUC between treatment and placebo, the use of extract is safe with no resultant hyperinsulinemia in the following hours post-treatment. This strongly indicates the possible mechanism of action of Fraxinus excelsior L. seed extract in reducing postprandial hyperglycemia.

Our preliminary study shows a decrease in plasma glucose AUC of 9\% of Fraxinus excelsior L. seed extract compared to the placebo. The paired Student's $t$ test indicated that differences $(299.8 \pm 28.9 \mathrm{~min} \mathrm{mmol} / \mathrm{l}$ vs. $273.3 \pm 25.3 \mathrm{~min} \mathrm{mmol} / \mathrm{l})$ in the effect of treatment (Fraxinus excelsior L. seed extract vs. placebo) on AUC (0-120 min) were statistically significant $(P=0.02)$ (Figure V-2B). This observation, in our acute study, has a clinical relevance. We have only studied the effect of Fraxinus excelsior L. seed extract on postprandial glycemia in healthy individuals, not in those with diabetes. Therefore, based on the current observations, further research is needed to evaluate the effectiveness of the extract in people with diabetes and safety over the long-term clinical investigations.

\section{Conclusion}

To our knowledge, there are no studies on the effect of Fraxinus excelsior L. seed extract on postprandial glycemia either in healthy subjects or diabetic patients. For the first time, through our standardized acute clinical studies, we have, thus reported its preliminary significant effect on glucose induced postprandial hyperglycemia and insulin secretion in 16 healthy subjects. Implications of the present results are promising. Our findings suggest that Fraxinus excelsior L. seed extract causes an acute insulinotropic effect in humans after a glucose challenge, and therefore promotes insulin sensitivity. Moreover, as the total postprandial insulinemia is not statistically different as compared to placebo, it may significantly prevent the development of insulin resistance. This evidence encourages 
continuing the research work to determine its bioavailability and possible hypoglycemic mechanism of action. More research is needed to, further, evaluate the efficacy and safety of Fraxinus excelsior L. seed extract in healthy volunteers as well as in people with diabetes over a long-term.

\section{Acknowledgements}

Financial assistance from Naturex is gratefully acknowledged. Special thanks to Dr. Prabhat Saxena and Mr. Ramesh Yadav of Kumar Clinic and Diabetes Care Unit for their professional and technical support. Warm thanks to the scientists and staff of Naturex and Lotus Nutraceutical Canada for their invaluable inputs and suggestions on an early version of the manuscript. The authors gratefully acknowledge MSc. Maxine Bober for her valuable assistance.

\section{References}

Ahmed,B., A.J.Al-Rehaily, T.A.Al-Howiriny, K.A.El-Sayed, and M.S.Ahmad. 2003. Scropolioside-D2 and Harpagoside-B: Two New Iridoid Glycosides from Scrophularia deserti and Their Antidiabetic and Antiinflammatory Activity. Biological \& Pharmaceutical Bulletin 26:462-467.

Al-Azzawie,H.F., andM.S.Alhamdani. 2006. Hypoglycemic and antioxidant effect of oleuropein in alloxan-diabetic rabbits. Life Sci 78.

Allen, G., 2007. The Herbalist in the Kitchen. University of Illinois Press, Illinois, p. 303.

Boisvert,C. 2003. Plantes et remèdes naturels. Genève.

Corona,G., X.Tzounis, D.M.Assunta, M.Deiana, E.S.Debnam, F.Visioli, and J.P.Spencer. 2006. The fate of olive oil polyphenols in the gastrointestinal tract: implications of gastric and colonic microflora-dependent biotransformation. Free Radic. Res. 40:647-658.

Damtoft,S., H.Franzyk, and S.R.Jensen. 1992. Excelsioside, a secoiridoid glucoside from Fraxinus excelsior. Phytochemistry 31:4197-4201.

Eddouks,M., andM.Maghrani. 2004. Phlorizin-like effect of Fraxinus excelsior in normal and diabetic rats. J Ethnopharmacol. 94:149-154. 
Eddouks,M., M.Maghrani, N.A.Zeggwagh, M.Haloui, and J.B.Michel. 2005. Fraxinus excelsior L. evokes a hypotensive action in normal and spontaneously hypertensive rats. Journal of Ethnopharmacology 99:49-54.

Edgecombe,S.C., G.L.Stretch, and P.J.Hayball. 2000. Oleuropein, an antioxidant polyphenol from olive oil, is poorly absorbed from isolated perfused rat intestine. J Nutr 130.

Egan,P., P.Middleton, M.Shoeb, M.Byres, Y.Kumarasamy, M.Middleton, L.Nahar, A.Delazar, and S.Sarker. 2004. GI 5, a dimer of oleoside, from Fraxinus excelsior (Oleaceae). Biochemical Systematics and Ecology 32.

El-Ghazaly,M., M.T.Khayyal, S.N.Okpanyi, and M.Arens-Corell. 1992. Study of the antiinflammatory activity of Populus tremula, Solidago virgaurea and Fraxinus excelsior. Arzneimittelforschung 42.

Gonzalez,M., A.Zarzuelo, M.J.Gamez, M.P.Utrilla, J.Jimenez, and I.Osuna. 1992. Hypoglycemic activity of olive leaf. Planta Med 58.

Gundermann,K.J., andJ.Muller. 2007. Phytodolor--effects and efficacy of a herbal medicine. Wien. Med. Wochenschr. 157:343-347.

Heacock,P.M., S.R.Hertzler, J.A.Williams, and B.W.Wolf. 2005. Effects of a medical food containing an herbal alpha-glucosidase inhibitor on postprandial glycemia and insulinemia in healthy adults. J. Am. Diet. Assoc. 105:65-71.

Hedrick,U.P. 1919. Sturtevant's Notes on Edible Plants. 1 ed. State of New York Department of Agriculture, Albany.

Jenkins,D.J., C.W.Kendall, L.S.Augustin, M.C.Martini, M.Axelsen, D.Faulkner, E.Vidgen, T.Parker, H.Lau, P.W.Connelly, J.Teitel, W.Singer, A.C.Vandenbroucke, L.A.Leiter, and R.G.Josse. 2002. Effect of wheat bran on glycemic control and risk factors for cardiovascular disease in type 2 diabetes. Diabetes Care 25:15221528 .

Jensen,S.R., andB.J.Nielsen. 1976. A new coumarin fraxidin 8-O-beta-d-glucoside and 10hydroxyligstroside from bark of Fraxinus exelsior. Phytochemistry 15:221-223.

Johnston,K., P.Sharp, M.Clifford, and L.Morgan. 2005. Dietary polyphenols decrease glucose uptake by human intestinal Caco-2 cells. FEBS Lett 579 .

Kottra,G., andH.Daniel. 2007. Flavonoid glycosides are not transported by the human $\mathrm{Na} /$ /glucose transporter when expressed in Xenopus laevis oocytes, but effectively inhibit electrogenic glucose uptake. J. Pharmacol. Exp. Ther. 322:829835 . 
Kunkel,G. 1984. Plants for Human Consumption. 1 ed. Koenigstein.

Kwon,O., P.Eck, S.Chen, C.P.Corpe, J.H.Lee, M.Kruhlak, and M.Levine. 2007. Inhibition of the intestinal glucose transporter GLUT2 by flavonoids. FASEB J. 21:366-377.

LaLonde,R., C.Wong, and A.Tsai. 1976. Polyglucosidic Metabolites of Oleaceae. The Chain Sequence of Oleoside Aglucon, Tyrosol, and Glucose Units in Three Metabolites from Fraxinus americana. Journal of the American Chemical Society 98:3007-3013.

Maghrani,M., N.Zeggwagh, A.Lemhadri, M.El Amraoui, J.Michel, and M.Eddouks. 2004. Study of the hypoglycaemic activity of Fraxinus excelsior and Silybum marianum in an animal model of type 1 diabetes mellitus. J Ethnopharmacol. 91.

Marles,R.J., andN.R.Farnsworth. 1995. Antidiabetic plants and their active constituants. Phytomedicine 2.

Meyer,B., W.Schneider, and E.F.Elstner. 1995. Antioxidative properties of alcoholic extracts from Fraxinus excelsior, Populus tremula and Solidago virgaurea. Arzneimittelforschung 45.

Middleton,P., F.Stewart, S.Al-Qahtani, P.Egan, C.O'Rourke, A.Abdulrahman, M.Byres, M.Middleton, Y.Kumarasamy, M.Shoeb, L.Nahar, A.Delazar, and S.Sarker. 2005. Antioxidant, antibacterial activities and general toxicity of Alnus glutinosa, Fraxinus excelsior and Papaver rhoeas. Iranian Journal of Pharmaceutical Research 2.

Okpanyi,S.N., R.Schirpke-von Paczensky, and D.Dickson. 1989. Anti-inflammatory, analgesic and antipyretic effect of various plant extracts and their combinations in an animal model. Arzneimittelforschung 39.

Parsa,A. 1959. Medicinal plants and drugs of plant origin in Iran III. In Springer Netherland (ed.) .

Pliûra, Alfas and Heuertz, Myriam. Technical Guidelines for genetic conservation: Common ash (Fraxinus excelsior). European Forest Genetic Resources Programme 1[1]. 2003. Ref Type: Journal (Full)

Schempp,H., D.Weiser, and E.F.Elstner. 2000. Biochemical model reactions indicative of inflammatory processes. Activities of extracts from Fraxinus excelsior and Populus tremula. Arzneimittelforschung 50.

Sievenpiper,J.L., J.T.Arnason, L.A.Leiter, and V.Vuksan. 2003. Null and opposing effects of Asian ginseng (Panax ginseng C.A. Meyer) on acute glycemia: results of two acute dose escalation studies. J Am Coll Nutr 22. 
Sievenpiper,J.L., J.T.Arnason, L.A.Leiter, and V.Vuksan. 2004. Decreasing, null and increasing effects of eight popular types of ginseng on acute postprandial glycemic indices in healthy humans: the role of ginsenosides. J Am Coll Nutr 23.

Sievenpiper,J.L., M.K.Sung, M.Di Buono, K.Seung-Lee, K.Y.Nam, J.T.Arnason, L.A.Leiter, and V.Vuksan. 2006. Korean red ginseng rootlets decrease acute postprandial glycemia: results from sequential preparation- and dose-finding studies. J Am Coll Nutr 25.

Sinclair,C.G. 1998. International Dictionary of Food \& Cooking. 1st ed. London.

Singh,I., M.Mok, A.M.Christensen, A.H.Turner, and J.A.Hawley. 2008. The effects of polyphenols in olive leaves on platelet function. Nutrition, Metabolism and Cardiovascular Diseases 18:127-132.

Somova,L.I., F.O.Shode, P.Ramnanan, and A.Nadar. 2003. Antihypertensive, antiatherosclerotic and antioxidant activity of triterpenoids isolated from Olea europaea, subspecies africana leaves. J Ethnopharmacol 84.

Strehl,E., W.Schneider, and E.F.Elstner. 1995. Inhibition of dihydrofolate reductase activity by alcoholic extracts from Fraxinus excelsior, Populus tremula and Solidago virgaurea. Arzneimittelforschung 45.

Ungar,G., L.Freedman, and S.L.Shapiro. 1957. Pharmacological studies of a new oral hypoglycemic drug. Proc. Soc. Exp. Biol. Med. 95:190-192.

Vergne,E. 2001. Moroccan Cafe: Casual Moroccan Cooking at Home. Silverback Books.

Vermeeren,C., andB.Gumbert. 2008. "Ontellicke boomen" or "countless trees": reconstructing the late medieval vegetation surrounding the 16th century St Margaretha Convent, Leiden, The Netherlands. Veget Hist Archaeobot 17:93-103.

Von Kruedener,S., W.Schneider, and E.Elstner. 1995. A combination of Populus tremula, Solidago virgaurea and Fraxinus excelsior as an anti-inflammatory and antirheumatic drug. A short review. Arzneimittelforschung. 45.

Von Kruedener,S., W.Schneider, and E.Elstner. 1996. Effects of extracts from Populus tremula L., solidago virgaurea L. and Fraxinus excelsior L. on various myeloperoxidase systems. Arzneimittelforschung. 46.

Vuksan,V., J.L.Sievenpiper, Z.Xu, E.Y.Wong, A.L.Jenkins, U.Beljan-Zdravkovic, L.A.Leiter, R.G.Josse, and M.P.Stavro. 2001. Konjac-Mannan and American ginsing: emerging alternative therapies for type 2 diabetes mellitus. J. Am. Coll. Nutr. 20:370S-380S. 
Vuksan,V., J.L.Sievenpiper, V.Y.Y.Koo, T.Francis, U.Beljan-Zdravkovic, Z.Xu, and E.Vidgen. 2000. American Ginseng (Panax quinquefolius L) Reduces Postprandial Glycemia in Nondiabetic Subjects and Subjects With Type 2 Diabetes Mellitus. Archives of Internal Medicine 160:1009-1013.

Vuksan,V., M.K.Sung, J.L.Sievenpiper, P.M.Stavro, A.L.Jenkins, M.Di Buono, K.S.Lee, L.A.Leiter, K.Y.Nam, J.T.Arnason, M.Choi, and A.Naeem. 2008. Korean red ginseng (Panax ginseng) improves glucose and insulin regulation in wellcontrolled, type 2 diabetes: Results of a randomized, double-blind, placebocontrolled study of efficacy and safety. Nutrition, Metabolism and Cardiovascular Diseases 18:46-56.

Welsch,C.A., P.A.Lachance, and B.P.Wasserman. 1989. Dietary phenolic compounds: inhibition of sodium-dependant D-glucose uptake in rat intestinal brush border membrane vesicles. J. Nutr. 119.

Wolever,T.M., D.J.Jenkins, A.L.Jenkins, and R.G.Josse. 1991. The glycemic index: methodology and clinical implications. Am J Clin Nutr 54.

Yamabe, N., Kang, K.S., Matsuo, Y., Tanaka, T., Yokozawa, T., 2007. Identification of antidiabetic effect of iridoid glycosides and low molecular weight polyphenol fractions of Corni Fructus, a constituent of Hachimi-jio-gan, in streptozotocininduced diabetic rats. Biological \& Pharmaceutical Bulletin 30, 1289-1296.

Yeh,G.Y., D.M.Eisenberg, T.J.Kaptchuk, and R.S.Phillips. 2003. Systematic review of herbs and dietary supplements for glycemic control in diabetes. Diabetes Care 26:1277-1294.

Zhang,C.Y., L.E.Parton, C.P.Ye, S.Krauss, R.Shen, C.T.Lin, J.A.Porco, Jr., and B.B.Lowell. 2006. Genipin inhibits UCP2-mediated proton leak and acutely reverses obesity- and high glucose-induced beta cell dysfunction in isolated pancreatic islets. Cell Metab 3:417-427. 


\section{DISCUSSION}

In this doctoral thesis, extracts derived from the edible parts of rosemary (Rosmarinus officinalis L.) and seeds of the ash tree (Fraxinus excelsior L.) were produced and analyzed. Moreover, their capacity to ameliorate metabolic disorders, such as obesity, hyperlipidemia, and hyperglycemia was evaluated. The plants studied are traditionally used in the Mediterranean basin as food and as treatments for several conditions (Aguilar et al., 2008;Eddouks and Maghrani, 2004).

Metabolic disorders are associated with increased oxidative stress, which can adversely affect the oxidation of LDL, the chief cause of atherosclerosis (Esterbauer et al., 1992). Persistent hyperglycemia increases oxidation and inflammation, which can be reverted by supplementation with appropriate herbal compounds (Omar et al., 2010). Moreover, several botanical extracts that contain natural antioxidants have antilipidemic and anticholesterolemic effects (Dinani et al., 2010; Yang et al., 2010).

Rosemary extracts are used as natural preservatives in foods and beverages. Consequently, such extracts that have been standardized for carnosic acid and carnosol content have attained the status of additive, receiving an E rating from the European Food Safety Authority (Aguilar et al., 2008). The antioxidant effects of the active compounds in rosemary have been reported extensively (del Bano et al., 2003;Wijeratne and Cuppett, 2007), but few studies on commercially available extracts that have been obtained through industrial processes exist.

To this end, in this research program 3 commercial rosemary extracts were developed —standardized to contain 20\% carnosic acid, 20\% rosmarinic acid, and 40\% ursolic acid - and were evaluated for their antioxidant activities by ORAC, FRAP, and ex vivo LDL oxidation assay.

Based on these results, depending on the extraction procedure, the antioxidant properties of rosemary extracts can vary significantly. In fact, the ursolic acid extract had very low antioxidant activity in all assays. In ORAC and FRAP, the rosmarinic acid extract had greater antioxidant activity than the carnosic acid extract. These results are consistent with previous reports that have demonstrated that bioactive compounds in rosemary have antioxidant effects (Fuhrman et al., 2000; Hsieh et al., 2007). 
Nevertheless, the rosmarinic acid extract, tested at $5 \mu \mathrm{g} / \mathrm{mL}$, had prooxidant activity in the ex vivo LDL oxidation assay. Apparently, rosmarinic acid accelerates the accumulation of hydroperoxides in LDL, induced by the reduced form of copper $\left(\mathrm{Cu}^{+}\right)-\mathrm{a}$ process that is unable to be balanced with an insufficient antiperoxidant activity. In a previous study, rosmarinic acid was noted to reduce transition metals that form reactive oxygen species and mediate LDL oxidation, especially when lipoproteins contained traces of lipid hydroperoxides (Esterbauer et al., 1992;Porter, 1993). Conversely, the carnosic acid extract was more effective than the rosmarinic acid extract in the LDL oxidation assay, suggesting that their antioxidant effects ex vivo differ from those in vitro.

Based on previous findings, this research program examined the capacity of rosemary that has been standardized to contain $20 \%$ carnosic acid (RE) to prevent metabolic disorders. The effects of RE on weight gain, lipid homeostasis, and glucose levels in mice that were fed a high-fat diet for 16 weeks were determined. Animals were given a low-fat diet (LFD), a high-fat diet (HFD), or a high-fat diet that was supplemented with $500 \mathrm{mpk}$ RE (HFD.RE). Physiological and biochemical parameters were measured throughout the 16 weeks of treatment; in addition, the inhibitory effects on pancreatic lipase and PPAR $\gamma$ agonist activity in vitro were assessed.

RE reduced gains in weight compared with HFD without affecting food intake or fat energy intake. RE also lowered epididymal fat tissue weight compared with the HFD. Further, total fecal lipid content rose in HFD.RE mice versus HFD animals, which is linked to the amount of total fecal fat energy that is excreted. RE inhibited pancreatic lipase and activated PPAR $\gamma$ in vitro.

This in vivo evidence is consistent with findings from other groups (Harach et al., 2009; Ninomiya et al., 2004), suggesting that imposing limitations in lipid absorption in the intestine is a mechanism by which RE prevents weight gain.

This hypothesis is supported by the inhibition of pancreatic lipase by RE in vitro. Moreover, similar effects have been reported recently with an ethanolic extract of rosemary that contains rosmarinic, carnosol, and carnosic acids (Harach et al., 2009) and with carnosic acid from other plant sources (Ninomiya et al., 2004). Thus, the effect of RE on fecal fat excretion and, consequently, on fecal fat energy excretion partially explains the observed reduction in body weight during the 16-week experiment. 
In addition to its effects on physiological parameters, RE significantly reduced the cholesterol levels that were induced by the high-fat diet. However, these effects have not been observed in other studies on rosemary or carnosic acid (Harach et al., 2009;Ninomiya et al., 2004). Dietary cholesterol absorption has been proposed to be associated with fat digestion, wherein minimal triacylglycerol hydrolysis is sufficient to increase cholesterol transport significantly from lipid emulsions to intestinal cells (Young and Hui, 1999). Consequently, the inhibition of pancreatic lipase has been hypothesized to constitute a mechanism by which lipid malabsorption is triggered to control triglyceride and cholesterol levels (Sheng et al., 2006).

In the present in vivo study, fasting glycemia declined in animals in the HFD.RE group compared with HFD mice. The current results confirm the antihyperglycemic properties of rosemary that have been observed by other groups (Bakirel et al., 2008;Erenmemisoglu et al., 1997). The glucoregulatory capacity of rosemary is attributed to its ability to activate PPAR $\gamma$, a nuclear receptor that regulates genes that control fatty acid uptake and storage, inflammation, and glucose homeostasis (Staels and Fruchart, 2005). These results corroborate previous findings regarding the capacity of carnosic acid and carnosol to stimulate PPAR $\gamma$ (Rau et al., 2006). Thus, this mechanism of action, linked to the regulation of weight gain by RE, accounts for its glucoregulatory activity.

Consequently, the current findings confirm the potential of RE for use in preventive strategies against metabolic disorders and encourage further studies to be initiated. Nutritional interventions are necessary to verify the physiological effects of RE in humans.

The other compound that was studied in this doctoral program, an aqueous extract of ash tree seeds, is a traditional antidiabetic agent that is consumed in Morocco as an infusion (Eddouks and Maghrani, 2004;Maghrani et al., 2004;Eddouks et al., 2005). Other groups have reported that ash tree seed extracts reduce blood glucose levels without significantly affecting insulin levels in animals (Eddouks et al., 2005;Maghrani et al., 2004). Its phlorizin-like effects in inhibiting renal glucose reabsorption is a potential mechanism of the hypoglycemic activity of the ash tree seed extract (Eddouks and Maghrani, 2004), but no clinical evidence exists in this regard.

Several classes of compounds in ash tree seed extract have been characterized, including secoiridoid glucosides, coumarins, flavonoids, phenylethanoids, benzoquinones, 
indole derivatives, and simple phenolic compounds (Kostova and Iossifova, 2007; Egan et al., 2004). Their bioactivities, however, have not been reported.

An adequate controlled industrial process was initially developed to generate an aqueous extract of ash tree seeds similar to those that are traditionally used in Morocco (Eddouks and Maghrani, 2004;Maghrani et al., 2004;Eddouks et al., 2005).

Several active compounds were identified by HPLC-MS and NMR and were assayed in vitro: (1) salidroside, a phenolic compound; and 9 secoiridoids glycosides: (2) oleoside-11methylester, (3) nuzhenide, (4) 1'"'-O- $\beta$-D-glucosylformoside, (5) excelside B, (6) Gl3, (7) Gl5, (8) excelside A, (9) ligstroside, and (10) oleoside dimethyl ester. Excelsides A and B are novel.

In in vitro assays, compounds 2-9 inhibited adipocyte differentiation in 3T3-L1 cells. Further, ash tree seed extract (at 1:10,000) and secoiridoids 3, 6-8, and $\mathbf{1 0}$ activated a PPAR $\alpha$ reporter cell system at $10^{-4} \mathrm{M}$, comparable to $10^{-8} \mathrm{M}$ WY 14,643 , a specific PPAR $\alpha$ agonist that has robust hypolipidemic effects (Chou et al., 2002). PPAR $\alpha$ pathways regulate lipid homeostasis and inflammation (Kliewer et al., 1997;Kostadinova et al., 2005;Szeles et al., 2007), rendering PPAR $\alpha$ the primary target of fibrate drugs for the treatment of hyperlipidemia, hyperglycemia, and obesity (Evans et al., 2004).

These preliminary biological profiles suggest that the inhibition of adipocyte differentiation and PPAR $\alpha$-mediated pathways is the mechanism to which the antidiabetic activity of ash tree seed extract is attributed and implicate the ash tree extract as having antiobesity properties.

Thus, the subsequent objectives were to determine whether ash tree seed extract limits weight gain and hyperglycemia and to evaluate its safety in a mouse model. To this end, the effects of a low-fat diet (LFD), a high-fat diet (HFD), and a high-fat diet $+0.5 \%$ ash tree seed extract (FED) on mice for 16 weeks were compared.

Although HFD mice grew steadily throughout the study, doubling in weight, the lowcalorie diet in the LFD group significantly lowered gains in weight after 3 weeks. Mice that were supplemented with FE grew similarly to HFD animals; at Week 9, FED animals began to experience significant reductions in weight gain, like healthy LFD mice.

These results complement work by Maghrani and colleagues (Maghrani et al., 2004), who reported that the administration of ash tree seed extract for 2 weeks $(20 \mathrm{mg} / \mathrm{kg})$ 
reduced body weight in streptozotocin-induced diabetic rats but not in normal animals. Similarly, the HFD group experienced increases in adipose tissue weight compared with LFD animals over 16 weeks, while FED mice did not gain as much fat, based on omental fat, retroperitoneal fat, and liver weight. Consequently, the incidence of fatty livers trended toward the lower levels that were observed in LFD animals. Thus, the decrease in fat levels in FED animals correlates with the current observations that secoiridoid glucosides from ash tree seed extract activate PPAR $\alpha$ and inhibit preadipocyte differentiation. These findings demonstrate that ash tree seed extract, due specifically to secoiridoid glucosides, has antiobesity effects in vivo.

Moreover, although significant increases in fasting blood glucose and fasting plasma insulin levels were observed after 16 weeks in obese HFD animals compared with baseline values, fasting blood glucose in the FED group did not differ significantly from the beginning of the study, when the mice were still healthy, despite their high-fat diet. Fasting insulin levels in FED mice decreased significantly compared with those of LFD animals. These observations demonstrate that ash tree seed extract has antihyperglycemic activity that is accompanied by improvements in insulin levels in FED mice and precludes the negative outcomes of obesity with regard to fasting glucose and insulin levels in HFD animals (Jeffcoat, 2007). As a chief consequence of having consumed ash tree seed extract, the mechanisms of fat accumulation in adipocytes of FED animals are impaired and insulin resistance is improved.

Current results also support the findings of animal studies by Eddouks and Maghrani (2004) and Maghrani et al. (2004), who observed that acute intravenous administration of $10 \mathrm{mg} / \mathrm{kg} / \mathrm{h}$ ash tree seed for 4 hours reduced blood glucose levels in normal rats and in streptozotozin-induced diabetic rats after chronic oral consumption of $20 \mathrm{mg}$ extract/kg/day for 14 days.

The results from this in vivo trial indicate that $0.5 \%$ ash tree seed extract does not induce any side effects in mice, as monitored principally by liver physiology and biochemistry.

Additionally, a clinical intervention trial was performed to test the hypothesis that ash tree seed extract reduces postprandial glycemia in healthy nondiabetic individuals following glucose intake $(50 \mathrm{~g})$. In this double-blind, randomized, crossover, placebo 
(wheat bran)-controlled study in 16 healthy volunteers, the underlying mechanisms of this activity by measuring serum insulin concentrations was determined.

In this pilot clinical trial, ash tree seed extract reduced incremental postprandial plasma glucose concentrations at $45 \mathrm{~min}$ and $120 \mathrm{~min}$ compared with placebo. It significantly lowered the glycemic area under the blood glucose curve. The seed also induced the secretion of insulin $90 \mathrm{~min}$ after glucose administration. However, the insulinemic area under the blood insulin curve did not differ from that of placebo. No adverse events were reported.

During the 90-min experiment, the incremental glycemic curve for the ash tree seed extract formed 2 phases compared with placebo-before and after the first $60 \mathrm{~min}$ of the experiment. One explanation for the first phase is that ash tree seed extract partially inhibits the absorption of glucose by blocking its uptake in the intestine, likely through interactions with the glycoside moieties of secoiridoids, similar to what has been reported for glycoside flavonoids (Johnston et al., 2005;Kottra and Daniel, 2007;Kwon et al., 2007). The second phase, accompanied by a significant increase in insulin production, suggests that active compounds in ash tree seed extract are absorbed and act on pancreatic islet beta-cells (Zhang et al., 2006).

These findings suggest that ash tree seed extract has an acute insulinotropic effect in humans after glucose challenge and therefore elicits insulin sensitivity. Moreover, because the resulting total postprandial insulinemia does not differ significantly compared with the effects of the placebo, ash tree seed extract might prevent the development of insulin resistance. No adverse events were observed during the study.

\section{References}

Aguilar,F., H.Autrup, S.Barlow, L.Castle, W.Dekant, K.H.Engel, N.Gontard, D.Gott, S.Grilli, R.Gürtler, R.Chr.Larsen, C.Leclercq, J.C.Leblanc, F.X.Malcata, W.Mennes, M.R.Milana, I.Pratt, I.Rietjens, P.Tobback, and F.Toldra. 2008. Use of rosemary exracts as a food additive. Scientific opinion of yhe panel on food additives, flavourings, processing aids and materials in contact with food. The EFSA journal 721:1-29. 
Bakirel,T., U.Bakirel, O.U.Keles, S.G.Ulgen, and H.Yardibi. 2008. In vivo assessment of antidiabetic and antioxidant activities of rosemary (Rosmarinus officinalis) in alloxan-diabetic rabbits. J Ethnopharmacol 116.

Chou,C.J., M.Haluzik, C.Gregory, K.R.Dietz, C.Vinson, O.Gavrilova, and M.L.Reitman. 2002. WY14,643, a peroxisome proliferator-activated receptor alpha (PPARalpha ) agonist, improves hepatic and muscle steatosis and reverses insulin resistance in lipoatrophic A-ZIP/F-1 mice. J Biol Chem. 277:24484-24489.

del Bano,M.J., J.Lorente, J.Castillo, O.Benavente-Garcia, J.A.Del Rio, A.Ortuno, K.W.Quirin, and D.Gerard. 2003. Phenolic diterpenes, flavones, and rosmarinic acid distribution during the development of leaves, flowers, stems, and roots of Rosmarinus officinalis. Antioxidant activity. J Agric. Food Chem. 51:4247-4253.

Dinani,N.J., A.Asgary, H.Madani, G.Naderi, and P.Mahzoni. 2010. Hypocholesterolemic and antiatherosclerotic effect of artemisia aucheri in hypercholesterolemic rabbits. Pak. J. Pharm. Sci. 23:321-325.

Eddouks,M., andM.Maghrani. 2004. Phlorizin-like effect of Fraxinus excelsior in normal and diabetic rats. J Ethnopharmacol. 94:149-154.

Eddouks,M., M.Maghrani, N.Zeggwagh, and J.Michel. 2005. Study of the hypoglycaemic activity of Lepidium sativum L. aqueous extract in normal and diabetic rats. J Ethnopharmacol. 97.

Egan,P., P.Middleton, M.Shoeb, M.Byres, Y.Kumarasamy, M.Middleton, L.Nahar, A.Delazar, and S.Sarker. 2004. GI 5, a dimer of oleoside, from Fraxinus excelsior (Oleaceae). Biochemical Systematics and Ecology 32.

Erenmemisoglu,A., R.Saraymen, and H.Usten. 1997. Effect of Rosmarinus officinalis leave extract on plasma glucose levels in normoglycaemic and diabetic mice. Pharmazie 52.

Esterbauer,H., J.Gebicki, H.Puhl, and G.J3rgens. 1992. The role of lipid peroxidation and antioxidants in oxidative modification of LDL. Free Radical Biology and Medicine 13:341-390.

Evans,R.M., G.D.Barish, and Y.X.Wang. 2004. PPARs and the complex journey to obesity. Nat. Med. 10:355-361.

Fuhrman,B., N.Volkova, M.Rosenblat, and M.Aviram. 2000. Lycopene synergistically inhibits LDL oxidation in combination with vitamin E, glabridin, rosmarinic acid, carnosic acid, or garlic. Antioxid Redox Signal 2. 
Harach,T., O.Aprikian, I.Monnard, J.Moulin, M.Membrez, J.C.B+®olor, T.Raab, K.Mac $+{ }^{\circledR}$, and C.Darimont. 2009. Rosemary (Rosmarinus officinalis L.) Leaf Extract Limits Weight Gain and Liver Steatosis in Mice Fed a High-Fat Diet. Planta Med.

Hsieh,C.L., C.H.Peng, C.C.Chyau, Y.C.Lin, H.E.Wang, and R.Y.Peng. 2007. Low-density lipoprotein, collagen, and thrombin models reveal that Rosemarinus officinalis L. exhibits potent antiglycative effects. J Agric Food Chem 55.

Jeffcoat,R. 2007. Obesity - A perspective based on the biochemical interrelationship of lipids and carbohydrates. Medical Hypotheses 68:1159-1171.

Johnston,K., P.Sharp, M.Clifford, and L.Morgan. 2005. Dietary polyphenols decrease glucose uptake by human intestinal Caco-2 cells. FEBS Lett 579.

Kliewer,S.A., S.S.Sundseth, S.A.Jones, P.J.Brown, G.B.Wisely, C.S.Koble, P.Devchand, W.Wahli, T.M.Willson, J.M.Lenhard, and J.M.Lehmann. 1997. Fatty acids and eicosanoids regulate gene expression through direct interactions with peroxisome proliferator-activated receptors alpha and gamma. Proc. Natl. Acad. Sci. U. S. A 94:4318-4323.

Kostadinova,R., W.Wahli, and L.Michalik. 2005. PPARs in diseases: control mechanisms of inflammation. Curr. Med. Chem. 12:2995-3009.

Kostova,I., andT.Iossifova. 2007. Chemical components of Fraxinus species. Fitoterapia 78:85-106.

Kottra,G., andH.Daniel. 2007. Flavonoid glycosides are not transported by the human $\mathrm{Na}+$ /glucose transporter when expressed in Xenopus laevis oocytes, but effectively inhibit electrogenic glucose uptake. J. Pharmacol. Exp. Ther. 322:829835.

Kwon,O., P.Eck, S.Chen, C.P.Corpe, J.H.Lee, M.Kruhlak, and M.Levine. 2007. Inhibition of the intestinal glucose transporter GLUT2 by flavonoids. FASEB J. 21:366-377.

Maghrani,M., N.Zeggwagh, A.Lemhadri, M.El Amraoui, J.Michel, and M.Eddouks. 2004. Study of the hypoglycaemic activity of Fraxinus excelsior and Silybum marianum in an animal model of type 1 diabetes mellitus. J Ethnopharmacol. 91.

Ninomiya,K., H.Matsuda, H.Shimoda, N.Nishida, N.Kasajima, T.Yoshino, T.Morikawa, and M.Yoshikawa. 2004. Carnosic acid, a new class of lipid absorption inhibitor from sage. Bioorganic \& Medicinal Chemistry Letters 14:1943-1946.

Omar,E.A., A.Kam, A.Alqahtani, K.M.Li, V.Razmovski-Naumovski, S.Nammi, K.Chan, B.D.Roufogalis, and G.Q.Li. 2010. Herbal Medicines and Nutraceuticals for 
Diabetic Vascular Complications: Mechanisms of Action and Bioactive Phytochemicals. Curr. Pharm. Des .

Porter,W.L. 1993. Paradoxical behavior of antioxidants in food and biological systems. Toxicol. Ind. Health 9:93-122.

Rau,O., M.Wurglics, A.Paulke, J.Zitzkowski, N.Meindl, A.Bock, T.Dingermann, M.AbdelTawab, and M.Schubert-Zsilavecz. 2006. Carnosic Acid and Carnosol, Phenolic Diterpene Compounds of the Labiate Herbs Rosemary and Sage, are Activators of the Human Peroxisome Proliferator-Activated Receptor Gamma. Planta Med 72:881-887.

Sheng,L., Z.Qian, S.Zheng, and L.Xi. 2006. Mechanism of hypolipidemic effect of crocin in rats: crocin inhibits pancreatic lipase. Eur. J. Pharmacol. 543:116-122.

Staels,B., andJ.C.Fruchart. 2005. Therapeutic Roles of Peroxisome Proliferator-Activated Receptor Agonists. Diabetes 54:2460-2470.

Szeles,L., D.Torocsik, and L.Nagy. 2007. PPARgamma in immunity and inflammation: cell types and diseases. Biochim. Biophys. Acta 1771:1014-1030.

Wijeratne,S.S.K., andS.L.Cuppett. 2007. Potential of Rosemary (Rosemarinus officinalis L.) Diterpenes in Preventing Lipid Hydroperoxide-Mediated Oxidative Stress in Caco-2 Cells. Journal of Agricultural and Food Chemistry 55:1193-1199.

Yang,X., L.Yang, and H.Zheng. 2010. Hypolipidemic and antioxidant effects of mulberry (Morus alba L.) fruit in hyperlipidaemia rats. Food Chem. Toxicol. 48:2374-2379.

Young,S.C., andD.Y.Hui. 1999. Pancreatic lipase/colipase-mediated triacylglycerol hydrolysis is required for cholesterol transport from lipid emulsions to intestinal cells. Biochem. J. 339 ( Pt 3):615-620.

Zhang,C.Y., L.E.Parton, C.P.Ye, S.Krauss, R.Shen, C.T.Lin, J.A.Porco, Jr., and B.B.Lowell. 2006. Genipin inhibits UCP2-mediated proton leak and acutely reverses obesity- and high glucose-induced beta cell dysfunction in isolated pancreatic islets. Cell Metab 3:417-427. 


\section{CONCLUSIONS}

In this doctoral thesis, analytical and industrial processes were developed to obtain botanical extracts from edible parts of rosemary and ash tree seeds that ameliorated the pathologies of several metabolic disorders.

The results demonstrated that depending on the method of extraction from a specific botanical, the antioxidant properties of the final extracts can vary significantly, as shown in experiments on rosemary, in which the carnosic acid extract had robust antioxidant properties in ORAC and FRAP and better hydrophilic and lipophilic antioxidant balance. Notably, rosmarinic acid had prooxidant activity at lower doses in the LDL oxidation assay. Because oxidized LDL is generated by hydrophilic-lipophilic interface in an oxidative reaction, the carnosic extract was more efficacious.

In vivo, the rosemary extract that was standardized to contain $20 \%$ carnosic acid controlled weight gain without affecting food intake in mice that consumed a high-fat diet. This effect was accompained by its capacity to regulate epididymal fat, cholesterol, and glycemia gains. Parallel in vitro studies demonstrated that the ability of the extract to inhibit pancreatic lipase and activate PPAR $\gamma$ accounted for the in vivo observations.

Therefore, this evidence confirms the potential of rosemary extract that has been standardized to $20 \%$ carnosic acid for use in preventive strategies against metabolic disorders. Further studies are necessary to confirm the physiological effects of this extract in humans.

Regarding the ash tree seed extract, this research program developed a novel industrial process to generate this traditional antidiabetic supplement. Also, its chief active compounds were identified by HPLC-MS and NMR and assayed in vitro-a phenolic compound and several secoiridoid glycosides. The compounds Excelsides A and B are novel. Many of the agents inhibited adipocyte differentiation and activated PPAR $\alpha$ mediated pathways in vitro. These preliminary biological profiles explain the antidiabetic activity of ash tree seed extract in animals and suggest that it has antiobesity properties.

It was also determined whether ash tree seed extract limits weight gain and hyperglycemia in mice and evaluated its safety in a mouse model. The results confirmed the capacity of ash tree seed extract to control body weight and support existing evidence 
of its antihyperglycemic effects and ability to improve insulin resistance. Moreover, in vivo, ash tree seed extract does not induce any side effect, as monitored by liver physiology and biochemistry.

The antihyperglycemic acute effects of ash tree seed extracts were confirmed in the randomized, controlled, pilot clinical intervention trial. The results suggest that active compounds from ash tree seed extract are absorbed in humans, effecting the production of insulin, likely through direct action on pancreatic islet cells.

The results of this research program encourage long-term clinical studies to be conducted to further evaluate the efficacy and safety of rosemary that has been standardized for carnosic acid content and ash tree seed extracts that contain glycoside secoiridoids. 


\section{ANNEX}

\section{Annex 1}

Ibarra,A., J.Cases, A.Bily, K.He, N.Bai, M.Roller, A.Coussaert, and C.Ripoll. 2010. Importance of extract standardization and in vitro/ex vivo assay selection for the evaluation of antioxidant activity of botanicals: a case study on three Rosmarinus officinalis L. extracts. J. Med. Food 13:1167-1175.

\section{Annex 2}

Ibarra A, Cases J, Roller M, Chiralt-Boix A, Coussaert A \& Ripoll C. 2010. Carnosic acidrich rosemary (Rosmarinus officinalis L.) leaf extract limits weight gain and improves cholesterol levels and glycaemia in mice on a high-fat diet. Br J Nutr, Accepted.

\section{Annex 3}

Bai,N., K.He, A.Ibarra, A.Bily, M.Roller, X.Chen, and R.Ruhl. 2010. Iridoids from Fraxinus excelsior with adipocyte differentiation-inhibitory and PPARalpha activation activity. J. Nat. Prod. 73:2-6.

\section{Annex 4}

Ibarra,A., N.Bai, K.He, A.Bily, J.Cases, M.Roller, and S.Sang. 2010. Fraxinus excelsior seed extract FraxiPure ${ }^{\mathrm{TM}}$ limits weight gains and hyperglycemia in high-fat diet-induced obese mice. Phytomedicine. doi:10.1016/j.phymed.2010.09.010

\section{Annex 5}

Visen,P., B.Saraswat, A.Visen, M.Roller, A.Bily, C.Mermet, K.He, N.Bai, B.Lemaire, S.Lafay, and A.Ibarra. 2009. Acute effects of Fraxinus excelsior L. seed extract on postprandial glycemia and insulin secretion on healthy volunteers. Journal of Ethnopharmacology 126:226-232. 
JOURNAL OF MEDICINAL FOOD

Mary Ann Liebert, Inc. and Korean Society of Food Science and Nutrition
DOI: 10.1089/jmf.2009.0259

Importance of Extract Standardization and In Vitro/Ex Vivo Assay Selection for the Evaluation of Antioxidant Activity of Botanicals:

A Case Study on Three Rosmarinus officinalis L. Extracts

Alvin Ibarra, Julien Cases, ${ }^{2}$ Antoine Bily, Kan He, Naisheng Bai, Marc Roller, ${ }^{2}$ Aurélie Coussaert, ${ }^{3}$ and Christophe Ripoll

'Naturex Inc., South Hackensack, New Jersey, USA; ${ }^{2}$ Naturex SA, Avignon; and ${ }^{3}$ Naturalpha SAS, Loos, France

ABSTRACT The overproduction of free radicals and oxygen reactive species is suspected to be implicated in a wide range of metabolic reactions that can have pernicious consequences in the development of a variety of human diseases. Botanical extracts are sources of antioxidants that counteract both free radicals and oxygen reactive species. The processing conditions used in the botanical extraction may influence the antioxidant composition; therefore, different extracts from the same plant may have different antioxidant properties. To illustrate this fact, we conducted a study using three commercial rosemary (Rosmarinus officinalis L.) leaf extracts. The three extracts were standardized to contain, respectively, 20\% carnosic acid, $40 \%$ ursolic acid, or 20\% rosmarinic acid. They were evaluated for their total (hydrophilic + lipophilic) antioxidant effects on oxygen radical absorbance capacity (ORAC), their ferric reducing/antioxidant power (FRAP), and their capacity to inhibil $\mathrm{Cu}^{2+}$-induced low-density lipoprotein (LDL) oxidation ex vivo. The ursolic acid extract showed the lowest antioxidant capacity on all models. The rosmarinic acid extract had an antioxidant capacity 1.5 times higher on ORAC and four times higher on FRAP than the carnosic acid extract. However the carnosic acid extract was better than the rosmarinic acid extract in inhibiting the oxidation of LDL ex vivo. These resuls encourage conducting further studies to evaluate the carnosic acid ind rosmaric acid extrets in vivo. Our study offers an exampe of the importance of the extroction procedures, on which tepends the $c$ a he evaluation of the anioxidat properties of botanical extracs.

KEY WORDS: • antioxidant capacity $\bullet$ carnosic acid $\cdot$ ferric reducing/antioxidant power $\bullet$ low-density lipoprotein oxidation $\bullet$ oxygen radical absorbance capacity $\bullet$ rosemary $\bullet$ rosmarinic acid

\section{INTRODUCTION}

The overproduction of free radicals and reactive oxygen species in living organisms can damage cellular
lipids, proteins, or DNA; this process contributes to loss of lipids, proteins, or DNA; this process contributes to loss of
functionality, which has been described as being related to the development of a wide range of human diseases, including cancer, cardiovascular disease, atherosclerosis, hypertension, ischemia/reperfusion injury, diabetes mellitus, neurodegenera Parkinson's disease), rheumatoid arthritis, and aging . $^{1}$ It has been postulated that sur icals such as polyphenols, including flavonoids, may offe some protection against these complications through their roles as free radical scavengers and antioxidant compounds. therefore reducing the negative effect of oxidative stress and free radicals.

Manuscript received 19 January 2009. Revision accepted 23 January 2010. Address correspondence to: Julien Cases, Naturex SA, BP 1218 site d'Agroparc, 84911
Avignon Cedex 9, France, E-mail: j.cases $@$ naturex.com
Botanical extracts are well-recognized sources of antioxidant molecules. They are commonly used in functiona foods and as dietary supplements, and contribute to the composition of several drugs. ${ }^{6}$ However, botanical extracts are not always well accepted because of issues concernin active compound identification, standardization, and quality active compound identification, standardization, and quality control. In obtaine technologies are in volved to produce botanical extracts at industrial levels; the most important include solvent extraction and column purification. ${ }^{8}$ It is noteworthy that the physical-chemical properties of the solvent, the extraction conditions, and the nature of resins in columns influence the nature of the extracted molecules with consequences on the nutritiona profile and, overall, on the physiological protective effiprofile and, overall, on the 89 .9 Therefore, different ciency of the finat extract. Therefore, different extract from the the fie bol extandardization rates and composition, providing different antioxidant properties, ${ }^{9}$ which may lead to ambiguous efficacy data when studied in clinical trials. ${ }^{7}$ Based on these considerations, it is of great interest to develop well-characterized 


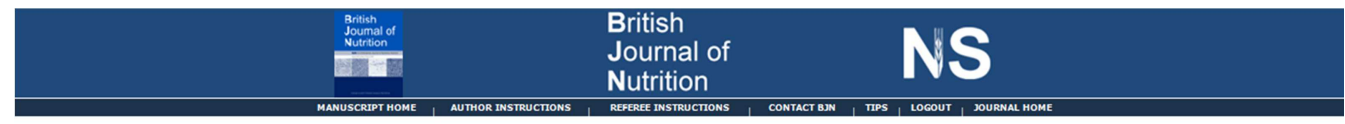

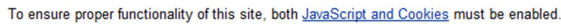

\begin{tabular}{|c|c|}
\hline Manuscript \# & BJN-2010-015656RR \\
\hline Current Revision \# & 2 \\
\hline Other Versions & BUN-2010-015656 BNN-2010-015656R \\
\hline Submission Date & 13th Feb 11 \\
\hline Current Stage & Accepted \\
\hline Title & $\begin{array}{l}\text { Carnosic acid-rich rosemary (Rosmarinus officinalis L.) leaf extract limits weight gains and improves cholesterol levels and glycaemia in mice on a high-fat } \\
\text { diet }\end{array}$ \\
\hline Running Title & Rosemary limits weight and glycaemia increase \\
\hline Manuscript Type & Research Article \\
\hline Special Section & N/A \\
\hline Category & Metabolism and Metabolic Studies \\
\hline Corresponding Author & Alvin Ibarra (a.ibarra@naturex.us) (Naturex Inc) \\
\hline Contributing Authors & Julien Cases , Marc Roller, Amparo Chiralt-Boix , Aurélie Coussaert, Christophe Ripoll \\
\hline Sources of Funding & The financial assistance from Naturex is gratefully acknowledged. \\
\hline Abstract & 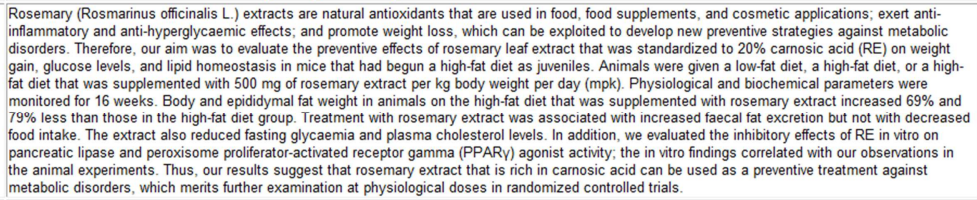 \\
\hline Key Words & Rosmarinus officinalis $L$, carnosic acid, pancreatic lipase, PPARY \\
\hline & Yes, having read the above statement, there is potential conflict of interest which $I$ have clearly detailed in the textbox below. \\
\hline Conflict of Interest & $\begin{array}{l}\text { Naturex is involved in research/development and marketing/sales of rosemary extracts as ingredients for food, cosmetic and nutraceutical industries. } \\
\text { Therefore Naturex has a commercial interest in this publication. Naturalpha, the conducting laboratory, was paid by Naturex to perform and report the } \\
\text { scientific work which formed the basis of the publication. Naturalpha and Naturex declare that the data presented in this publication represent a true and } \\
\text { faithful representation of the work performed }\end{array}$ \\
\hline Word Count & 2686 \\
\hline
\end{tabular}




\section{Full Papers}

Iridoids from Fraxinus excelsior with Adipocyte Differentiation-Inhibitory and PPAR $\alpha$ Activation Activity

Naisheng Bai, Kan He, ${ }^{*}{ }^{\star}$ Alvin Ibarra, ${ }^{\dagger}$ Antoine Bily, ${ }^{\dagger}$ Marc Roller, ${ }^{\star}$ Xiaozhuo Chen, ${ }^{\S}$ and Ralph Rühl ${ }^{\perp .1 . \nabla}$

Naturex, Inc., 375 Hivyler Street, South Hackensack, New Jersey 07606, Naturex SA, Site d'Agroparc BP 1218, 84911 Avignon Cedex 9, France. Department of Biomedical Sciences and Edison Biotechnology Institute, Ohio University, Athens, Ohio 45701, Department of Biochemistry and Molecular Biology, Medical and Health Science Center, University of Debrecen, Hungary, Apoptosis and Genomics Research Center, Hungarian Academy of Sciences, Debrecen, Hungary, and Paprika-Bioanalytics BT, Debrecen, Hungary

Received May 20, 2009

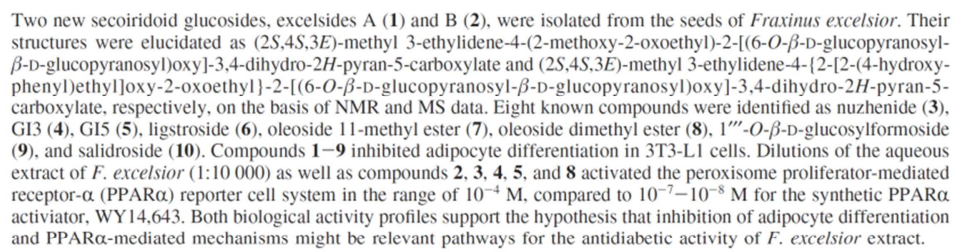

The plant Fraxinus excelsior L. (Oleaceae) is known as "common ash" or "European ash" in temperate Asia and Europe. ${ }^{1.2}$ The plant is also widely distributed throughout the southeast of Morocco (Tafilalet). where it is locally known as "Lissan Ettir" and its seeds as "l'ssane l'ousfour". This region is a rich source of ethnobotanicals and an are in which phytotherapy has been well developed. ${ }^{2-4}$ Aqueous seed extract of $F$. excelsior $(\mathrm{FE})$ has been shown to be highly potent in the reduction of blood glucose levels without sionificantly affecting insuli levels ${ }^{3-5}$ The phlorizin-like effect of inhibiting renal glucose reabsorption is a potential mechnism for the hypoglycemic effect of FE. srevious in a postigations on rovis glucosides, coumarins, flavonoids, phenylethanoids, benzoquinones,
indole derivatives, and simple phenolic compounds. indole derivatives, and simple phenolic
bioactivity studies have not been reported.

bioactivity studies have not been reported.
During prescreening, FE was found to activate PPAR $\alpha$ and mildly During prescreening, FE was found to activate PPAR $\alpha$ and mildly
inhibited adipocyte differentiation in 3T3-L1 preadipocytes. PPAR $\alpha-$ inhibited adipocyte differentiation in 3T3-L1 preadipocytes. PPAR $\alpha$ -
or PPAR $\gamma$-mediated pathways have been associated with protection against diabetes. ${ }^{10-12}$ Various synthetic PPAR $\alpha / \gamma$-selective agent have been reported to have potent antidiabetic activity. ${ }^{12.13}$ The focus of this study was to isolate and characterize the potential active principle(s) of FE and evaluate their biological activity in adipocyte 3T3-L1 cells) differentiation and PPAR $\alpha$ reporter assays. Sequentia combination of normal, reversed-phase, and gel permeation colum chromatography led to the isolation of nine secoiridoids including the new excelsides A (1) and B (2), the known nuzhenide (3) ${ }^{14} \mathrm{GI} 3(\mathbf{4}),{ }^{1}$ GI5 (5), ${ }^{8,16}$ ligstroside (6), ${ }^{17}$ oleoside-1 1-methyl ester (7), ${ }^{18}$ oleoside dimethyl ester (8) ${ }^{19}$ and 1'"'-O- $\beta$-D-olucopyranosylformoside $(\mathbf{9})^{20}$ and the phenylethanoid salidroside (10). ${ }^{21.22}$ Herein, we report the structures

* To whom correspondence should be addressed. Tel: (201) 440-5000

Fax: (201) 342-8000. E-mail: k.he@ naturex.us.

Naturex, Inc
Naturex SA

Ohio University.

University of Debrecen

Hungarian Academy of Sciences
₹ Paprika-Bioanalytics BT

of $\mathbf{1}$ and $\mathbf{2}$, the inhibitory effects of the iridoids $\mathbf{1 - 9}$ on adipocyt differentiation in $3 \mathrm{~T} 3-\mathrm{Ll}$ cells, and the activation of PPAR $\alpha$ by 2 $\mathbf{3} \mathbf{- 5}$, and $\mathbf{8}$, as potential mechanisms underlying the reported antidiabetic activity of $\mathrm{FE}$

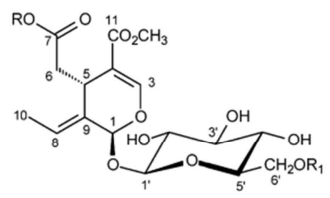

1: $\mathrm{R}=\mathrm{CH}_{3}, \mathrm{R}_{1}=\beta$-D-glucopyranosyl

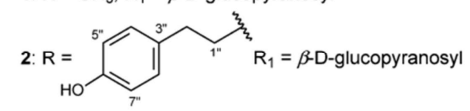

Results and Discussion

Excelside A (1) was obtained as an amorphous powder. Its molecular formula, $\mathrm{C}_{24} \mathrm{H}_{36} \mathrm{O}_{16}$, was established on the basis of it HRFABMS $\left(\mathrm{m} / \mathrm{z} 603.1890\left[\mathrm{M}+\mathrm{Na}^{+}\right.\right.$, calcd for $\mathrm{C}_{24} \mathrm{H}_{26} \mathrm{O}_{16} \mathrm{Na}$ 603.1901 ) and was supported by NMR data. The IR spectrum of showed hydroxy absorption at 3401 and carbonyl absorptions at 173 and $1717 \mathrm{~cm}^{-1}$. The ${ }^{1} \mathrm{H}$ and ${ }^{13} \mathrm{C}$ NMR data indicated that 1 was a oleoside-type secoiridoid glucoside based on proton signals at $\delta 7.5$ $(\mathrm{s}, \mathrm{H}-3), 5.94(\mathrm{~s}, \mathrm{H}-1), 6.09(\mathrm{q}, J=7.2 \mathrm{~Hz}, \mathrm{H}-8), 1.72(\mathrm{~d}, J=7.2 \mathrm{~Hz}$ $\left.\mathrm{H}_{3}-10\right)$, and $4.80\left(\mathrm{~d}, J=7.6 \mathrm{~Hz}, \mathrm{H}-\mathrm{l}^{\prime}\right)$, as well as the corresponding ${ }^{13} \mathrm{C}$ NMR signals at $\delta_{\mathrm{C}} 155.2(\mathrm{C}-3), 94.8(\mathrm{C}-1), 124.7$ (C-8), 13.6 (C$10)$, and $100.6\left(\mathrm{C}-1^{\prime}\right)$. The 'H NMR signals at $\delta 3.62$ and 3.70 an corresponding ${ }^{13} \mathrm{C}$ NMR ( $\mathrm{gHMQC}$ ) resonances at $\delta_{\mathrm{C}} 51.9$ and 52.3 were ascribed to two methoxy groups. The two methoxy groups showed correlations with C-7 $\left(\delta_{c} 173.7\right)$ and C-11 $\left(\delta_{c} 168.7\right)$ in gHMBC spectrum, respectively, indicating that 1 possesses a 7,11 


\begin{tabular}{lcl|}
\hline & Contents lists available at ScienceDirect & Phytomedicine \\
\hline ELSEVIER & Phytomedicine \\
\hline
\end{tabular}

Fraxinus excelsior seed extract FraxiPure ${ }^{\mathrm{TM}}$ limits weight gains and hyperglycemia in high-fat diet-induced obese mice

Alvin Ibarra ${ }^{\mathrm{a}, *}$, Naisheng Bai ${ }^{\mathrm{a}}$, Kan He ${ }^{\mathrm{a}}$, Antoine Bily ${ }^{\mathrm{a}}$, Julien Cases ${ }^{\mathrm{b}}$, Marc Roller ${ }^{\mathrm{b}}$, Shengmin Sang ${ }^{\mathrm{c}}$

a Naturex Inc., 375 Huyler St., South Hackensack, NJ 07606, USA

'Center for Excellence in Post-Harvest Technologies, North Carolina Agricultural and Technical State University, North Carolina Research Campus, 500 Laureate Way, Kannapolis, NC 28081, USA

A R T I C L E I N F O

Keywords:

Fraxinus excelsio

Secoiridoids

PPAR $\alpha$

Body weight

Blood glucos

Introduction

The common ash (Fraxinus excelsior L., Oleaceae) is a tree that grows naturally in temperate regions across Europe and Asia (Pliûra and Heuertz 2003; Eddouks et al. 2005) and exists throughout southeastern Morocco (Eddouks et al. 2002). Several reports have demonstrated that ash seeds have been used traditionally as food and condiments (Hedrick 1919; Kunkel 1984; Sinclair 1998; Vergne 2001; Boisver 2003; Eddouks and Maghrani 2004; Maghrani et al. 2004; Eddouks et al. 2005) and administered to improve several health conditions (Parsa 1959; Eddouks and Maghrani 2004).

In Europe, there is evidence that these seeds have been collected since the Middle Ages (Vermeeren and Gumbert 2008). The aqueous seed extract of the ash tree is recognized as an effective hypoglycemic and antidiabetic agent by traditional healers in Morocco (Eddouks et al. 2005). Moreover, ash seed extract has hypoglycemic and antidiabetic effects in normal and

Corresponding author. Tel.: +1 201440 5000x145; fax: +1 2013428000 streptozotocin-induced diabetic rats (Eddouks and Maghrani 2004: Maghrani et al. 2004)

In a previous study, we developed a well-standardized extract of F. excelsior seeds (FraxiPure ${ }^{\mathrm{TM}}$, Naturex Inc.) (Visen et al. 2009), in which a glucose screen $(50 \mathrm{~g})$ was used to assess the effects of FraxiPure $^{\mathrm{TM}}$ on plasma glucose and insulin levels. The intervention was double-blinded, randomized, crossover design that tested FraxiPure ${ }^{\mathrm{TM}}(1.0 \mathrm{~g})$ versus matching placebo ( $1.0 \mathrm{~g}$ of wheat bran) in 16 healthy volunteers. FraxiPure ${ }^{\mathrm{TM}}$ significantly reduced the glycemic area under the curve (Visen et al. 2009).

In a separate study, we identified (1) salidroside, a phenolic compound, and 9 secoiridoid glucosides in FraxiPure ${ }^{\mathrm{TM}}$ : (2) oleoside11-methylester, (3) nuzhenide, (4) 1"'--O- $\beta$-D-glucosylformoside, (5) excelside B, (6) Gl3, (7) Gl5, (8) excelside A, (9) ligstroside, and (10) oleoside dimethyl ester (Bai et al. 2010). In an in vitro study, we demonstrated that compounds $\mathbf{2 - 9}$ inhibited adipocyte differentiation in 3T3-L1 cells (Bai et al. 2010). Further, FraxiPure ${ }^{\mathrm{TM}}$ (at 1:10,000) and secoiridoids $\mathbf{3}, \mathbf{6 - 8}$, and $\mathbf{1 0}$ activated a peroxisome proliferator-activated receptor al pha (PPAR $\alpha$ ) reporter cell system in the range of $10^{-4} \mathrm{M}$, comparable with $10^{-8} \mathrm{M}$ WY 14,643 , a specific PPAR $\alpha$ agonist that has robust hypolipidemic effects (Chou et

0944-7113/S - see front matter $\bigcirc 2010$ Elsevier GmbH. All rights reserved, doi:10.1016/.jphymed.2010.09.010

Please cite this article in press as: Ibarra, A., et al., Fraxinus excelsior seed extract FraxiPure ${ }^{\mathrm{TM}}$ limits weight gains and hyperglycemia in high-fat diet-induced obese mice. Phytomedicine (2010), doi:10.1016/j.phymed.2010.09.010 
Journal of Ethnopharmacology 126 (2009) 226-232

Contents lists available at ScienceDirect

Journal of Ethnopharmacology

Acute effects of Fraxinus excelsior L. seed extract on postprandial glycemia and insulin secretion on healthy volunteers

Pradeep Visen $^{\mathrm{a}, *}$, Binduja Saraswat ${ }^{\mathrm{b}}$, Aastha Visen ${ }^{\mathrm{c}}$, Marc Roller ${ }^{\mathrm{d}}$, Antoine Bily ${ }^{\mathrm{d}}$, Claire Mermet $^{\mathrm{d}}$, Kan $\mathrm{He}^{\mathrm{e}}$, Naisheng Bai ${ }^{\mathrm{e}}$, Benoit Lemaire ${ }^{\mathrm{d}}$, Sophie Lafay ${ }^{\mathrm{d}}$, Alvin Ibarra ${ }^{\mathrm{e}}$

Risk Factor Modification Centre, St. Michael's Hospital, Faculty of Medicine, University of Toronto, 70 Richmond Street East, Main Floor, Toronto, Ontario, Canada M5C 1N8 אumar Clinic and Diabeles Care Unit, Lucknow, India

Naturex france

Naturex, USA

A RTICLE INFO

Article history:

7 form 7 August 2009

Accepted 25 August 2009

Keywords:

ostprandial blood glucose

Insulinemia
Secoiridoids

Nuzhenide

$\mathrm{Gl} 3$

\begin{abstract}
A B S T R A C T
Aim of the study: Fraxinus excelsior L. (Family: Oleaceae) seeds are consumed as a food, condiment, and folk medicine. The seeds are traditionally used as a potent hypoglycemic agent, but no clinical evidence exists containing 6 gard. We assessed the clinical efficacy and safety of the seed extract (FraxiPure , Naturex). $(50 \mathrm{~g})$ induced postprandial glycemi

Materials and methods: Preselected dose $(1.0 \mathrm{~g})$ was used in a double blind, randomized, crossover, placebo (wheat bran) controlled study on 16 healthy volunteers. Each treatment was given immediately after fasting blood glucose sample $(0 \mathrm{~min})$. Postprandial plasma glucose levels were estimated at $0,15,30,45$, 60,90 and $120 \mathrm{~min}$; and postprandial plasma insulin at $0,30,60,90$ and $120 \mathrm{~min}$.

Results: The extract lowered the incremental postprandial plasma glucose concentration as compared to placebo at $45 \mathrm{~min}(P=0.06)$ and $120 \mathrm{~min}(P=0.07)$. It statistically $(P=0.02)$ reduced the glycemic area under the blood glucose curve. The seed, also, induced a significant $(P=0.002)$ secretion of insulin at $90 \mathrm{~min}$ after glucose administration. However, the insulinemic area under the blood insulin curve was not different than the placebo. No adverse events were reported.

Conclusions: Our findings confirm the hypoglycemic action of Fraximus excelsior L. seed extract. These promising results, thus, encourage conducting long-term clinical studies to further evaluate the efficacy and safety of Fraxinus excelsior L. seed extract in healthy and diabetic volunteers and also to explore the
\end{abstract}

(O) 2009 Elsevier Ireland Ltd. All rights reserved.

\section{Introduction}

Plant derivatives with purported hypoglycemic properties have been used in folk medicine and traditional healing systems around the world (e.g., Native American, Indian, Jewish, Chinese, East Indian, Mexican) (Ungar, 1957; Yeh et al., 2003). But on the other hand, as indicated by Marles and Farnsworth (1995), not all of the plants, based on anecdotal use, reported to be entirely safe, and they emphasize the need for carefully planned scientific research to identify those hypoglycemic plants with true therapeutic efficacy and safety. To provide evidence-based herbal medicine, we must standardize suitable clinical models and utilize rande, we controlled trials (RCTs) to determine what herbs are efficacious * Corresponding author. Tel.: + 1416992 7477; fax: + 14168645538.

列 doi: 10.1016/.j.jep.2009.08.039 for what diseases and standardized them according to their health use.

In this pursuit, the present study, utilizing our wellstandardized acute clinical model, was undertaken with the common ash, Fraxinus excelsior L. (Family: Oleaceae). It grows naturally in Europe, North Africa, and Asia from the shores of the Atlantic Ocean in the West to the Volga River in the East (Pliûra and Heuertz, 2003; Eddouks et al., 2005). Several reports reveal that the seeds of Fraxinus excelsior L. have been traditionally used as food, condiment, and folk medicine (Hedrick, 1919; Kunkel, 1984; Boisvert, 2003). The ash tree is known in Morocco as "Lissan Ettir", and its seeds as "I'ssane l'ousfour", one of the ingredients of the condiment "Ras el Hanout" used to prepare the famous tagines and other typical Moroccan plates (Sinclair, 1998; Vergne, 2001: Allen 2007) In The Netherlands, there is evidence of the use, 0 ; Allen, since the Netherlands, there is evidence of the use of ash seeds In Iran, the ash seeds are employed as carminative and to destroy 